$A D-$

FINAL REPORT

IRO REPORT No.251

0
0
0
4
0
4
0

\title{
STUDY OF ARMY MAINTENANCE FLOAT POLICIES AND MANAGEMENT PRACTICES
}
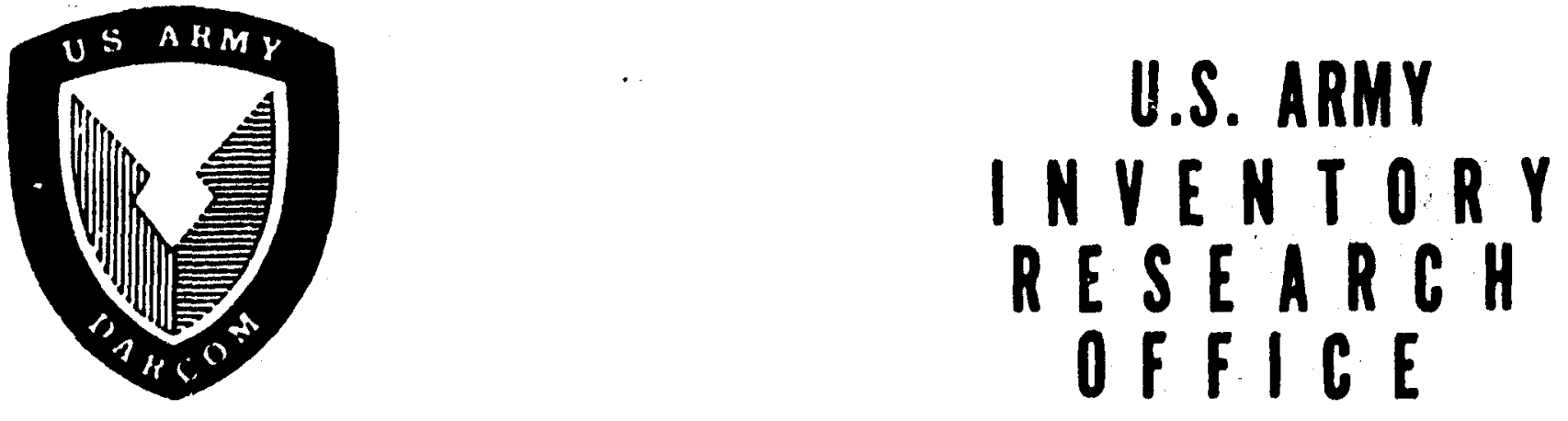

Septomber 1977

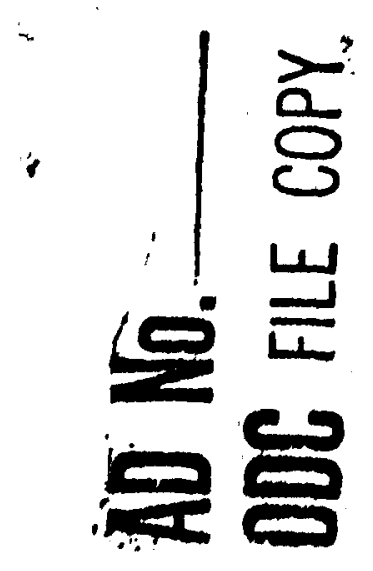

ROOM 800

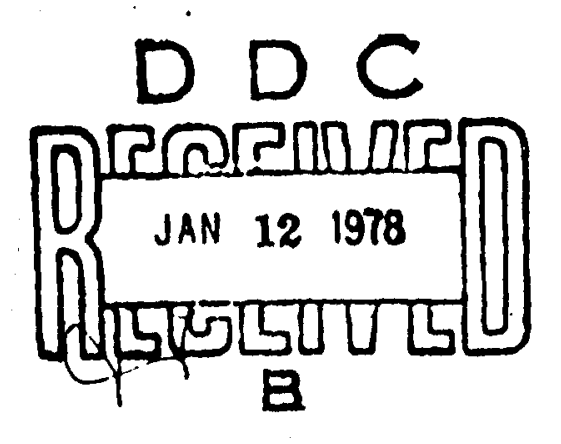
U.S. CUSTOM HOUSE

2nd and Chastnut Strools Philadalphia Pa. 19106 


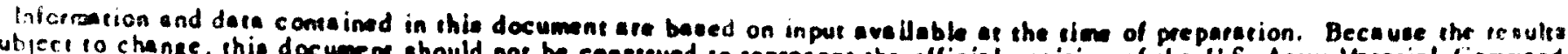

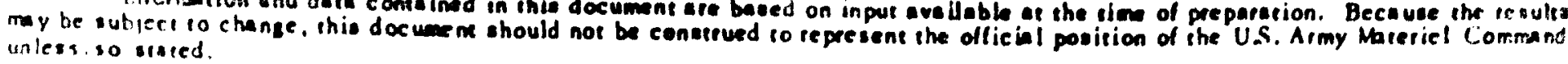


STUDY OF ARMY MAINTENANCE FLOAT

POLICIES AND MANAGEMIENT PRACTICES

FINAL REPORT

BY

EDWIN GOTWALS, IRO

LARRY SMITH, AMSAA

W. KARL RRUSE, IRO

JOHN FORTUNE, MMC

SEPTEMBER 1977

APPROVED FOR PUBLIC RELEASE; DISTRIBUTTION UNLIMITED

US ARMY INVENTORY RESEARCB OFTICE

US ARMY LOGISTICS MANAGEMENT CENTER ROOM 800

US CUSTOY HOUSE

2ND AND CHESTNUT STREETS

PHILADELPHIA, PA 19106

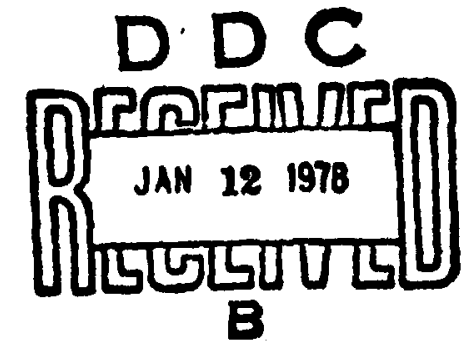


INNCIASSIFIED

SECURITY CLASSIFICATION OF THIS PAGE (mmon Dete Entorod)

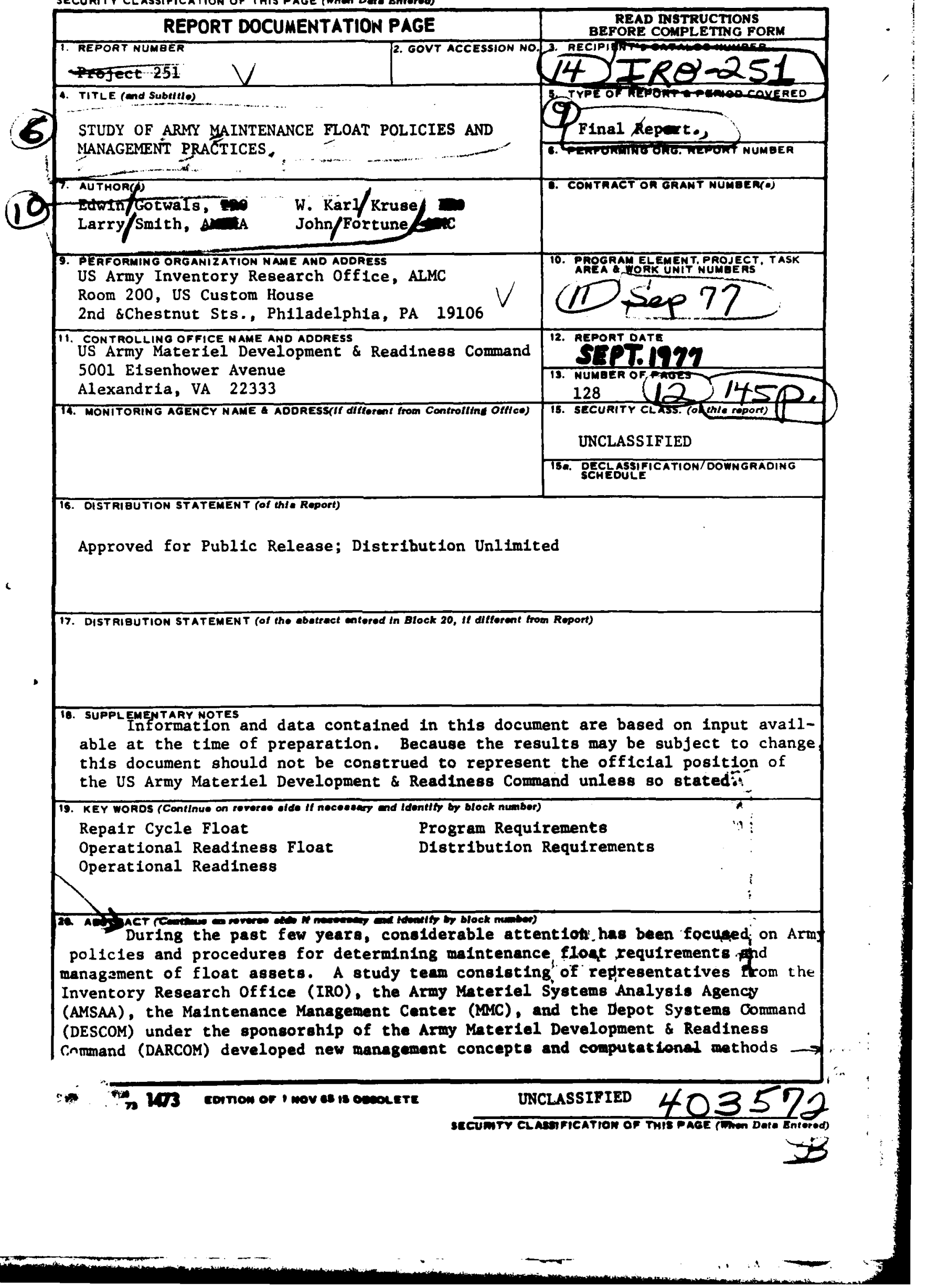


UNCLASSIFIED

SECURITY CLASBIFICATION OF THIS PAOE(Tmen DaLE Entomod)

Abstract continued.

designed to improve the current policieg governing maintenance float.

The study methodology Included: (a) two sets of questionnaires, one sent to the DARCOM major support commands and project managers and the other sent to DARCOM fleld malntenance technlclans; (b) model development to calculate repair cycle float (RCF) and operational readiness float (ORF) requirements; (c) a review of existing policies and regulations; and (d) the identification of potential data sources which can be used to perform float calculations and verification. The study findings resulted in 14 recommendations relating to the computation of maintenance float distribution and program requirements and the evaluation of float levels against an objective criterion.
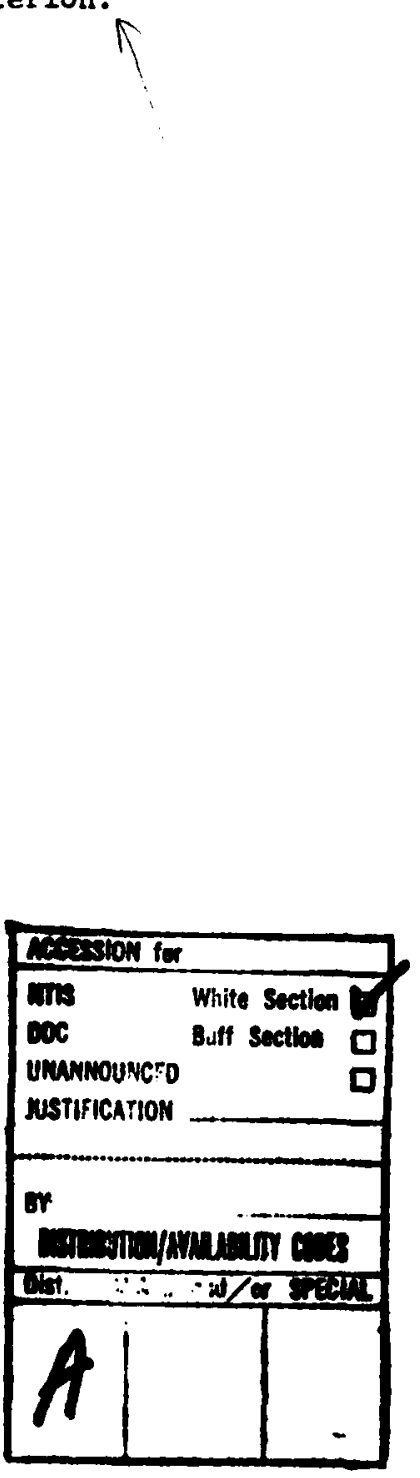
I. Summary.

1.1 Background............................... 1

1.2 Study Objectives. $\ldots \ldots \ldots \ldots \ldots \ldots \ldots \ldots \ldots \ldots \ldots \ldots \ldots \ldots, 3$

1.3 Summary of Analysis. ........................

1.4 Recommendations. .........................4

I. Introduction.

2.1 Direction............................... 7

2.2 Problem. ............................. 8

2.3 Scope of Study $\ldots \ldots \ldots \ldots \ldots \ldots \ldots \ldots \ldots \ldots \ldots \ldots \ldots \ldots$

2.4 Methods. ............................ 8

III. Operatior.al Readiness Float (ORF).

3.1 Current Policies...............................

3.2 Problems With Current Policies........................ 14

3.3 Proposed ORF Policies. .........................20

3.4 ORF Distribution Requirement.. .................. 20

3.5 ORF Program Requirement. .......................

IV. Repair Cycle Float (RCF).

4.1 Current Policies.................................29

4.2 Problems With Current Policies........................

4.3 Proposed Method for Computing the RCF Distribution Requirement. . 34

4.4 Proposed Policies for the RCF Program Requirement... . . . . . . . 35

Appendixes.

A. References..................................1

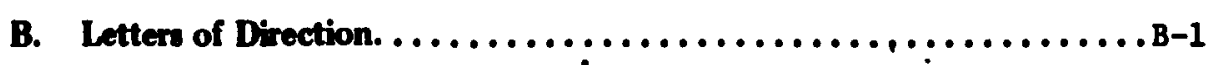


C. Wholesale Questionraire.

C.I Introduction. ............................ -1

C.2 Sample Questionnaire and Letter of Directions...........

C.3 Summary of Responses. $. \ldots \ldots \ldots \ldots \ldots \ldots \ldots \ldots \ldots \ldots,-11$

D. Field Questionnaire.

D.1 Introduction. $\ldots \ldots \ldots \ldots \ldots \ldots \ldots \ldots \ldots \ldots \ldots \ldots \ldots, D-1$

D.2 Sample Questionnaire and Letter of Direction........... D-1

D.3 Summary of Responses. ....................

E. ORF Data Collection (Distribution Requirement) $\ldots \ldots \ldots \ldots \ldots \ldots$ E-1

F. ORF Peacetime Distribution Model. ...................

G. Float Effectiveness Report. $\ldots \ldots \ldots \ldots \ldots \ldots \ldots \ldots \ldots \ldots \ldots \ldots, G-1$

H. Example of Proposed RCF Wartime Calculations.............

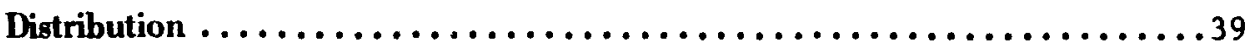


As project sponsor, Dan Taber, DARCOM, contributed the guidance and direction needed during the conduct of the study. He was also instrumental in the development and distribution of the questionnaires. Eileen Farrell (SDC) transmitted the initial data used in demonstrating the models, guided $u s$ in its use, and later processed additional data at MMC on alternative weapon systems. Conrad Weiser, DESCOM, responded to questions in the area of depot workloading and management of RCF along with the use of depot standards. Sally Frazza, IRO, performed the data processing work required to demonstrate the models. Bernard Rosenman, IRO, was active during the early developmental phases of the study and coordinated the individual tasking within the study group.

A special acknowledgement is given to the DARCOM major subordinate commands, project managers, and DARCOM field maintenance technicians for their replies to the questionnaires. 


\section{STUDY OF ARMY MAINTENANCE FLOAT POLICIES \\ AND MANAGEMENT PRACTICES \\ (DARCOM IRO PROJECT NO. 251)}

I. SUMMARY.

\subsection{BACKGROUND.}

1.1.1 During; the past few years, considerable attertio: has beer focised on Arm! policies and procedures for determining maintenance font requirements and management of float assets.

1.1.2 Several investigations and studies have been conducted to determine adequac! of Army maintenance loat policy and effectiveness of management procedires and to recommend improvements. I: the period between Jt:ly 1974 asd September 1975, the Army Audit Agency (AAA) conducted andits of mainterance float policy and manacement procedures at lieadquarters, Department of the Army (HQ DA), U.S. Army Materiel Development and Readiness Command (DARCOM), U.S. Army Communications and Electronics Materiel Readiness Command (CERCOM), U.S. Army Depot Systems Comm.urd (DESCOM), U.S. Army Missile Materiel Readiress Command (MIRCOM), U.S. Army Tank-Automotive Materiel Readiness Command (TARCOM), and units urder the control of U.S. Army Forces Command (FORSCOM), U.S. Army Training and Doctrire Command (TRADOC), and U.S. Army, Europe (USAREUR). The AAA Report, NE 76-214, dated 26 March 1976 and titled, "Maintenance Float and Direct Exchange," mainly cited problems and inadequacies within the existing policy for selectiry equipment and urits stpported with float and procedures for establishing and evaluating quantities of equipment required for float.

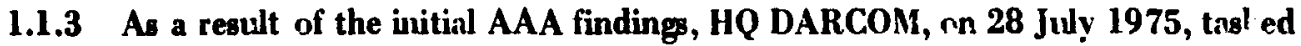
the U.S. Army Maintenance Manacement Center (AMMC) to evaluate the roie of maintenance float in contributing to operational readiress and to ascertain the cost impact of maintenance float. The AMMC atudy was directed mainly towards methods for determining float requirements, management of float assets within the depot sid wholesale supply system, and management of float at FORSCOM and TRADOC installations. The AMMC study report, "A Study to Determine the Cost Impact of Maintenance Float," dated 
April 1976. provided useful recommendations for improving̨ man:gement and utility of float equipment and so reducing the quantity and cost of ownership of identifiable float stock.

1.1.4 The General Accrunting Office (GAO) also performed a stıdy of Army maintenance float. Its report, dated 5 April 1977, was titled. "Better Manarement of Spare Equipment Will Improve Maintenance Productivit: and Save the Arm: Millions." In general, the GAO reiterated mary of the fiadings of the $\triangle A A$ and AMMC studies and considered the responses b: 11Q DARCON and DA to the AAA andit. It corclined that elimination of operational readiness float (ORF) for noncombat units atd improvements in computational methods for repair cycle float (RCF) would save the Army many millions of dollars. The report also recognized that this ongoing DARCOM stıdy was directed towards improving computational methods and correcting some of the GAO findings.

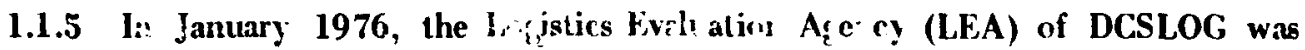
directed to conduct a study, "Review of Operational Hloat Concept." Their final report. dated June 1977, addressed itself essentially: to needed ma:agement improvements of ORF in areas cited b; AAA and GAO.

1.1.6 This study was initiated in: September 1976 to evaluate and recommend improvements to current policies, management guidance, and methods used to compute RCF requirements. It was to be a complimentar: study to the one being performed by LEA on ORF. The scope of the stidy was later expanded to include those aspects of ORF not addressed by LEA, particularly computational methods and field management of ORF assets. During the performance of this study, participants studiously avoided duplication of efforts that went into performance of those studies mentioned above. However, the findings, recommendations, and methodologies were evaluated for compatibility or modification in light of findings of this study. In addition, participants cont buted knowledge gained during other projects such as the Depot Maintenance Mobilization Plan Study in professing alternative management attitudes about float and new computational methods. 


\subsection{STUDY OBJECTIVES.}

The study objectives as established by DA ODCSLOG were:

a. Determine the adequacy of current policies, management guidance, practices, and methods used in computing ORF/RCF.

b. Identify any portion of ORF/RCF policy or guidance which is in need of change.

c. Idertify and justify changes which should be incorporated in DA ORF/RCF policy and other guidance.

d. Develop data as necessary to justify methods to compute ORF/RCF requiremests a! d/or justify any proposed changes in computation.

\subsection{SUMMARY OF ANALYSIS.}

A team was formed with represen:tatives from the Inventory Research Office (IRO), the Army Materiel Systems Analysis Agency (AMSAA), the Maintenarce Management Center (MMC), and the Depot System Commard (DESCOM). IRO served as the lead agenc! and was responsible for overall coordination, and was specifically resporsible for computation techniques. AMSAA was responsible for $\mathrm{ORF/RCF}$ policy ard its relationship to the DARCOM Depot Mobilization Plan; MMC was responsible for manngement and data for ORF at the retail level; and DESCOM was responsible for the worlloading and management of RCF at the depot and also the evaluations of depot standards.

The primary methods used by the study team were:

a. Two sets of questionnaires--one sent to the DARCOM major stpport commands and project managers dealing with policies for determining and verifying maintenance float requiremerts, and the other dealing with float riaragement practices in the field sest to DARCOM field maintenance technicians.

b. Review of existinc policy and procedures, regulations, ard a:ency visits. 


\section{c. Model development to calculate RCF and ORF requirements.}

d. Identification of potential data sources which can be used to perform noat calculations and verifications.

\subsection{RECOMMENDATIONS.}

The following is a set of recommendations based on the research dore by the study team and findings of preceding studies cited in the appendix. With each recommendation is a reference to the paragraph in the study where the support for the recommendation is discussed.

In order to improve the effective use and management of maintenance float, it is recommended that :

a. ORF items should be those items that are "reportable for unit readiness reporting purposes in accordance with AR 220-1." (Paragraph 3.2.5)

b. ORF program quantity (wartime) should be provided for deploying combat inits (Active Army and Reserve Components) and should be based on their Modificatio:s Tabie of Organization and Equipment (MTOF) "Required" quantities. (Paragraph 3.5.1)

c. The ORF program requirements should be calculated as the average pipeline using wartime data as described in Paragraph 3.5.2. (Paragraph 3.5.3)

d. ORF should be distributed in peacetime to Continental United States (CONUS) installations and to support maintenance units overseas to insture that the irits which they support have sufficient assets to carry out their peacetime training mission and to deploy is: time to meet mobilization or other contingency requirements. As far as deployment and training readiness are concerned, it is the overall availability (troop unit plus the float pool) which matters. (Paragraphs 3.2.1 and 3.2.6)

e. For each CONUS installation, the model in Appendix $F$ should be used to calculate ORF distribution required to achieve the target availability levels of the s!pported units which are authorized float support. (Paragraph 3.4.3) 
f. Oversea commands should continue to be atthorized their fill wartime ORF requirement and that the distribution of ORF among the wits within the command is left to the discretion of the major command. However, the CONUS distribution model will be made available for OCONUS use and its use encouraçed.

g. ORF distribution should he based upon recest performance of the stipply ard maintenance system as reflected in the failure and downtime data which will be collected per Appendix E utilizing the materiel readiness reports (DA Form 2406). (Parą̧raph 3.2.4)

h. To insure maximum accessibility of float, the General Supply Ui:it (GSU) shovid be the primary holder of float (Appendix F.3).

i. General Support Forces and Reserve Component Units shorld ba authorized OPF support only on an exception basis, with DA approval. (Para'xaphs 3.2.2 3.2.3, and 3.2.4)

j. The float management's report ciled in Appendix (; should be used to tracl. lloat effectiveness. (Paraçraph 3.4.2)

6. The criteria used for issuing ORF to the usisg unit sho:ld be based nn lncal conditions and administrative convenience ond should include issı : when eqpipmer.ts are ir: Direct Support (DS), Gereral Support (GS), or oreanizatiomal repair. (Paragraphs 3.2.6 and 3.2.7)

I. Repair cycle float should be defined as an additional qusntity of selected end items/major components of equipment approved for stoctiage in the wholesale supply system to replace like items of equipment withdrawn from using activities for any authorized depot maintenance. (Paragraph 4.2.2)

m. The RCF program requirements should be computed as part of the DARCON! Depot Maintenance Mobilization Plan, and in so doing the interaction between combat consumption and RCF should be considered. (Paragraplı 4.4)

n. The RCF distribution requirement should be produced bv the Total Army Equipment Distribution Plan (TAEDP) by counting the assets in the depot pipeline in the not-ready-for-issue account, as is presently done, and by replacing the RCF claimani 
requirement by a quantity equal to the forecasted return rate times the order chip time. (Paragraphs 4.2.4 and 4.3) 


\section{INTRODUCTION}

\subsection{DIRECTION.}

2.1.1 This study was initiated as the result of a letter from the Depinty Chief of Staff for Logistics (DCSLOG), dated 7 September 1976, subject: Repair Cycle Float (RCF). The letter stated in part:

"There is a need to revalidate the Repair Cycle Float policies of the Department of the Army.

To satisfy this need, it is requested that a study be undertaken to be titled, 'Department of the Army RCF Policy, Management Guidance, Practices, Procedures, and Methods Used to Establish Repair Cycle Float Requirements'."

2.1.2 Investigations were conducted within HQ DARCOM to define the scope and magnitude of the subject and identify those DARCOM activities most capable of contributing to its success. A proposed study plar: was drafted and forwarded to DCSLOG for approval on 9 November 1976. The DARCOM Inventory Research Office was selected as the lead activity and was directed to proceed by DRCPA-S letter, dated 16 November 1976. Other participating DARCOM activities were: AMMC; DESCOM; and AMSAA.

2.1.3 The DCSLOG letter, dated 30 December 1976, aubject: "Repair Cycle Float Study," directed expansion of the scope of the study. It stated in part:

"Because maintenance float is the total number of spare major components and end items required to suntain military operations at a desired level while repair or overhaul is performed, it is the combined effect of ORF and RCF which relates to operational readiness. . . . Consequently, all float sosets, both ORF and RCF, and their individual and collective impacts on availability or serviceable items to the user should be atudied. 
Request the DARCOM study plan be modified to include methods for establishing ORF requirements and manacement of ORF, as well as for RCF. Care should be exercised to avoid duplication of efforts already expended by the LEA during their study, referenced $1 b$ above."

2.1.4 As the result of this added requirement. the IRO prepared and stibmitted $\sigma_{-3} 3$ February 1977 a completely revised study plan.

NOTE Complete documents are contained in Appendix B.

2.2 PROBLEM. Conduct a study of policy, practices. procedures, ard methods for determining $\mathrm{ORF}$ and $\mathrm{RCF}$ requirements and advocate necessary changes for improving the efficiency and effectiveness of maintenance float by the Army.

2.3 SCOPE OF STUDY. Perform an indepth analysis of current and proposed Army policies, management practices, and computational methods for ORF and RCF in srder to define problem areas ranging from establishment of requirements to management at the user level. Develop and propose new or modified policies, procedures, and computational methods for achieving the greatest econumy for ownership of float assets commenstrate with preservation of the required peacetime and mobilization operational readiness of the Army. Develop, modify, or identify existing models which can be applied to determine operational readiness and repair cycle float requirements and validate the selected nodel(s).

\subsection{METHODS.}

2.4.1 Use of a team effort composed of personnel with diverse skills and representi:ı⿰ organizations within DARCOM having interests and responsibilities for varied aspects of float policy and management.

2.4.2 Identification and review of all existing DOD Directives, Army Regulations (AR's), and DA and DARCOM Pamphlets and Circulars bearing on policy and proredires for maintenance foat.

2.4.3 Review of all past studies for findings 'ind methods uned duriss the investigation and analysis of findings. 
2.4.4 Identification and evaluation of existing analytical models for application or possible modification for use as new computational methods for optimizing noat requirements. Develop new models as appropriate.

2.4.5 Use of two sets of questionnaires. One was sert to DARCOM major subordinate commands and project managers dealing with policies for determining and verifying float requirements. The other was sent to DARCOM field maintenance technicians and covered float management practices in the field.

2.4.6 Determination of data sources which can be used to perform float calculations and verification. 


\section{OPERATIONAL READINESS FLOAT (ORF)}

\subsection{CURRENT POLICIES.}

\subsubsection{Purpose of ORF Paragraph 7-1b of AR 750-1 (1972) states}

that: "Operational readiness floats are established and maintait:ed at CONUS installations and support maintenance units overseas to extend the capability of these activities and units to respond to the materiel readiness requirements of supported activities. This is accomplished by providin:e supported activities with scrvicealble replacements from ORF assets when mission essential items of equipment of these activities currot be repaired within prescribed time limits (Table 7-1)."

3.1.2 Fstablishment and Use of ORF. Normally, ORF assets are located at the installation level in CONUS (including those authorized TOE DS units located on the irstallation) and at DS units to replace unserviceable, economically reparable items which have a replacement issue priority of IPI) 1 through 8 and which carrot be repaired by support mair:tenance within the following time limits (AR. 750-1, par. 7.9):

$\begin{array}{ccc}\text { Priority } & \text { Overseas } & \text { CONUS } \\ & & \\ \text { IPD 1-3 } & 12 \text { Calendar Days } & 8 \text { Calendar Days } \\ \text { IPD 4-8 } & 15 \text { Calendar Days } & 12 \text { Calendar Days }\end{array}$

The decision to issue ORF assets is normally made by' the support unit commander; however, the results of the field questionnaire and visits made by members of the stud: team indicated that the commander of the supported unit plays a strong role in the decision:, and that the exchange is normally regotiated.

The proposed revision to AR 750-1 deleted the time limits and delegat.d the responsibility for estahishment of these exchance policies to the major commanders. It did :nol, however, provide a basis upon which to calculate ORF requirements. The revision states that ORF assets are provided "whes! like items of equipment of stpported activities casnot be repaired/modified in time to meet operational requirements." 
3.1.3 Items to be Supported by ORF. AR 750-1 states that the number of line items to be provided float support should be held to a minimum and that alternatives such as the use of direct exchange of modules, standby equipment authorizations, and shifting of support maintenance capabilities to the organizational maintenance level should be considered (par. 7-2).

Paragraph 7.3 of AR 750.1 states that:

"7-3. Maintenance float eligibility criteria. a. Items selected for operational readiness float support must be:

“(1) Mission essential.

“(2) Maintenance significant.

"(3) Authorized maintenance support, on a repair and return to user basis, by maintenance activities below depot level, and above the organizational maintenance level."

Paragraph 7-3d states that end items which are primarily repaired by the replacement of their component end items will be provided ORF support, when warranted, on a component end item basis.

\subsubsection{Detemination of ORF Requirements.}

Paragraph 7-4 of AR 750-1 states that:

“a. Quantitative requirements for operational readiness float will be determined b):

"(1) Use of appropriate analytical or simulation models; or

“(2) Applying approved ORF factors to TOE/TDA distribution requirements for end items and component end items as reflected in procram dociunents and/or the DA Major Item Distribution Plan. See AR 700-120. 
"b. Initial requirements for operational readiness float for a system which is to be provided as component end items will be determined uing an allocation model anch - the Techniques for Determining Optimal Operational Readiness Flont model available from the U.S. Army Materiel Command Maintenance Support Center, Letterkenny Army Depot, Chamberaburg, PA 17201.

"c. An operational readineas float requirement will not be computed for aircraft in TDA units."

In paragraph 7-4e it is stated that:

"Program/budget maintenance float (ORF and RCF) requirements will be computed as indicated in current 'PEMA Policy and Guidance for Preparation of Part 1 of the AMP"."

\subsubsection{Maintenance Float Factors.}

Section 7-5b, AR 750-1, required that ORF factors be computed on a line-item basis by national level materiel managers. Separate factors are required for each of several major commands or geographic areas.

Paragraphs 7-5e requires that the factors be reviewed at 2-year intervals, and recomputed when actual experience data indicates that the values used in computing the factors are invalid. Paragraph 7-17 presents the somewhat confusing requirement for an annual review of float levels.

Appendix $L$ presents two methods for computing ORF factors. The first uses the formula

$$
\text { ORF factor }=\frac{(\text { OR) }(\text { MTTR })}{\text { MTBF }+ \text { MTTR }}
$$

*NOTE: This document has been superseded by the "Procurement Planning and Policy Guidance," dated 1 December 1975. 
where

a. MTBF is the average time between failures which require float issue.

b. MTTR is the average time required to repair items at the stpport level. It includes transportation time and time awaiting repair as well as shop or bench time.

c. OR is an operational readiness rate specified in program documents or materiel readiness regulations.

The second method presented is a nomograph (Figure $L$-1) which gives ar ORF factur as a function of MTBF, MTTR for those actions requiring a flont transaction, and the number of items being supported. The nomograph is designed to yield a fluat factor which provides 80-percent float availability.

The regulation is very confusing as to when each of the two methods is to be used.

It should be noted that the draft revision to AR 750-1, dated April 1977 deletes the annual review and the nomograph. Instead of the mandatory 2-year review cycle, it requires that the factors be reviewed when the availability rates for the equipment. worldwide or specific major command, as reflected in DA level materiel readiress reports ior three consecutive reporting periods show a deviation of 5 percent or more from the DA standard.

\subsubsection{Data Sources for Updating ORF Factors.}

Paragraph 7-5f specifies that data for updating ORF factors will come from:

a. The mainterance management system.

b. Sample data collection.

c. Maintenance float transaction and wage reports (on DA Form 2407). 
d. Information provided by field commands to justify recommended changes in float allowances.

However, no specific procedure is prescribed for data collection and analysis.

\subsubsection{Units for Which ORF is Provided.}

Authorizations of ORF for the program (wartime) force is contained in the "Procurement Planning and Policy Guidance," and for the distribution (peacetime) force in AR 700-120.

The "Procurement Planning and Policy Guidance" specifies that ORF is to be calsulated for the units included in the approved program force, at their "Required" MTOE/TDA levels.

AR 700-120 states that the ORF distribution requirement is to be based on the MTOE/TDA "Authorized" quantities for CONUS Active Army units and the "Required" quantity for overseas units. Reserve Component inits are not authorized ORF until mobilized. ORF for aircraft and related items are authorized at the "Required" levels for all commands, Active and Reserve (par. 2-5). ORF is issued to mairtenance support units and activities tunder the same priority as that assigned to supported units for initial issue of items.

3.2 PROBLEMS WITH CURRENT POLICIES. The stıdies by the General Accourtin Office and Army Audit Agency surfaced several problems with the current ORF policies. The study by USALEA addressed most of those problems. During the coirse of this independent study, it was felt that some of the problems had been adequately addressed by: LEA. In several other areas, however, this study takes a different view.

\subsubsection{Distribution Requirement ve. Program Requirement.}

Although the current version of AR 750-1 mentions both a program (wartime) and distribution (peacetime) requirement for ORF, the emphasis is clearly on the peacetime. This emphasis has led some to assume that a reduction in the distribution of ORF would save vast sums of money, since those assets would not need to be prociured. This is not true. 
since the AAO is composed, in part, of the ORF program requirement, not the distribution requirement. Thus, a reduction in the distribution requirement has no effect on procurement levels.

ORF is distributed in peacetime to CONUS installations and to support maintenance tunits overseas to insure that the units which they stipport have sufficient assets to carry out their peacetime training mission and to deploy in time to meet mobilization or other contirgency requirements.

Given that the AAO has been filled, the decision to distribute assets as ORF is really a choice between keeping the assets in storage or putting them in the hands of the troops. Items which are distributed and not used will deteriorate faster than if l.ept in climate-controlled storage. Also, the concern has been expressed that items which are distributed may be used excessively for training which is only marginally effective, and the equipment may be worn out when it is required for war.

If assets are in short supply, the distribution of too much float to some of the higher priority units may degrade the readiness balance of the overall force.

A further problem arises in the distribution of ORF to CONUS installations. The units which they support in peacetime will be deployed elsewhere in wartime, and the ORF will have to be redistributed at a time when the demands upon the transportation and management control systems will be heaviest.

The policies which govern the distribution of ORF in peacetime must reflect these different conditions, and should vary with the type of unit, its location, and its deployment priority.

The calculation methodology for the ORF factor and the data sources for updating are also based on peacetime maintenance rates and turnaround times. DA Form 2407 and sample data collections are cited a the primary source for updating the factors, with no mention given to the need for using the data as a starting point for producing wartime predictions. 
The USALEA study states erroneously, it is felt, that the ORF factors contained in SB 710.1.1 are wartime factors, and that the Army has not updated the ORF factors since 1971 because there is little need to do so every 2 years if the "following procediure for determining wartime (sic) ORF factors for new items in paragraph 7.2 or AR 750.1 is followed:". AR 750-1, however, is clearly oriented toward producing peacetime factors.

It should be noted that a wartime ORF factor would lil.ely be hicher than the current factor and that the Army has probably been buying too little ORF.

The proposed revision to AR 750-1 states much more clearly the difference between the program and distribution requirements. It too, however, specifies only one factor, a wartime factor. This factor, when applied to the peacetime force levels, will probably overstate the distribution requirement. This is likely to be much less serious than the understatement of the program requirement.

\subsubsection{ORF for General Support Forces.}

The LEA report recommends that General Support Forces be authorized ORF support only on an exception basis, with DA approval. They point out that in peacetime, these units (primarily in the CONUS training base) can often obtain assets from an allocated TOE unit without degrading the readiness condition of the loaning unit.

It should be noted that the wartime requirement for these units depends heavily upon the scenario. A short war which requires a "go with what you have" approach woild lessen their need for float; whereas, a longer war would place a heavier burden on the training base and increase their float requirement. In that case, however, the trainiur? requirement may build up late enough so that the production base may be able to provide the needed equipment.

The exception basis for authorization thus seems quite reasonable.

*USALEA report, p. 5-1. 


\subsubsection{ORF Requirements for Reserve Components.}

The LEA finding that the program requirement for Reserve Component units is valid, but that the distribution be done on an exception basis (essentially the current AR 750-1 policy) is adequately supported. Their recommendation to revise AR $11-11$ to resolve the discrepancy as to the distribution question naturally follows from their study resilts.

3.2.4 Use of Supply and Maintenance Performance Standards for ORF Distribution.

The LEA implication that supply and maintenance standards be used for float computation is felt to be not valid.

This study proposes to base the ORF distribution instead upon the recent performance of the supply and maintenance systems as reflected in the failure and downtime data which will be collected (see Appendix E). In the first place, as discussed in Section 3.2.1, the distribution of ORF affects mainly the split between the items kept in storage versus those distributed to the field units. Secondly, many of the factors which affect supply and maintenance performance are beyond the control of the units (e.g., personnel strengths, budgets, NICP performance, etc.).

The purpose of the ORF distribution is to maintain deployment and training readiness, not to be used as a club to effect other manarement improvements. If the supply and maintenance management systems work properly, then the data upon which the distributions are based will reflect tinis. If the systems are not working properly, it would be shortaighted to "penalize" units by withholding float. To do this is to ultimately penalize the readines of the force.

\subsubsection{ORF Item Selection Criteria.}

Since the purpose of ORF is to maintain the materiel readiness of the force, the iteme selected for ORF support should be consistent with the materiel readin requirements. In revising AR 220-1, "Unit Readiness Reporting," DA has recognized that an item which is "miasion essential" for one unit may not be for another. Accordingly, a change in the method of designating equipment to be reported for readiness status has been 
i:titiated b: IA. This change will annotate ever: line item !umber (LIN) in each TOF, with on: of the following codes by January 1978 :

$\begin{array}{ll}\text { Cede } & \text { Readiness Identificatior } \\ \text { A } & \text { Primary Weapons and Iquipment } \\ \text { B } & \text { Auxiliary Fquipment } \\ \text { C } & \text { Adruiristrative Srpport Equipme:t }\end{array}$

Primar: Veapons and Equipment (PIVI) is defined as a major item of equipment es:ential to and enpluy'ed directly in the accomplishment of tl.e rust's primary operational mission. It is these items which will be reported in the wit readiness reports.

Until that annotation is complete, the revised AR 220-1 requires reporti:g on all RICC-! items.

The current criterion of "mission essential" should, therefore, be replaced with: "reportable for unit readiness reporting purposes in accordance with AR 220-1."

\subsubsection{Turnaround Time Limits for Issuring ORF.}

AR 750.1 establishes criteria for issuing float, based on the forecast of the time inpluired to repair the item at stpporl maintenance. The proposed revision deleted these time limits and dele ated the responsibilit; for establishment of the erchange policies to the major commands. It did not, howe;er, provide a basis upon which to calculate the ORF requirements.

These time limits are really an administrative fool which leeps the rumber of float exchanges to a manageable level. In peacetime, the criterio: should vary depending upon local conditions. For example, if a troop unit is abont to hegin a field training exercise, the time limit should be low 80 that noat assets required for the exercise can be drawn. Conversel:; at times when assets are not required for traisunc or deployment, there is 
little need to make the exchange. Issuing float based on administrative convenience is consistent with the replies received from the questionnaire.

The effect of reducing the time limit is to shift availability from the noat pool to the using unit. As far as deployment and training readiness is concerned, it is the overall availability (troop unit plus the float pool) which matters. Discrssions with DA DCSOPS personnel revealed that the readiness of the float is not reported in wit readiness reports. This is the apparent cause of some of the problems of float abuse and cantibalization cited in the LEA report and in the field questionnaire (see Appendix D).

In wartime, units are lil.ely to require ORF whenever an item is li! ely to be down for an extended period. Discussions with U.S. Army Logistics Center personuel involved in maintenance restructuring studies indicated that the trend is toward doing as much mainterance in the forward areas as is practical. This trend makes much less clear the difference between "organizational" and "support" maintenarce.

\subsubsection{Support v8. Organizational Maintenance.}

As noted in Section 3.1.1, the purpose of ORF according to AR 750.1 is, in! effect, to retain the materiel readiness of the force. Given the vagueness, thouch nonetheless the importance of readiness, it seems prudent to place few restrictions nu: the ise of float equipments. Yet, current policy allows float draw only when an equipment failure requires support maintenance. Limiting float draw to these cases implicitly assimes that TOE quantities have a built-in safety factor to protect against amounts in orgarizational maintenance. This, however, is prohibited by AR 310-34.

Especially in the light of ongoing maintenance restructurirg studies, which are obscuring the difference between support and organizational maintenance, the use of ORF to compensate for equipment in organizational maintenance is as much a need as to compensate for support maintenance.

If float items were not permitted to be exchanged for items in organizational maintenance, then more float would be required to meet the unit's readiness goals. This seemingly paradoxical conclusion follows because a given float item is able to be ised more 
frequently, and hence more effectively, if it is used to cover organizational as well as support maintenance. For example, if a unit's item is in organizational repair, snd the tunit needs that item then not allowing the unit to exchange for an available float item arbitrarily penalizes the readiness position, and wastes an available float item. On the other hand, if there were no float items available for exchange, then as far as readiress is concerned, it does not matter in any practical way if float is permitted to cover organizationsl repair or not. Consequently, for a given amount of float stock, unit readiness is improved by allowing the items to cover both organization and support maintenance. That there will be more demands for float if organizational repair is covered, only means that the given amount of float will be used more effectively to maintain readiness. It does not mean that more float will be required. It is important to note that in paragraph 3.2.6, it is recommended that the criteria for drawing float is left up to the commander and should be based on administrative convenience.

It, therefore, appears that the restriction that float may not be issued to cover organizational maintenance downtimes should be removed. The change in the float management procedure required to effect this change should not be too drastic.

If the troop unit needs a float item to replace an item which is down for organizational maintenance, a loan can be effected. Alternatively, a delayed excharme can be effected with the unserviceable item being sent to the float pool after it is repaired.

\subsection{PROPOSED ORF POLICIES.}

The remainder of this chapter presents the proposed policies for determining ORF distribution (peacetime) and program (wartime) requirements, and methods for calculating them.

\subsection{ORF DISTRIBUTION REQUIREMENT.}

\subsubsection{Purpose of ORF in Peacetime.}

ORF is distributed in peacetime to CONUS installations and to support maintenance units overseas. The objective is to instre that the units which they support have sufficient assets to carry out their peacetime training mission and to deploy in time to 
meet mobilization or other contir:gency requiremen ts. These requirements will vary with the type of unit and its location. The policies which govern the distribution of ORF in peacetime must reflect these different conditions.

\subsubsection{Overseas Commands.}

These units will be the first to engage in combat ia the sycal if war. Becertse of this, their readiness and training requirements are hich. The clirrent policy allocates to them their full wartime requirement (the wartime ORF factor times the "Requirad" MTOF: quantities). Distribution of ORF among the urits within the command is leit to the dis : tion of the major command. The distribution regulation. AR 700-120 (par. 2.17i)! states that the overseas command need not requisition the full requirement if dema:?d experience or the lacli of adequate storage facilities makes it desirable. These policies appe:s reasonable, so long as the commander has an adequate management contmol sustem to instre that $\mathrm{ORF}$ which is distributed to the units is being properly utilized.

It is proposed, therefore, that for the Major Item Distribition Plan (MIDP), overseas commands continue to be authorized their full wartime requiremeri. To assist the overseas commands in maling their troop unit allocations, the model which is proposed for CONUS units (discussed in a subsequent section of this chapter and Appendix: F) should be provided to them. Also, it is proposed that the float management report which is discussed in Appendix $G$ be used to track float effectiveness.

\subsubsection{CONUS Based Active Army Units.}

These units must also maintain a high state of readiness in order to be read: to deploy in time to meet the requirements of approved contingency plans. This deployment requirement also imposes a training requirement which is fairly constant.

The deployment (and hence the training) priority of these units may vary, however, and this should be reflected in their ORF authorizations.

The proposed revision to AR 220-1 provides varying equipment availability targets, depending upon the unit's Authorized Level of Orgarization (ALO). For ALO 1 units, the target is an averace availability rate for all reportable items of 90 percent. In 
addition, AR 220-1 identifies certain "pacing itens" by TOE series. Pacing items are defined as: "Major weapons systems and selected command and control equipment of such inporta:ce that they are stbject to continuous monitoring and management at all levels of conmand. These items pace Army readiness as a whole" (par. A-2m). The pacing items for an ALO 1 unit are required to meet the DA availability standard specified in Table 1, AR 750-52 or Appendix A, AR 95-33 (for aircraft).

The following table summarizes the requirements for the different ALO's.

\section{AUTHORIZED \\ LEVEL OF \\ ORGANIZATION}

ALO 1

ALO 1

ALO 3

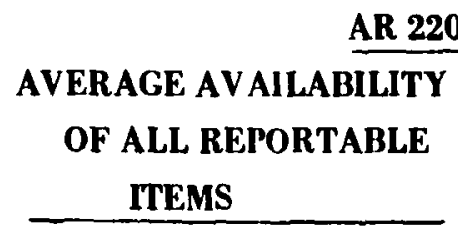

$90 \%$

$80 \%$

$70 \%$

\section{AR 220.1 TARGETS}

PACING

ITEM

AVAILABILITY

DA STD

DA STD-5\%

DA STD-.10\%

For each CONUS installation, it is proposed to apply the model described in Appendix F. The model calculates the peacetime ORF level which is required to achieve the tarcet availability levels of the supported units which are authorized float support (see Section 3.2.2).

For a given item, the model is applied as follows:

Step 1: For each unit at a given installation, the "Authorized" quantity and the unit's ALO is obtained from the Structure and Composition System (SACS).

Step 2: The overall availability requirement for the item at the i'stallation is calculated as follows: 


$$
A_{R}=\sum_{i=1}^{M} N_{i} A_{i} / \sum_{i=1}^{M} N_{i}
$$

where $\mathbf{A}_{\mathbf{R}}=$ availability requirement at the installation level

$M=$ number of units authorized the item

$\mathbf{A}_{\mathbf{i}}=$ availability target for the item, dependi:? upon the ALO of unit $i$

$N_{i} \quad=$ "Authorized" quantity of the item for ?wit $i$

Step 3: The failure rates and maintenance turnaround times for the item at the given installation is then obtained in accordance with Appendix E.

Step 4: The model described in Appendix $F$ is then applied to determine the ORF requirement for the installation.

Step 5: The ORF requirements for each installation is then rolled up by major command (FORSCOM/TRADOC).

\subsubsection{Reserve Component Units.}

As noted in Section 3.2.3, it is proposed that ORF be authorized to Reserve Component units only on an exception basis. For those units which are authorized ORF, the method of Section 3.4 .3 is proposed.

\subsection{ORF PROGRAM REQUIREMENTS.}

\subsubsection{Purpose of ORF in Wartime.}

ORF for wartime in provided to sustain the capability of combat units by providing replacement mets for those item which require maintenance and which cannot be repaired and returned to the unit in time to meet operational requirements. Since the 
program requirement is intended to support the wartime force, it mut reflect anticipated equipment and logistics system perfornance under fullecale wartime conditions. based on approved scenarios.

ORF should be provided for all deployiug combat units (Active Army and Reserve Comprnents) and should be based on their MTOE "Required" quantities.

\subsubsection{Inputs Required for Calculating Wartime ORF Factors.}

Basically, the type of estimates required to calculate wartime ORF arc the same as those for percetime (i.e., maintenance frequencies and turnaround times).

The estimates must reflect anticipated wartime conditions, though.

\section{A. Wartime Maintenance Frequency.}

The frequency with which items require maintenance must be based ipon anticipated combat end-item utilization rates (e.g., miles/month/vehicle) and should include those mairitenance actions resilting from normal wear and tear and from nonlethal combat damage. These estimates are not yet available. However, two studies have been done, one by AMSAA (on the All-1 helicopter) and one by the Ordinance Center and Schnol (the CODAM Study on the M60 tank) to predict combat damage.

A pilot program is currently being initiated by DA DCSLOG to combine the results of nonlethal battle damage with combat operation wear and tear of equipment to estimate repair parts and maintenance requiremests for combat essential equipment. This will be a follow-on effort to the CODAM and AMSAA AN-1 studies. Initial results of the pilot project for the M-113, AH-1S, and AN/TSQ-73 will not be available until the third quarter of FY 78. A limited number of other combat essential equipment will be addressed in follow-on studies. When data becomes available from this program, it should be applied to determine wartime ORF. Until such data is available, other data such as engineering estimates, WARPAC FM' $r$ data from test projects such as BART, and the wartime/peacetime failure factors which are being developed by DARCOM in support of the TLR/S effort should be used. 


\section{B. Niaintenance Turnarol's!d Tinies.}

These Iurnaround tinies depend upon the in-theatre transportatios: system, parts availability, and mair:tenance s! stem capacities.

\section{(1) Transportation Times.}

The study team has been unahle to find a source for definitive estimates of these times. The osly estimates which were found were provided by the USAOC\&S to the U.S. Army Logistics Center, and were for M60 tanh engines, based on a force in the SCORES MEII scenario.

$\begin{array}{lll}\text { TRANS. } & \text { TIMES } & \text { (HRS) } \\ \text { MIN } & \text { PROB } & \text { MAX }\end{array}$

\begin{tabular}{|c|c|c|}
\hline User tc organization maintenance & 2 & 3 \\
\hline Org. maint. to DSU (forward) & 7 & 15 \\
\hline DSU (forward) to DSU (rear) & 10 & 12 \\
\hline DSU (rear) to GSU & 12 & 24 \\
\hline
\end{tabular}

The estimates of transportation times depend upon the item to be moved, the deployment, and the availability of transportation resources. The most lijely soirce of such information would be a theatre-level war game, such as that dore at the Concepts Analysis Agency. Their current models, however, do not calculate transportation times.

(2) Availability of Repzir Parts.

Standards do exist in AR $\mathbf{7 1 0 - 2}$ which provide a basis for extimating the average waiting time for parts. That regulation specifies target demand accommodation rates (percent of items stocked) and demand satisfaction rates (percent of demand for stocked items which can be satisfied immediately, from stocli on hand). These otandards could be used as follows: 


$$
\text { Let } \begin{aligned}
\mathbf{d} & =\text { demand accommodation rate } \\
\mathbf{B} & =\text { demand satisfaction rate for a stock ed item } \\
\mathbf{r} & =\text { reorder cycle time for a stocl ed item } \\
\mathbf{t} & =\text { time required to obtain a nonslocl.ed item }
\end{aligned}
$$

The averaye wait for parts is

$$
\begin{aligned}
& W=\text { [Expected wait for stoclied items] X [Prob demand is for } \\
& \text { a stocked item ] } \\
& +[\text { Expected wait for nonstocked items] X [Prob demand is for } \\
& \text { a nonstocked ilem] }
\end{aligned}
$$

The expected wait for a stoclied item is simply the

[Expected wait giver the item is out of stocl.]

[Prob item is out of stock]

Now the expected wait given the item is out of stoct is one half of the expected stocl.out period or $(1-8) \mathrm{r} / 2$; and the probability the item is out of stock is simply 1 s.

The overall average wait is thus

$$
W=(d)(1-s)^{2}\left(\frac{r}{2}\right)+(1-d) t
$$

For example, assume

that nonstocked items must be requisitioned from CONUS and that the UMMIPS time standard (DODD 4500.32R) for IPG 1 applies. Then $t=12$ days

that the reorder cycle, $r=30$ days 
that $\mathrm{d}=\mathbf{8}$

that $\mathrm{s}=.75$

Then the average wait would be

$$
W=(.8)(.25)^{2}(30 \text { days } / 2)+(.2)(12 \text { days })=3.15 \text { days }
$$

A possible extension of this approach would be to calculate the proportion of the repair parts in prepositioned war reserves versus that in CONUS, apply an in-theatre requisition time to the former, and the UMMIPS time to the latter.

(3) Maintenance Times.

Estimates of the wartime maintenance times depend upon the availability of maintenance units and their capacities given that they are sctually deployed.

If the planned maintenance units cannot be deployed dia to strategic lift constraints or the shortage of other required assets, more float must be bonght to account for the additional waiting time. This would impact most heavily upon early deploying units. Ore approach would be to tse the actual deployment schedtse, and include waiting time based upon that schedule. This would be extremely cumbersone, however. The impact of assuming that the maintenaice units are deployed as required would be minimized by the fact that the ORF quantity which is calculated for the total force would be available for use by the early deploying units until the maintenance system can catch i'p. This latter approach is recommended.

Given that the maintenance urits exist, their capacities in terns of the projected wartime repair times must be estimated. Currently, no generally accepted estimates exist. Until the DCSLOG pilot project (previously cited) is completed, interim estimates such as those in the WARPAC. FM's mist be used.

(4) Waiting Times at Maintenance Facilities.

The time which an item spends waiting in a queue at the maintenance facility depends upon the capacity of the facility relative to the damands which are placed upon it. 
The current method for sizing maintenance organizations is not based upon a waiting time limit. The MACRIT process merely oizes the maintenance ocganization to provide enough direct labor man-hours to match the anticipated workload in terms of the man-hour requirement.

The most reasonable option at this time is to use peacetime data and accept the float resuirement as a lower bound.

\subsubsection{Method of Calculation.}

Given the current parcity of input data, it is recommended that the ORF program requirement be calculated as the average pipeline quantity. That is:

ORF Program Quantity = Failure Rate

(Per Deployed Item)
Average Turnaround

Time $\mathbf{x}$ Wartime Iritial
Isgue Quantity

A further reason for adopting this approach is that the AAO (wartime) is relatively insensitive to the ORF component. For many of the major firepower items, the combat consumption requirement greatly overshadows the ORF, and the estimate of combat consumption is greatly dependent upon assumptions concerning deployment schedules, enemy threat, and tactics.

The precision to be gained by using more sophisticated models for. ORF just would not be worth the extra effort. Later, as better forecasts become available, it mey be worth using more precise models. 


\section{REPAIR CYCLE: FLOAT (RCF).}

\subsection{CURRENT POLICIES.}

\subsubsection{Purpose of RCF.}

Paragraph 7-1c of AR 750-1 states the purpose of RCF as follows: "The repair cycle float is established to permit withdrawal of equipment from using organizatio:is of commands for scheduled cyclic depot maintenance and for the repair at depot mairtenarre facilities of crash-damaged aircraft without detracting from the materiel readiness of the organization or command. The RCF is used to exterd the economic service life of Arm: mate iel by providing for its timely depot maintenance on a cyclic basis. Quantities of RCF assets as authorized b: OICSLOG, DA are maintained within the supply system to provide exchange assets to usin: organizations or commands for equipment enterin: DA scheduled depot maintenance programs and for those crash-damayed aircraft evactated to depot maintenance facilities for corrective maintenance."

\subsubsection{Establishment and Use of RCF.}

The establishment and use of RCF is controlled by HQ DA and is soverned by the requirements of funded end item depot averhatil program (AR 759-1, par. 7-6f). Accourtability for RCF is maintained by the NICP and cortrol over allocation is the responsibility of the depot overhaul program manager (AR 750-1, par. 7-10b).

\subsubsection{Items to be Supported by RCF.}

Paragraph 7-3b, AR 750-1 states that: "Items selected for repair cycle float support must be :

“(1) Mission essential.

"(2) Authorized for withdrawal from using units/commands for overhaul in depot maintenance facilities after scheduled periods of use (calendar time) or operation (hours, miles, or rounds fired)." 


\subsubsection{Determinzation of RCF Requirements.}

Paragraphs 7-4d and e of AR 750-1 states that:

“d. Quantitative requirements for repair cycle float (RCF) will be determined by:

"(1) Use of appropriate analytical or simulation model; or

"(2) Applying approved RCF factors to that increment of the population of items authorized RCF support forecasted for or included in approved depot maintenance (overhaul) programs.

“e. Program/budget maintenance float (ORF and RCF) requirements will be computed as indicated in current 'PEMA Policy and Guidance for Preparation of Part I of the AMP"."

AR 700-120 states that the RCF distribution requirement is based on the density of equipment authorized in the MTOE's and TDA's of the inits being stpported and is utilized to cover equipment awaiting overhaul, in the overhaul process, and in transit to and from depot overhaul (par. 2-9).

The "Procurement Planning and Policy Guidance" states that the RCF program requirement is obtained b) multiplying the RCF factor from the SSN file times the MTOE "Required" quantities of the program force (par. 3.2.1b).

\subsubsection{RCF Factors.}

Paracraph 7.5d of $\Lambda \mathbf{R} 750.1$ requires that RCF factors be computed on a line item basis by national level materiel managers for all end items selected for RCF support. Separate factors are required for: (1) USAREUR, (2) USARPAC, and (3) other areas.

Appendix $L$ cives the following formula for computing the RLF factor:

$$
\mathrm{RCF}=\mathrm{OCT} / \mathrm{TBO}, \text { where }
$$


OCT is the overhaul cycle time and TBO is the time between overhatls. Basically, the formula provides an RCF quantity equal to the average unserviceable pjpeline.

The overhaul cycle time is the time required to evacuate items scheduled for cyclic overhaul from using commands to depot maintensnce facilities and to accomplish the scheduled overhaul. Paragraph L-5 specifies that for new items the OCT should include the standard traisportation time from the usin: command to the depot, the estimated time required to perform the overhaul, and a waiting time equal to twice the time reqi:ired to perform the overhaul. For items deployed 2 years or more, paragraph L.8 specifies that the OCT should be determined from depot maintenance performance reports.

Paragraph L .5 requires that estimates of the time between overhail (TBO) for new items be derived from acquisition and maintenance support planniag doctuments. For items deployed 2 years or more, the TBO is to be determined from the reported mileage, usage, or acquisition data, or from data of items actually overhauled (par. L-8).

For aircraft, the same basic procedure is used, except that the RCF factor includes the element of crash damage.

In February 1976, DARCOM implemented a progran for updating RCF factors based on data in the DESCOM files. TBO data is tal en from the unserviceable generation factor (UGF) file. The UGF is a 3-year moving average of actual returns per fielded end item density.

The OCT includes a pipeline time of $1 / 2$-month for CONUS, $2 \frac{112}{2}$ months for Europe, and 4 months for the Pacific. (This will be used until better pipeline data can be collected from the Continuing Balance System). The "repair cycle time" (shop time to overhaul the item) is taken from DESCOM's Master File for Maintenance (MFM). The time awaiting overhaul is set at twice the repair cycle time.

\subsection{PROBLEMS WITH CURRENT POLICIES.}

\subsubsection{Distribution Requirement vs. Program Requirement.}

Much of the discuasion of this problem in the chapter dealing with ORF applies to RCF as well. The current RCF factors are based on peacetime. A further problem which 
exists for RCF is that the compesition of the CONIS depots' worliloads may be drasticall: different in wartime than in peacetime. Thus, there mat be an RCF requirement in the $\mathrm{AAO}$ when there are no plans for depol mairtenince of that item during wartime. Conversely, there mas be no RCF peacetime requiremetil even though there are plans for wartime depot mair:tenaice.

\subsubsection{Restriction of RCF to Overhatul.}

Current policies restrict RCF to a level sufficient to stpport finded overhaul programs (AR 750-1, par. 7-5h). Jlowever, depot level maintenance operatiors are not restricted to cyclic (which is a term which, loosely taken, encompasses the new Reliability-Centered Maintenarce Concepts) overhaul. Table 1-2, AR 750-1 irdicates that the depots perform other $t_{y}$ pes of maintenance, too. Since the purpose of RCF in peacetime is to mai tain force readiness, it must be provided to cover all authorized maintentivece operations which require evacuation of isms from the field units to the CONUS depots. Therefore, it is cecommended that repair cycle float be defined as an additional quantity of selected end items/major components of equipnent approved for stocl age in the wholesale supply s: slem to replace like items of equipment withdrawn from tsing activities for depot mainteance.

\subsubsection{Forecastinge of Fquipment Return Rates.}

The GAO report (Chapter 4) points out that the current method of forec:astirg unserviceable equipment returns to the depots, which uses a 3-year noving averare, nay not be responsive to changes in maintenance concepts and other factors affecting future depot maintentunce requirements.

A previous IRO study * determined from the dat: which was then availahle, that the moving average, dessit: related, forecast performed better thar other statistical forecasting techniques. It is obvious, however, that policy chauces may isivalidate :n! purcl: statistical forecast a:d that the system should reflect such changes and selectivel: adiust thic forecasts.

*W. Karl Kruse, "Comparison of Asset Return Forecasting Techniques," IRO Report No. 212, Dec 74. 


\subsubsection{Relationship of Peacetime RCF to the Fusided lepot Maintenance Program.}

Amorg the distribution requirements for field units included in the Cateror: II MIDP are those quantities required for: (1) filling shortaces to the units' authorizations: (2) replacement of normal attrition; and (3) replacement of those items which are evacuated to the CONUS depots for maintenance (RCF).

Wthowh these separate requirements are calculated, an separate accour.ting is done for three separite pols of equipment. The CONUS depots' assets are merely classified as "ready for issue" (RFI) and as "not ready for issue" (NRFI). The RFI quantity is increased by receipts from procurement and by the output of the depot mairtenance process. It is decreased by the actual distribution of the items.

In practice, assets are distributed by fillirer requisitions or: the hasis of the priorities established by AR 11-12. A unit which returns an imserviceable asset for depot maintenance transfers accountability for the item to the NICP. As far as the unit is concerned the item is lost, just as if the asset were lost through altrition. Wher: the unserviceable asset has bren repaired, it is placed in an RF1 statrs and becomes available to fill the highest priority requisition. Thus, the unit with the hi; hest priorit: will receive in asset first, irrespective of the cause for its requisition (to fill a shortage to its authorization, to replace an asset which was consumed, or to replace an asset which was rett:rned for depot maintenance).

If a high priority unit requisitions an asset to replace one which was returred for depot maintenance, its requisition will be filled even if the RFI pool inclides no items which have come from depot maintenance. If assets are availuble, the tuit's effective order ship time is that which is required to fill its requisition.

Currently, the MIDP RCF procedures doubly account for the RCF requirement by both adding an RCF requirement for each cloimant to he filled with ready-for-issue stock, and also by ger.erating the assets in the depot maintenance pipeline which appear in the not-ready-for-issue account. The MIDP is scheduled to be replaced by the Total Arm: Equipment Distribution Plan (TAEDP), in June 1978. The double accounting has been corrected in the TAEDP by removing the assets ir the depot pipeline from the not-ready-for-issue account. However, our proposed method requires that the TAFDP retain 
the depot pipeline amoints in the not-ready-for-issue arcoint, and replace the RCF claimant requirement by the computation as discussed 4.5. This method is easily able to handle fluctuations in the depot maintenance pipeline due to chinging retur: quantities. Moreover, it also more closely simulates reality b: recognizing thit the output of depot maintenance can be used to fill at:y distribution requirement.

\subsection{PROPOSED METHOI) FOR COMPUTING; THE RCF DISTRIBUTION REQUIREMENT.}

Based on the discussion in Section 4.2.4, it is recommended that the RCF distribution requiremeit be calculated similar to that for attrition losses, as found in AR 700-120, par. 7-2. Under that procedure, the overseas commands are authorized an "operating level" (specilied b: AR 11-11) and a pipeline quantity ("in-use" density times the consumption" (loss) rate times an order ship time). The total quantity is limited to 150 days of supply.

The main difference for RCF is that there should be ro "operating level" quantity. The term "operating level," as used in AR 700-120, reall: corresponds to a safety level in supply management terminology. Since returns for depol maiitenance are more predictable :hai attrition losses, and are somewhat conirollable, there is little need for such a safet: level.

The RCF distribution requirement should be calculated as follows:

$$
\begin{aligned}
& \mathrm{RCF}=(\mathrm{RR})(\mathbf{O S T}) \\
& \text { when } R R=\text { the forecasted return rate (using either a } \\
& \text { historioal average unserviceable qeneration: } \\
& \text { factor times the in-use density or a: adjusted } \\
& \text { forecast, as required.) } \\
& \text { OST } \quad=\text { The same order ship time as used for the } \\
& \text { attrition requirement. }
\end{aligned}
$$

The OST would be limited to 150 dar s minus the AR $11-11$ operating !evel. 


\subsection{PROPOSED POLICIES FOR THE RCF PROGRAM REQUIREMENT.}

\subsubsection{Relationship Between RCF and the Depot Maintenance Mobilization Plan.}

The program (wartime) requirement for RCF depends tpon the decisions which are made regarding the planned depot maintenance mobilization workload. It mist be consistent with the forecasts of items to be returned from the combat theatre and upon the projection of the depots' capabilities to restore items to serviceability. It also depends upon the ability of the transportation system to move assets from and to the theatre.

Conversely, decisions concerning the sizing of the depot complex to meet the wartime worlJoad depend upon the cost of the float which would be required to support a gives: allocation of the depot maintenance capacity.

The determination of the RCF program requirement must, therefore, be done as part of an integrated planning system, that is the DARCOM Depot Maintenance Mobilization Plan. This plan is required to be dzveloped biesnially, each even calendar year. The discussion which follows shows how the determination of the RCF requirement can be integrated with that plan.

Figure 4-1 shows the cumulative generations of urserviceables and the cimulative returns from the depots over the duration of a wartime scenario $\left(t_{w}\right)$, from the perspective of the combat theatre. A graph such as this would be constructed for each item (major or secondary) which is included in the Depot Maintenance Mobilization Plan (DMNP).

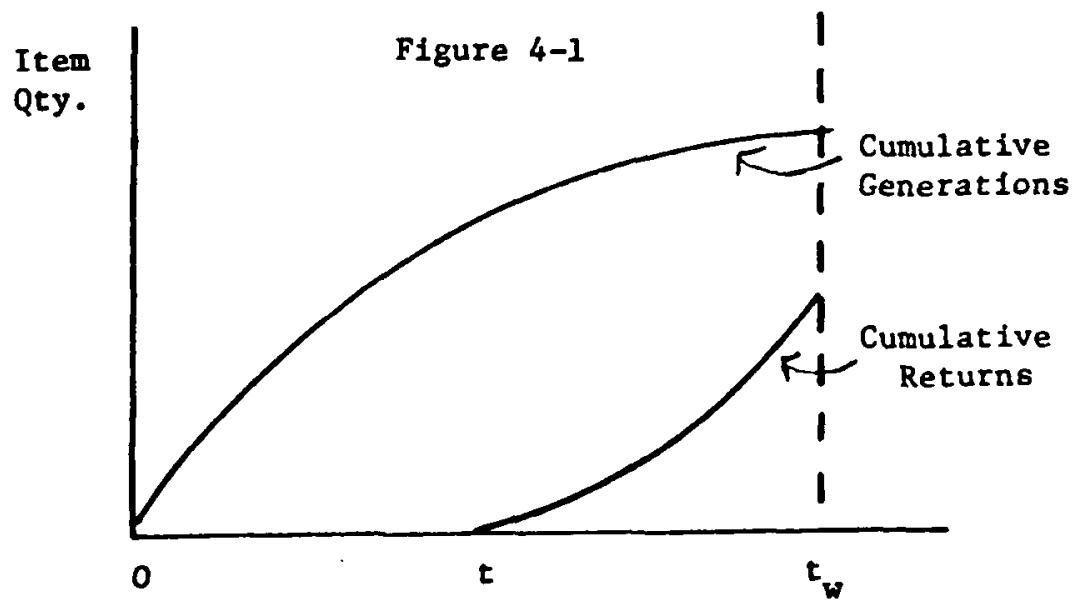


The cumulative generations curve is the basic input to the DMMP and depends upon the deployment schedules, intensity of equipment usage, and the rate at which items become unserviceahle (eg., quantity/mile/end itern deployed).

The slope of the cumulative returns curve depends upon the output rate of the depot over time, which is based upon the portion of the depot capacity which is allocated to the repair of the item. It should be noted that the cumulative return curve reflects only the depots' output of these items which were evacuated during the war.

The initial time lag, $t$, depends upon the transportation times, the time required by the depot to reduce the bacllog of M-day unserviceables, and the depot turnaround time for the item.

The monthly RCF requirement is computed from the difference between these two curves, and the maximum being the overall RCF requirement.

It should be noted that this is basically the same method which is used to calculate the combat consumption quantity for the AAO. Losses are accumulated over the duration of the war, and the maximum quantity is tal.en (see Figure 4-2 grrph). Unlile the proposed RCF, there are no offsetting returns to use; therefore, the maximum occurs at the end of the war.

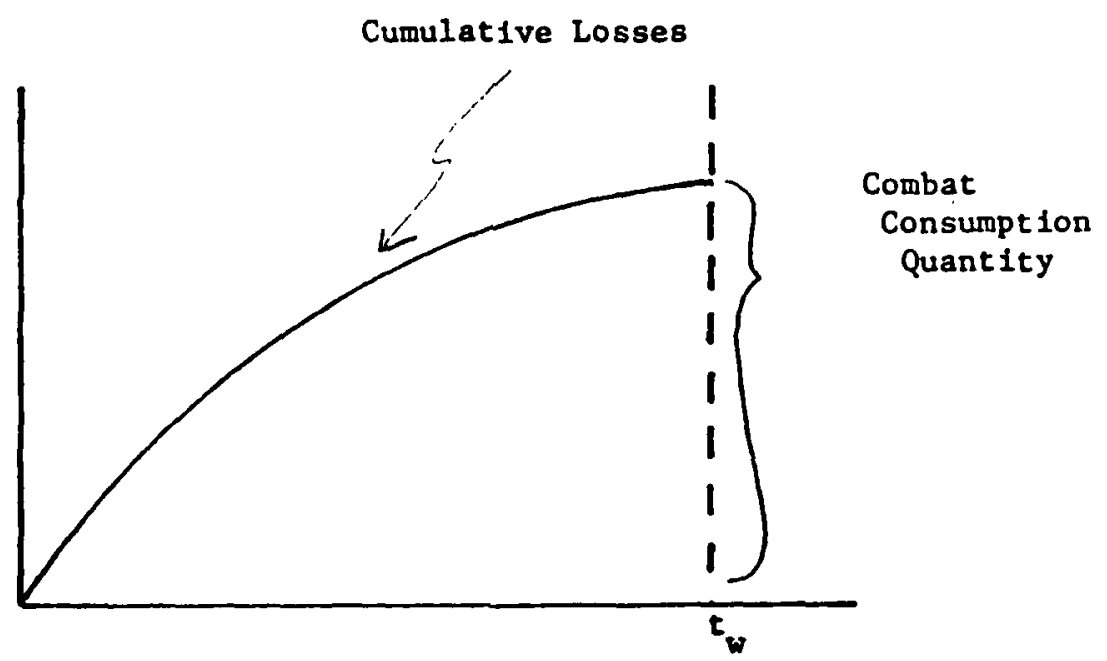

Figure 4-2 
Example number 1 in Appendix $I$ illustrites the applicatior: of the proposed method to a hypothetical item.

\subsubsection{Interactions Between the Conbat Consumption and Repair Cycle Flu:t} Requirements.

For items which have a combat consumption requirement, a quantit: if equipment is included in the AAO to replace combat losses diering the war. As previou sl: mentioned, the method used is basically the same as that which is beirg proposed for RCF. It should be noted that the requirement for replacing losses occurs over time, however. Therefore, if we have boingt the total AAO, assets which were boriht for combat co: :mption may be available to serve as repair cycle fluat. Conversely', if the maxin:' ' $n$ repair cycle float requirement occurs early in the war (as ir: the example). the depets' ontput will be available to replace cumbat losses later. It is quite possible, therefore that separate calculations of combat consumption and RCF may overstate the total requirement.

Example ntuber 2 of Appendix $H$ illustrates how the joi:t requiremert determination car be done.

\subsubsection{Updating in: Odd Calendar Years.}

Sirce the DMMP is required to be routinely undated each even calerdar :ear. there will be years when the RCF computation nust be based on a DMMP which is based on! a different deployment schedule. One method of updatiz: the RCF requirement world be to:

(1) Recompute the cenerations ising the ratios of gesserations to density from the DMMP times the new deployed densities.

(2) Use the transportation and depot repair times and the maximum indiction rates from the DMMP.

(3) Update the forecast of the D.Day unserviceables. 
(4) Recalculate the cumulative generations and depot output based on the above.

(5) Combine the output of (4) with the updated cumulative combat consumption quantity and determire the joint requirement. 


\section{APPENDIX A}

\section{RFFERFNCES}

1. Letters, DRCMM-M, dated 9 Nov 76 and 22 Dec 76, subject: Repair Cycle Float Study.

2. Letter, DRCPA-S, dated 16 Nov 76, subject same as 1 .

3. Letter, DRCMM-MS, dated 2 Dec 76, subject same as 1.

4. Letter, DALO-SML, dated 30 Dec 76, subject same as 1.

5. Report of Audit, "Commodity Command Functional Audit Maintenance Float and Direct Exchange U.S. Army Tank-Automotive Command, Warren, Michigar," Audit Report: NE 75-54, U.S. Army Audit Agency, 28 Apr 75.

6. "Audit of Maintenance Float and Direct Exchange," Audit Report: NE 76-214, U.S. Army Audit Agency, 26 Mar 76.

7. Report of Audit "Maintenance Float U.S. Army Electronics Command, Ft. Monmouth, NJ," Audit Report: NE 75-68, U.S. Army Audit Agency, 30 Jun 75.

8. Draft "Improvements Needed in Computing the Requirements for Spare Equipment at Army Maintenance Activities to Maintain Operational Readiness," DA (Code 9472.6) prepared by U.S. General Accounting Office, 19 Sep 76.

9. "Better Management of Spare Equipment Will Improve Maintenance Productivity and Save the Army Millions," LC0-76442, prepared by U.S. General Accounting Office, 5 Apr 77.

10. "A Study to Determine the Cost Impact of Maintenance Floats," U.S. Army Maintenance Management Center, Lexington, KY, April 1976.

11. Draft, "Review of Operational Readiness Float Concept," U.S. Army Logistic Evaluation Agency, New Cumberland, PA, Nov 76. 
12. "Review of Operational Readiness Float Concept," I.S. Army Logistics Evaluation Agency, New Cumberland, PA, Jun 77.

13. AR 1-1, Planning, Programing, and Budgeting Within the DA, 25 May 76.

14. AR 220-1, Usit Readiness Reporting, 17 March 1975.

15. AR 700-120, Materiel Distribution Management, 14 Mar 74.

16. AR 750-1, Army Materiel Maintenance, Concepts, and Policies, 1 May 72, Draft Charge 1, 5 Dec 75, Draft Change

17. AR 750-37, Sample Data Collection, The Army Maintenance Management System (TAMMS), 24 Mar 71.

18. AMCP 750-6, Maintenance of Supplies and Equipment, Techniques for Determining Optimal Operational Readiness Float, Jun 71.

19. AMCP 750-7, Techniques for Determiniric Repair Cycle Float, Jun 71.

20. TM 38-750, The Army Maintenance Management System (TAMMS), Nov 72.

21. TM 38-750-1, The Army Maintenance Management System (TAMMS) Field Command Procedures, Nov 72.

22. Sherbrooke, Craig C., "An Extension of Palm's Theorem for (M G s) Qneues to the Case Where Arriva! and Service Rates Depend on the Number of Busy Chanrels," P-3406-1, The RAND Corp., Nov 66.

23. Sherbrooke, Craif C., "Metric: A Multi-Echelon Technique for Recoverable Item Control, "Memorandum RM-5078-PR, The RAND Corp., Nov 66.

24. Muckstadt, John A., "Model for Multi-Item, Multi-Echelon, Multi-Indenture laventory Systems," Management Science, Volume 20, No. 4, Dec 73. 
25. Muchstadt, Joh: A., "Fstimation of Optimal Depot Stock in Two-Echelon Inventor: Systems for Recrverable Items," The RAND Corn.

26. Trletype, DALO-SML, dated 7 March 77, s'biec:l: Operational Readiness Ilerit Study. 


\section{APPENDIX B}

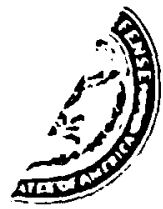

DEPARTMENT OF THE ARMY

OFFICE OF THE DEPUTY CHIEF OF STAFF FOR LOGISTICS

WASHINGTON, D.C. 20310

DALO-SMI

SUBJECT: Repair Cycle Float Study

Commander

US Army Materiel Development

and Readiness Command

5001 Eisenhower Avenue

Alexandria, VA 22333

1. References:

a. Letter DALO-SML dated 7 Sentember 1976, subject, Repair Cycle Float (RCF).

b. LEA Draft Report, dated November 1976 , subject, Review of Operational Readiness Float (ORF) Concept.

2. Referenced letter requested DARCOM perform a study on the Repair Cycle Float (RCF) portion of Maintenance Float. Because maintenance float is the total number of spare major components and end items required to sustain military operations at a desired level while repair or overhaul is performed, it is the combined effect of ORF and RCF which relates to operational readiness. It makes 1 ittle or no difference to the user whether the items are being repaired at DSU/GSU or at a depot; in either case they are not available to him. Consequently, all float assets, both ORF and RCF, and their individual and collective impacts on availability or serviceable items to the user should be studied.

3. The problems of the float manager/user at the Division and separate Brigade level are keynote to this study. Request that in conjunction with the overall maintenance float study, a survey to disclose current problems at the retail level be conducted. This"should result in a philosophy of investing ORF resources only in high payoff strategies.

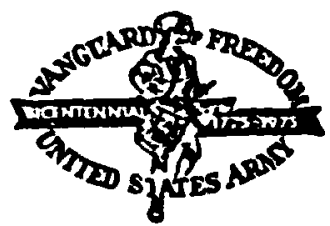

B-1

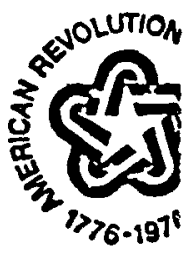


DALO-SML 21190

: 0 UEC 1976

SUBJECT: Repair Cycle Float Study

4. Request the DARCOM study plan be modified to include methods for establishing ORF requirements and management of $O R F$, as well as for RCF. Care should be exercised to avoid duplication of efforts already expended by the LEA during their study, referenced l.b. above.

5. This additional requirement does not change the expected completion date of May 1977.

FOR THE DEPUTY CHIEF OF STAFF FOR LOGISTICS:

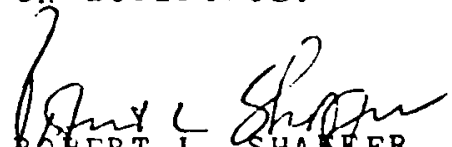

KOEERT L. SHA FER

$\mathrm{COL}, \mathrm{GS}$

Chief, ILS and Maintenance

Engineer1ng Division 
DRCPA-S

SUBJECT: Repair Cycle float (RCF)

Director

Inventory Research Office, ALMC

Room 800, US Custom House

$2 \mathrm{~d}$ and Chestnut Streets

I iladelphia, PA 19106

1. Reference is made to inclosed DF, DRCMM-M, 15 November 1976 , subject as above.

2. Request that your office take the lead in the subject study. Actual participation of other DARCOM activities, centers and offices on the study will be determined during the meeting referred to in paragraph 5 of the referenced DF. The study plan is also included in the referenced DF.

3. Points of contact for this effort will be Mr. Dan Taber (DRCMM-M/ Autovon 284-8575) and Mr. Clair Weiss (DRCPA-S/Autovon 284-9456).

l Incl

as

CF:

DRCMM-M

Cmdt, ALMC (DRXMC)

Cmdt, ALMC (DRXMC-ISO)

Dir, AMSAA (DRXSY-CL)

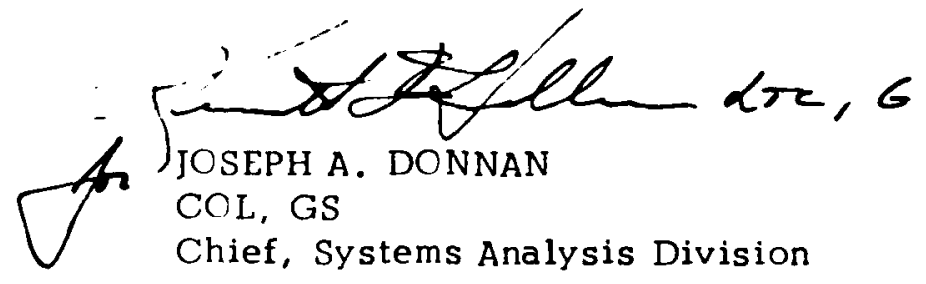




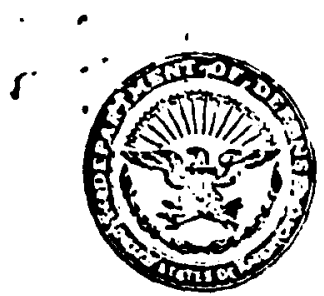

DALO-SML 1939 ?

SUBJECT: Repair Cycle Float (RCF)

Commander

US Army Materiel Development

and Readiness Command

ATTN : DRCRE

5001 Eisenhower Avenue

Alexandrla, Virginia 22333

1. There is a need to revalidate the Repair cycle Float pol1cles of the Department of the Army.

2. To satisfy this need it is requested that a study be undertaken to be titled "Department of the Army RCF Pollcy, Management Guidance, Practices, Procedures and Methods Used to Establ1sh Repair Cycle Float Requirements". The objectives of this study should be:

a. Determine the adequacy of current pollcies, management guldance, practices and methods used in computing RCF,

b. Identiflcation of any portion of RCF pollcy or guidance which is in need of change.

c. Identification and Justification of changes, which should be incorporated in DA RCF policy and other guidance,

d. Development of data as necessary to justify methods used to compute RCF requirements and/or justify any proposed changes in computation.

3. It is further requested that HQDA (DALO-SML), Washington, D.C. 20310 be advised NLT 20 Sep 76 as to the activity which w1ll conduct the study and a general study plan with milestones

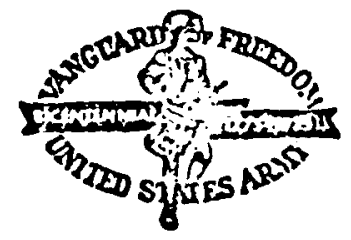

B-4

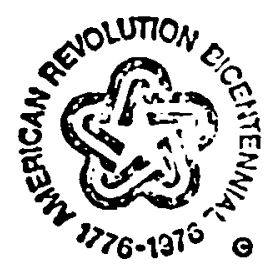

Dad. I. 
DALO-SML

SUBJECT: Repalr Cycle Float (RCF)

Including the projected date on which results of the study can be made avallable to HQDA (DALO-SML). Further request that a point of contact for matters concerned with the study be designated. HQDA contact $1 \mathrm{~s} \mathrm{Mr,} \mathrm{W.H,} \mathrm{N1chols,} \mathrm{HQDA} \mathrm{(DALO-}$ SML), telephone: 675-6962.

FOR THE DEPUTY CHIEF OF STAFF FOR LOGISTICS:

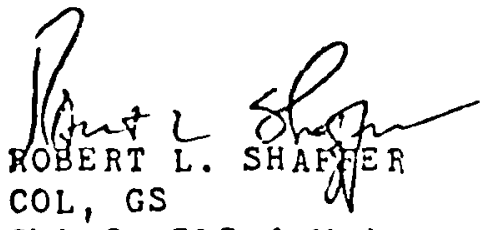

Chief, ILS \& Ma1ntenance

Engineering Division 
DRCM-M

SURJECI: Repaly Cycle Mate (RCP)

NOV $9 \$ 976$

BQ DA (DALO-GRL)

WASH DC 20310

1. Reference 10 made to letter DALO-S:LL dated 7 septecter 1976, subject, Repasr Cycle Float (RCP.) v/lst Ind DRCIM-k's ceted 23 septerber $2370 ́$.

2. An outline study plan, wth a schedule ior accomplishwent, has been developed based or evaluation of the eco:e and iagnitude of suoject letter that rust be addressed. It is forvaried for your infoimation.

3. Point of contact for tinis project in Bq Drico.1 is Mr. Dan Taber, telephone, $274-3535$.

FOR THE CCANAAIDER:

¿Incl

aB

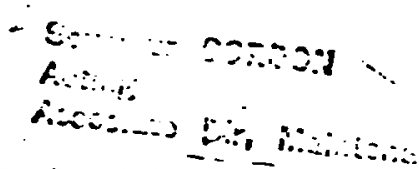

R. D. DSscomeñú

Colonel, GJ

Associate Director for

Masntenance

CY FURNISHED:

DRCPA 


\section{STUDY PLAN}

TITLE:

RHEERENCE:

PURPOSE:

SPONSOR:

STUDY LEAD AGENCIES/

ACTIVITIES
U.S. Army Repair Cycle Float Policy and Procedures

Letter DALO-SML dated 7 September 1976. subject, Repair Cycle Float (RCF)

Review and recommend changes as appropriate to Army RCF policy, management guidance, practices, and procedures and methods used to establish ard vilidate RCF requirements.

U.S. Army Development and Readiress Cumnand Directorate for Materiel Management

ATTN: DRCMM-M

5001 Eisenhower Avenue

Alexandria, VA 22333

U.S. Army DARCOM Inventory Research Office

U.S. Customs House

2d and Chestnut Streets

Philadelphia, PA 19106

U.S. Army Maintenance Management Center ATTN: DRXMD-M

Lexington, $\mathrm{KY} \mathbf{4 0 5 0 7}$

PARTICIPATING AGENCIES/ ACTIVITIES:
U.S. Army Depot System Command

Chambersburg, PA 17201

U.S. Army Materiel Systems Analysis Activity ATTN: DRXSY.P

Aberdeen Proving Ground, MD 21005 
1. Review and evaluate current policies and procedures for establishing and validating $R C F$ requirements including DOD, DA, DARCOM, and DARCOM Commodity/Readiness Commands.

2. Review recent studies and reports on RCF for problem areas and alleged deficiencies in present policies and procedures, sn as to avoid duplication of effort. (AAA Audits, GAO Draft Report, AMMC Stıdy, etc.)

3. Identify and evaluate methods for establishing float factors and control of float assets used by other services for possible applicability to Army.

4. Review technical and operations research literature for developed nethods which may be adaptable to Army use.

5. Study depot programing and scheduling process to ascertain validity of current formulas and standards.

6. Develop new formulas for establishing RCF factors, if appropriate.

SCHEDULE: $\quad$ l. October 1976

a. Preliminary studies by HQ DARCOM and the Inveatory Research Office to define scope of project.

b. Review AVSCOM projects to validate Maintenance Float Factors and new methods for predicting attrition rates.

2. November 1976

a. : Establish Study Advisory Group (SAG) comprised of representatives from HQ DARCOM, Lead and Participating Activities.

b. Prepare and issue specific tasling instructions to all participants. 
3. Dec:mber 1976 -Mar:lı 1977 Participats :ondict strdie: i. assigred areas. Monthly progress meetio os by SAR.

4. April 1977-Prepare draft report.

5. Nay 1977--Staff report and forward to INA. 


\section{APPENDIX C}

\section{WHOLESALE QUESTIONNAIRE}

\section{C.1 Introduction.}

A questionnaire was developed and sent out to the DARCOM major support commands and project managers in an effort to find out how Repair Cycle and Operational Readiness Float requirements are established and managed at the wholesaie level.

Section C.3 summarizes the responses to this questionnaire (complete questionraire responses are in the IRO files). Project manager responses are simmarized along with the MSC responses. It should be kept in mind, however, the PM's enter the float determination process mainly when the item is in the development stace.

\section{C.2 Sample Questionnaire and Letter of Direction.}


SUBJECT: Study on Repa1r Cycle Floata

TO: SEE DISTRIBUTION ATTACHED

1. References:

a. AR 750-1, Army Materiel Maintenance Concepts and Policles, May 1972.

b. AMC Pamphlet 750-7, Techniques for Determining Repalr Cycle Float.

2. DARCOM has been requested by the DCSLOG to conduct a comprehensfve study of the Army Maintenance Float policies and procedures. To this end, a study project has been inftlated with the DRC Inventory Re--search office (IRO) as the lead study activity; other-activities thatwill be involved in the project are the Army Materiel Systems Analyolo Activity (AMSAA), the Depot Systems Command (DESCOM) and the Maintenance Management Center (MAC). Head of the Study Advisory Group for the study 1s Mr. Dan Taber of DARCOM (DRCMM-M).

3. As one of the first tasks, we want to find out how Repair Cycle and Operational Readiness Float requirements are established and managed by :-your organization. A questlonnalre has been developed for this purpose and is inclosed. Would you please fill tt out to the best of your ab111ties and return $1 t$ by no later than 4 February 1977 to -

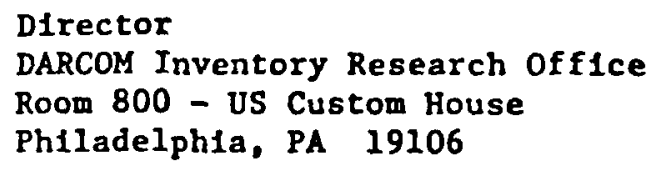

If there are any questlons, please call Mr. Rosenman or Mr. ' stwals at the IRO (AV 348-6984).

4. It is 11kely that there will be a few meetings while new policles and methodologies are under development and participation by your Activity

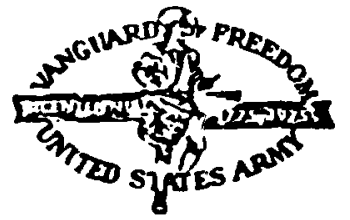

C2

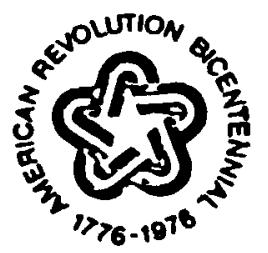


DRCIRO

SUBJECT: Study on Repair Cycle Floats

w11l in all likelihood be desired. Would you please deslgnate someone who could serve as focal point for future contacts and give his organization symbol and phone number?

Incl as

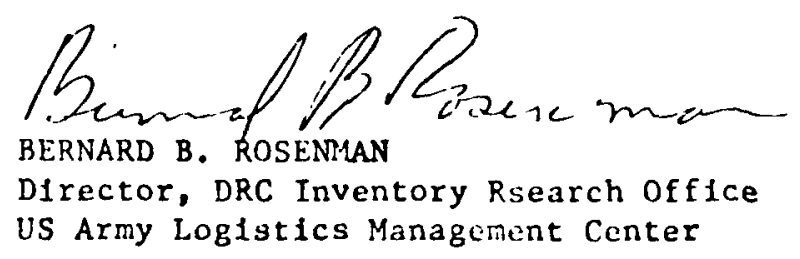

Coples furnished:

AMSAA - Larry Smith, DRXSY-CL

MMC - Conrad Weisser, DRSDS-LL

DESCOM - John Fortune, DRXM-MS

Ray Astor, Logistics Evaluation Agency

DRCMM-M - Dan Taber

$\begin{aligned} \text { CC: } & \text { - } \\ & \text { DRCIRO Prof } 2.51 \text { File } \\ & \text { DRCPA-S } \\ & \text { ALMC Reading F1le }\end{aligned}$ 


\section{MisikriguTION}

\section{COPUNDS}

US Ariay Tank-iutomotive Research \& Development Corimand

US Aring Tank-hutomotive Materfel keadfuess Cominand

US Army Armament Comand

US Army lilectrontes Con:mand

US Aliny Mssile Cominand.

IIS Ar:ny Troop Support Coriand

lis Ariny hutation Syitcris Colisind

lis Aluny Test o Evaluatfou Colinand

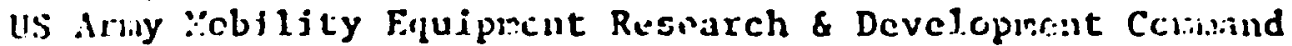

\section{P!()JECT MAACLRS}

COL Edward M. Brissire, AVSCOM

COI Russell W. Parker, ARitiCOM

LiC William R. Gren, YCOM

UG Willicm J. Hils;:an, HoOM

rol Ronald E. Philipp, Piratinay Aisconal

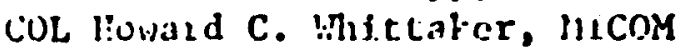

Col Cliarles F. Drenz, iviscom

COr, Fred lije:song, Jr., TARCOM

COI, Artlur L. Coolial1, HICOM

ror. $\because a x$. B. Scheider, Ft. Belvolr, VA

iOL Wil.liam J. Harrtson, ECOM

COL Kenneth S. Heltzke, HICOM -

$\because A J$ John W. Hocking, TARCOM

(b) Charles C. Adsit, TARADCOM

()I, Donald P. Nhalen, MICOM

CO! Rubert E. Eutler, TARCOH

IíC Brinjarin A. Hluggin, ARMCOM

COL Roy A. Cunniff, ThRCOM

LF Stian R. Sheridan, TARADCOM .

(i). Ralph H. Slevers, Jr., Springficld, YA

$\because$ Cirarles F. reans, Uricom

Cit, T.arey H. liunt, liTco:A

CoL :i11iem D. Clingelpeel, FCOM

Cor. I. -vjd F. Green, iICOM

EG Fi:ink P. Rigano, MICOM

(i)L Richard D. Kenjon, AlsCOM

col libert W. Iacquement, MICOM

:G robert J. E::cer, TAPADCOM

COL Patrick M. Reddy, Redstone Arsenal 


\section{MAINTENANCE FLOAT QUESTIONNAIRE:}

(U'se Separate Pages to the Extent Necessary)

1. What organization in your activity is responsible for:

a. Determining the end items for which Maintestance Float should be authorized?

(1) Repair Cycle Float.

(2) Operational Readiness Float.

b. Performing the calculations to determine Maintenance Float quantities?
(1) RCF.
(2) ORF.

c. The approval of $\mathrm{la}$ and $\mathrm{lb}$ for budget submission?
(1) RCF.
(2) ORF.

2. What criteria are used in selecting the end items and major components for which a Maintenance Float should be authorized? Not authorized?
(1) RCF.
(2) ORF.

3. What model(s) or formulas are used at your Activity for calculating Maintenance Float quantities? (Cite references-e.g., AR, DARCOM Pamphlet, Technical Report. etc.-where the model(s) are described.)
(1) RCF.
(2) ORF. 
4. Do you talie into account the Operational Readiness or Availability Target(0) for the end items for which Maintenance Floats are calculated?

a. If so, how are these targets expressed?

(1) RCF.

(2) ORF.

b. Where are these targets obtained (e.g., AR)?

(1) RCF.

(2) ORF.

5. Select five representative systems for which float has been authorized and tell us what percentage of the RCF and ORF was actually procured.

\begin{tabular}{|c|c|c|c|c|}
\hline \multirow[b]{2}{*}{ System } & \multicolumn{2}{|c|}{ RCF } & \multicolumn{2}{|c|}{ ORF } \\
\hline & Quantity & $\%$ of Authorized & Quantity & $\%$ of Authorized \\
\hline & Procured & & Procured & \\
\hline
\end{tabular}

(1)

(2)

(3)

(4)

(5) 
6. How do you estimate the following demands on the Repair Cycle Float for the RCF calculations?

a. Scheduled overhauls?

b. Failures from GSU.DSU?

c. Unscheduled overhauls?

d. In determining the above estimate, do you consider wartime or peacetime conditions?

7. How do you estimate the demands on the Operational Readiness F loat?

8. How do you estimate the Depot Repair Cycle Time for the RCF calculations?

a. Do you estimate the elements of the Depot Repair Cycle Time? If so, how?

(1) Time awaiting induction into depot overhaul?

(2) Actual shop time?

(3) Time awaiting pickup (i.e., assignment either to user or transfer to RCF)?

9. How do you estimate the DSU/GSU repair time for the ORF calculations?

10. From what sources, and how, do you obtain the data needed for Questions 6, 7, 8, and 9 ? 
11. Do you maintain a data base for the purpose of Maintenance Float calculations and updating? If yes,

a. In what form is the data base (i.e., hard copy, computer tapes)?

(1) RCF.

(2) ORF.

b. How often is the data base updated?

(1) RCF.

(2) ORF.

12. Do you have in process any study at your activity designed to improve the Maintenance Float calculations? If so, please describe the nature of the effort. (Who's doing it? What approaches are being taken, etc.?) 
13. In terms of Float Ma: acement:

a. Is thoat stock difierentisted from other stocl ?
(1) RC.F.
(2) ORF.

b. Do end items which were exchanged for fluat items ard stbsequent!:, renaired or overhauled return to the float or to other stock. such as war r.serve or PON!CIS?
(1) RCF.
(2) ORF.

c. Is any maintenauce performed on Mainten:ance Float stw.h?
(1) RCF.
(2) ORF.

d. How is serviceable RCF treated at depot, e.s.: preserved for storage, exercised regularly, modifications applied, etc.?

e. Are urserriceables, waiting for overhaul or repsir considered part of the float quantity?

(1) RCF.

(2) ORF.

f. Is there a specific organization within your activity responsible for float management? If so who? 
1. In a lew words please describe what is involved in issuing an end item from the Maintenance Float including the:

a. Decision process in determining whether an issue should be made.

b. Timing of the exchange.

c. Responsible activity.

(1) RCF.

(2) ORF.

15. What suggestions could you offer to improve the policies governing the establishment and control of Maintenance Float and for improving the methods by which the Maintenance Float quantities are calculated? 


\section{(..3 SUNMARY OF RLSPONSFS TO THE COMMOIOTY COMMAND WHOLISALE, QUFSTIONNAIRE.}

1. What organization in your activity is responsible for:

a. Determining the end items for which Maintenance Float should be authorized?

Except for AVSCOM and MIRCOM, the MSC Maintenance Directorates decide what items should have maintenance floats. At AVSCOM, float authorizations are reserved for IIA decision. At MIRCOM, the authorization decisions are made jointly by the maintenance and engineering directorates and the project manager. PM's also participate in the decision-making process at the other MSC"s to varving degrees.

b. Pertorming the calculations to determine maintenance float quantities:

RCF and ORF calculations are made mostly in the maintenance directorates. It MIRCOM. PM's may take an active part in quantititive determinations on some sy=tem. At AVit.(O). the Systems Analysis Office has periormed ORF calculations on some aircraft and their methodology has been approved by IMA for general use on future aircraft ORF calcrlativis. As a general rule, the PNIs are responsible for generating the data needed for float calculations for systems in developmental stages.

c. The approval of $1 \mathrm{a}$ and $\mathrm{lb}$ for budget submission?

Answers to this question were quile varied indicating perhaps that the question was interpreted differently by the respondents. In most instances, the maintenance directorates are involved in the approval process, along with materiel management directorates and project managers. At MIRCOM, the PM's are are responsible for the budget stbmission and, at AVSCOM, DA takes an active part in budget development.

2. What criteria are used in selecting the end items and major components for which a Maintenance Float should be authorized? Not authorized?

All respondents indicated that the criteria contained in $A R$ 750.1 are applied in deciding which items should have floats. ECOM indicates that they will sometimes use the 
inerahzed Hertronics Maintenance Model (CFMM) to determine which items need floats in order to achieve operational availability tarogets.

3. What model(s) or formulas are used at your activity for calculatin maintenance float quantities? (Cite references-e., AR, DARCOM Pamphet, Technical Report, etc.-where the model(8) are described.)

All commands indicate that they use AR $750 \cdot 1$ and, in some instantés, AHCD 750.6 and 750-7, for fluat calculations. At MIRCOM, however, where Repair Cycle Floats have not been requested in the past, special studies have been undertaken for certain missile systems to determine whether RCF's should be acquired. Also at MIRCOM, a specially designed multiechelon simulation model was used to determine HAWK and IHAWK ORF requirements: and, as indicated above, ECOM has used GEMM, and AVSCOM has used a model developed by their Systems Analysis Oifice, for some systems.

4. Do you take into account the operational readiness or availability target(s) for the end items for which Maintenance Floats are calculated?

a. If so, how are these targets expressed?

b. Where are these targets obtained (e.g., AR)?

Responses to these questions were quite varied. For the most part, however. commands seem to be using at least implicitly the 80-percent satisfaction of demands for ORF items target civen in AR 750-1. No target is used for RCF. One response mentioned use of the required operational capability document as the basis and source of its operational availability target and, in another instance, the Materiel Need document was cited as the basis for determining system overhaul frequency and, thus, the RCF requirement. Surprisingly, no response mentioned readiness or equipment availability targets griven in AR 220-1 and AR 750-52.

7. Select five representative systems for which float has been authorized and tell us what precentage of the RCF and ORF was actually procured. 
Three of the commands reported that they did not have tite tiatit to answer this: question, although they could iell us what portion of the AAO was suthorized a:d prociured. Statistics or: two of the others (ARRCON and TARCOM) ware as follows:

\begin{tabular}{cccc}
$\begin{array}{c}\text { NO. OF SYSTEMS } \\
\text { REPORTED }\end{array}$ & $\begin{array}{c}\text { \% AUTH RCF } \\
\text { PROCURED }\end{array}$ & $\begin{array}{c}\text { NO. OF SYSTENS } \\
\text { REPORTED }\end{array}$ & $\begin{array}{c}\% \text { AUTH ORF } \\
\text { PROCURE. }\end{array}$ \\
\hline
\end{tabular}

$\begin{array}{llll}5 & 100 & 6 & 100\end{array}$

$\begin{array}{llll}3 & 0 & 1 & 0\end{array}$

MIR OM is a special ciuse becas:a of systems lile HAWK and PERSHING where differeis amounts of ORF are authori reported on 19 major il.n's as shows below:

NO. OF MAIOR ITEMS

12

3

4
\% FLOAT PROC.UREI)

100

$85--99$

less than 85

MRCOM had no R.CF"s authorized.

6. How do you estimate the following demands no the Repair Cycle Floct for the RCF calculations?

a. Scheduled overhatus?

b. Failtires from (iSU.DSU?

c. Urscheditled overharils?

d. In determining the above estimate, do :on co:sider wartir?s r.r rescetims conditions? 
$\therefore$ How do you estimate the demands un the Operational Readiness Float?

8. How do you estimate the Depot Repair Cycle Time for the RCF calculations?

a. Do you estimate the elements of the Depot Repair Cycle Time?

(1) Time awaiting induction into depot overhaul?

(2) Actual shop time?

(3) Time awaiting pickup (i.e., assignment either to user or transfer to RCF)?

9. How do you estimate the DSU/GSU repair time for the ORF calculations?

10. From what sources, and how, do you obtain the data needed for Questions 6, 7, 8, and 9?

Answers to Questions 6-10 can all be summarized together.

In developmental stage, most commands that do float calculations use engineering data and data collected for the Logistics Support Analysis Record (LSAR) in their float calculations. Standard Transit, Awaiting Repair and Days in Ship Times in AR 750-1, Appendix L, are used when other data are not available. As mentioned above, AVSCOM has used regression techniques on data obtained from DA 1352 Reports (Aircraft Status and Flying Hours) to obtain estimates of maintenance frequencies and times for some aircraft and will presumably use these techniques more generally in the future.

In responding to the question of whether peacetime or wartime conditions are assumed when estimating RCF requirements, three commands responded WAR; two PEACE! (MIRCOM did not respond since they did not compute RCF's.) Obviously, here is an area where policy must be clarified.

11. Do you maintain a data base for the purpose of Maintenance Float calculations and updating? If yes:

a. In what form is the data base (i.e., hard copy, computer tapes)? 
b. How often is the data base updated?

Most commands have data base at least partially automated that contain data needed for float calculations when systems are in the developmental stage. With the exception of AVSCOM, however, which used an automated DA 1352 file, none of the commands has any data from which RCF and ORF determinations could be reviewed after the equipment has been deployed. There is information coming from the field on maintenance actions or float status except to a limited degree that these Sample Data Collection (SDC) plans but even here it does not appear that these data contain sufficient information to run RCF and ORF calculations. Indeed, several commands commented that the AR 750-1 requirement for biennial updating of float factors should be deleted unless a field data collection program can be set up.

12. Do you have in process any study at your activity designed to improve the Maintenance Float calculations? If so, please describe the nature of the effort. (Who's doing it? What approaches are being taken, etc.?)

With the exception of the work done by the AVSCOM Systems Analysis Office, no commands reported any significant study efforts in progress.

13. In terms of float management:

a. Is float stock differentiated from other stock?

Except for locomotives, all commands reported that float items are handled like any other items, being issued in accordance with AR $11-12$ priorities. We interpret their replies as applying to float items in the hands of the NICP's, since responses to field questionnaires show that some differentiations are observed.

b. Do end items which were exchanged for float items and, subsequently, repaired or overhauled return to the float or to other stock such as War Reserve or POMCUS?

All are returned to Condition Code A stock and issued in accordance with AR 11-12 priorities. 
c. Is any maintenance performed on Maintenance Float stock?

Five commands responded yes to the question; one did not know.

d. How is serviceable RCF treated at depot, e.g., preserved for storage, exercised regularly, modifications applied, etc.?

Five commands responded that RCF items are treated like any other A stock (preventive maintenance, maintenance in storage); one did not know.

e. Are serviceables, waiting for overhaul or repair, considered part of the float quantity?

Since float assets are not differentiated, this question is not germane.

f. Is there a specific organization within your activity responsible for float management? If so, who?

The answer to this was uniformily "No."

14. In a few words please describe what is involved in issuing an end item from the Maintenance Float including the:

a. Decision process in determining whether an issue should be made.

b. Timing of the exchange.

c. Responsible activity.

From the NICP's standpoint, float assets are not differentiated from other assets and are isoued in response to customer requisitions in the same way as requivitions for other purposes, in accordance with AR 725-50 and AR 11-12. 
15. What suggestions could you offer to improve the policies governing the establishment and control of maintenance floats and for improving the methods by which the Maintenance Float quantities are calculated?

The most frequently voiced suggestion was to remove the AR 750-1 requirement for biennial update of RCF/ORF factors until data can be obtained for this purpose. Allied to this is the suggestion that a feedback reporting system be set up on float utilization.

One command recommended that the term "wartime" needs a much more specific definition before it can be used in RCF/ORF calculations.

One other command felt that the recent GAO/AAA recommendations were appropriate. Further, it was proposed that float at wholesale level be abolished and that major commands be permitted to determine and justify their float requirements. 


\section{Precedang Page BLank - Filmed in}

APPENDIX D

FIELD QUESTIONNAIRE

\section{INTRODUCTION}

D.1 As an additional requirement to this study, DA requested that a field survey be conducted to uncover curent problems in management and itilization of operational readiness float resources at the retail level. The intent of the survey is to help in determining strategies for the use of ORF stock.

In an effort to perform this task, a field queetionnaire was prepared under the auspices of DARCOM and distributed through the commodity command Logistics Assistance Offices (LAO) to the field maintenance technician (FMT). By so doing, it was hoped that we would get to those people most familiar with the problem. A diversity of opinion was obtained by sampling across the commodity commands and MACOM's. The responses reflected a sincere and cooperative effort between MACOM personnel and the FMT to report the facts.

Thirty responses were received in time for evaluation. These represented the six Commodity Commands and the four MACOM's and also from company level to battalion. The majority of the responses appeared to be from the FMT and clearly opell out their thoughts concerning retail management and use of ORF. By this type of response, we assume that we have what "is" and not what "should be."

In reporting the results from this survey (Section D.37), we will take each question and give a brief synopeis of the responses to indicate the general trend (most popular reply) and indicate any differences between command and theatres. A more detail breakdown of the replies can be found on spread sheets which are available from the Army Inventory Research Office.

D.2 Sample Queationnaire and Letter of Direction. 


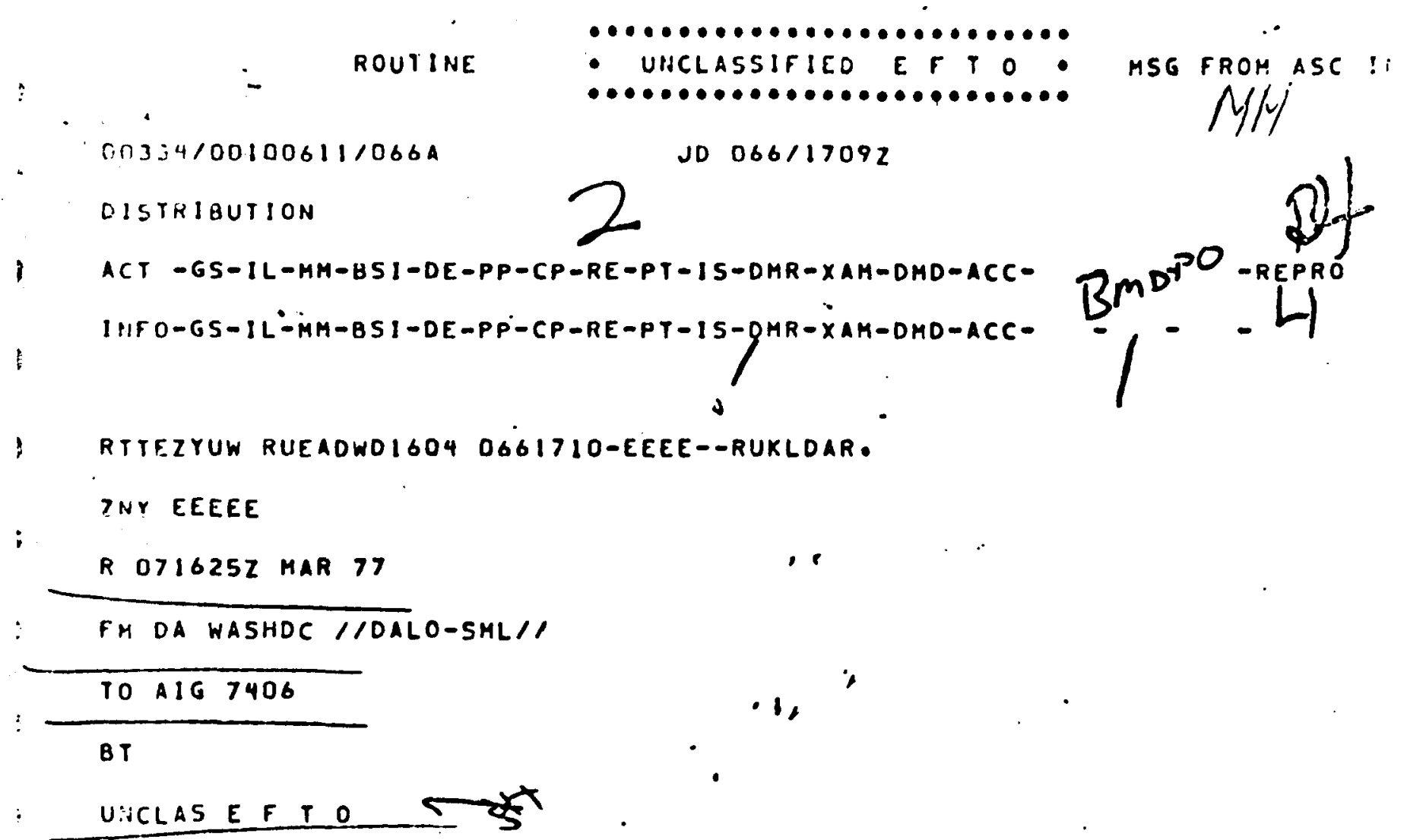

SUBJECT: . OPERATIONAL REAOINESS FLOAT (ORF) SURVEY

1. BY DIRECTION OF HADA, DARCOM IS CONDUCTING A STUDY OF

MAINTEHANCE FLOAT TO DETERMINE' WHAT MANAGERIAL IMPROVEHENTS ARE

REOUIRED to aCHIEVE THE maXIMUM READINESS PAYOFF FROM the

MAIHTEHANCE FLOAT INUESTMENT. AS PART OF THIS.STUDY DARCOM HAS

BEEN SPECIFICALLY REOUESTED TO CONDUCT A SURVEY OF THE PROCESS AND

PROBLEMS OF THE FLOAT MANAGER/USER AT THE DIVISION aND SEPARATE

BRIGADE LEVEL.

2. in ôdé, to collect the kequired information and oata wiYh the

LEAST POSSIBLE BURDEN TO YOUR HO, SUPPORT UNITS AND SUPPORTED

UNITS, THE DARCOM SURYEY PLAN PROVIDES FOR INFO COLLECTION BY THE

COMMODITY/REAUINESS COMMAND FIELO HAINTENANCE TECHNICIANS (FMTI.

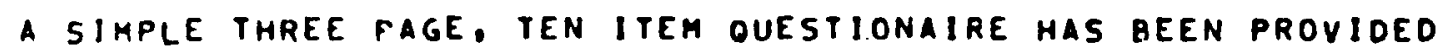

THE FIITS TO HE COMPLETED THROUGH INTERVIEW WITH FLOAT MANAGERSI

USERS AT SELECTEO SUPPORT UNITS. NO MOIE THAN THREE SUPPORT UNITS D-2 


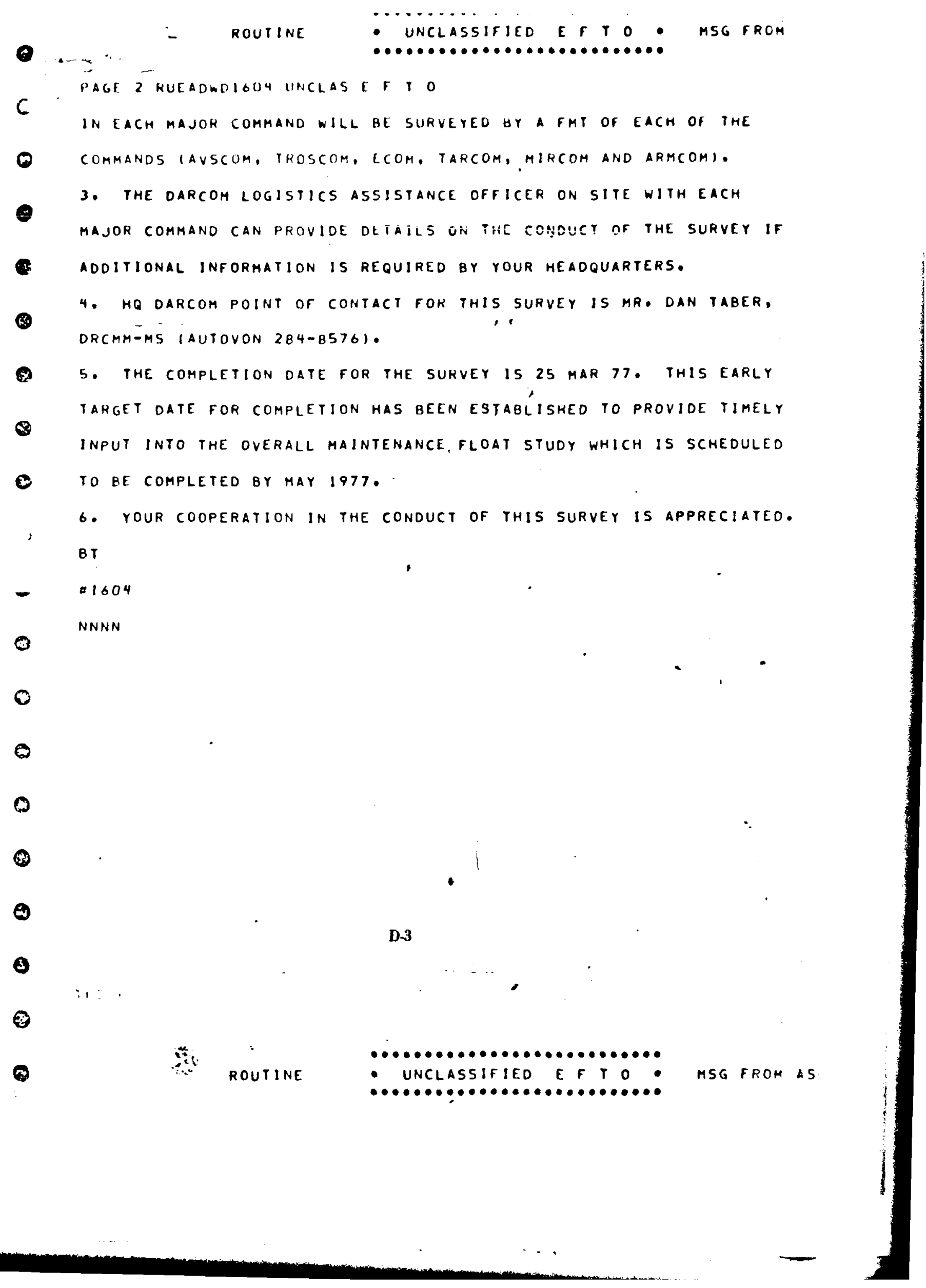


HEADOUARTERS US ARMY MATERIEL DEVELOPMENT AND READINESS COMMAND SOO 1 EISENHOWER AVE., ALEXANDRIA, VA. 22333

DRCMM-MS

SUBJECT: Maintenance Float Study

SEE DISTRIBUTION

1. Reference is made to DRGM-M letter dated 25 Pebruary 1977, subject as above (Inclosed).

2. This Command has been requested by the $\mathrm{DA}$ to conduct a survey of Operational Readiness Flost a part of the overall study of Maintenance Float. We belfeve that the most accurate information for such a survey can be obtained by having it gathered by our fleld maintenance technicians (FII). These people have the most intimate acquaintanceship with personnel in the support units and the operations of those units. Accordingly, we have prepared a questionneire to be filled out by the FMI's. A copy of the questionnatre and instructions for its use are attached for your information.

3. Distribution of the questlonnaires will be made by the Darcout Ccmodity/Readiness Cownands to their Senior Staff Technical Representatives. The survey 18 to be conducted on only a sample number of support units in each MCOA. In no case will it exceed three per commodity group per MCOM. Because of the limited scope of the sample, some LAO's may not be Involved in the survey. However, if these questionnaires arrive in your area, request that you provide your support during conduct of the survey.

4. The DA DCSLOG is sending a masage to all of the MCOM' s requesting their soperation in this undertaking.

FOR THE COMMANBR:

Incl

as
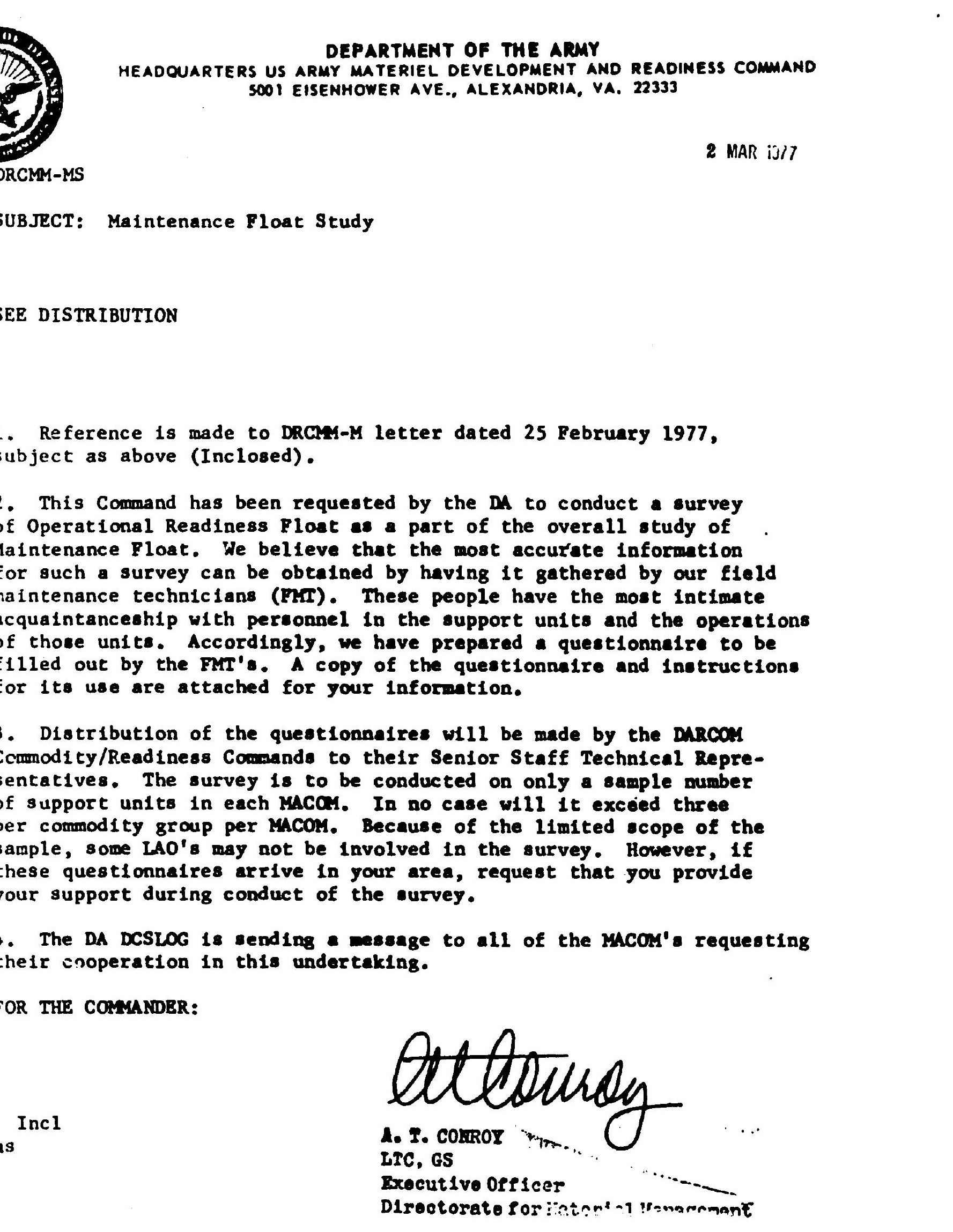
DK, MM-MS

SUB.JECT: Maintenance Float Study

DISTR IBUTION:

Chief

US Army Logistic Assistance Office, ACC

ATTN: DRXLA-AC

Room 2117, Greely Hall

Fort Huachuca, AZ 85613

Chief

US Army Logistic Assistance Office, Europe

C / O ODCSLOG USAREUR

ATTN: DRXCA-E

APO New York 09403

Chief US Army Logistic Assistance Office, Japan ATTN: DRXLA-J

PO Box 771

FPO Seattle 98773

Chilef

US Army Logistic Assistance Office, Korea

ATTN: DRXIA-K

APO San Francisco 96301

Chis:f

U:; Arny Logistic Assistance Office, FORSCOM

ATRN: DRXIA-FO

Muildiug 274

iort McPherson, GA 30330

Ci:itis

il: Army Logistic Assistance Office, Ft. Richardson

ATTN: DRXLA-F-RD

Ho) BOX 5507

APO Seattle 98749

Clict

US Army Logistic Assistance Office, Ft. Bragg

ATTN: DRXIA-F -BG

Building 1-1333

Fort Bragg, NC 28307

2

D.5 


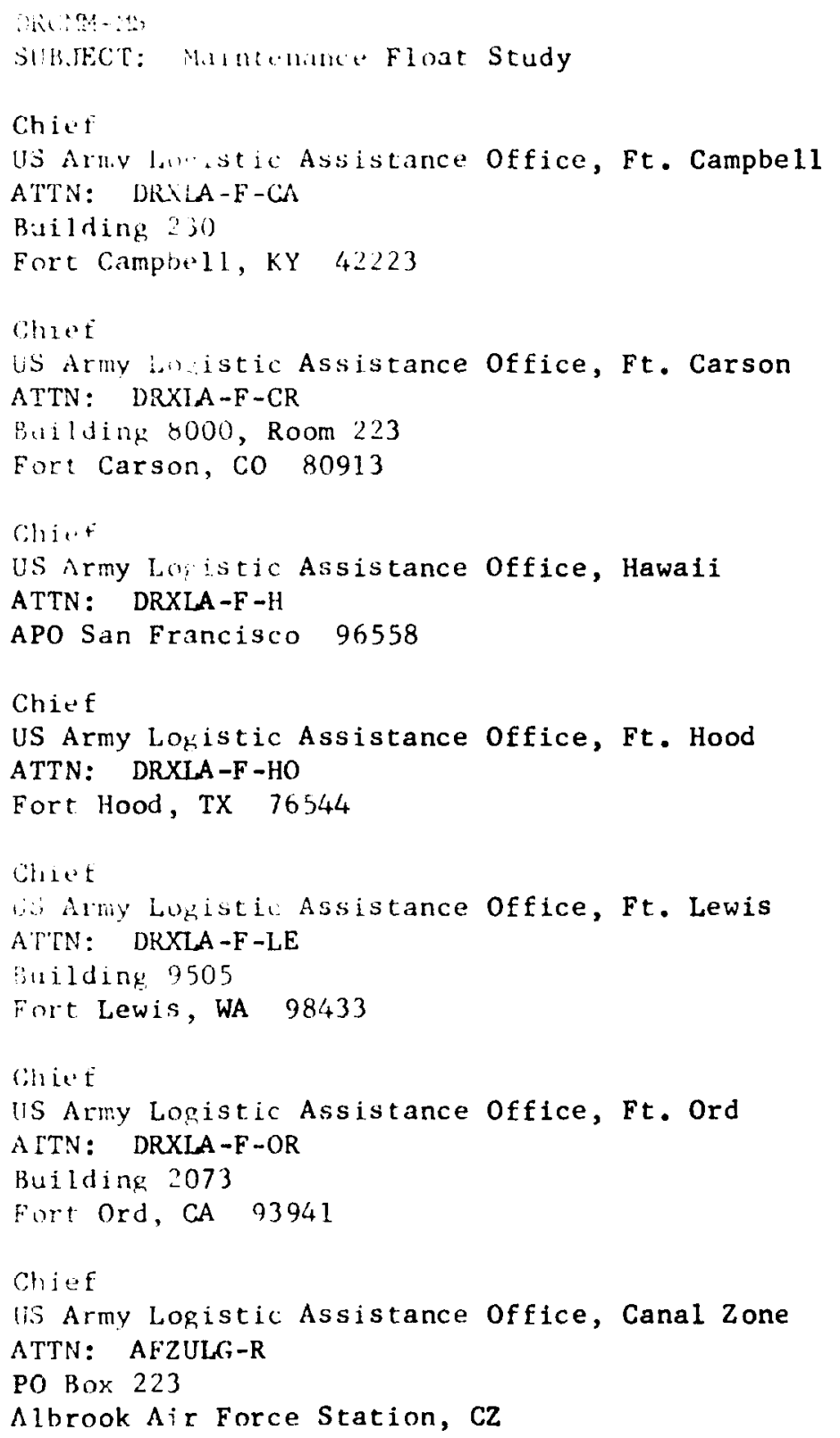




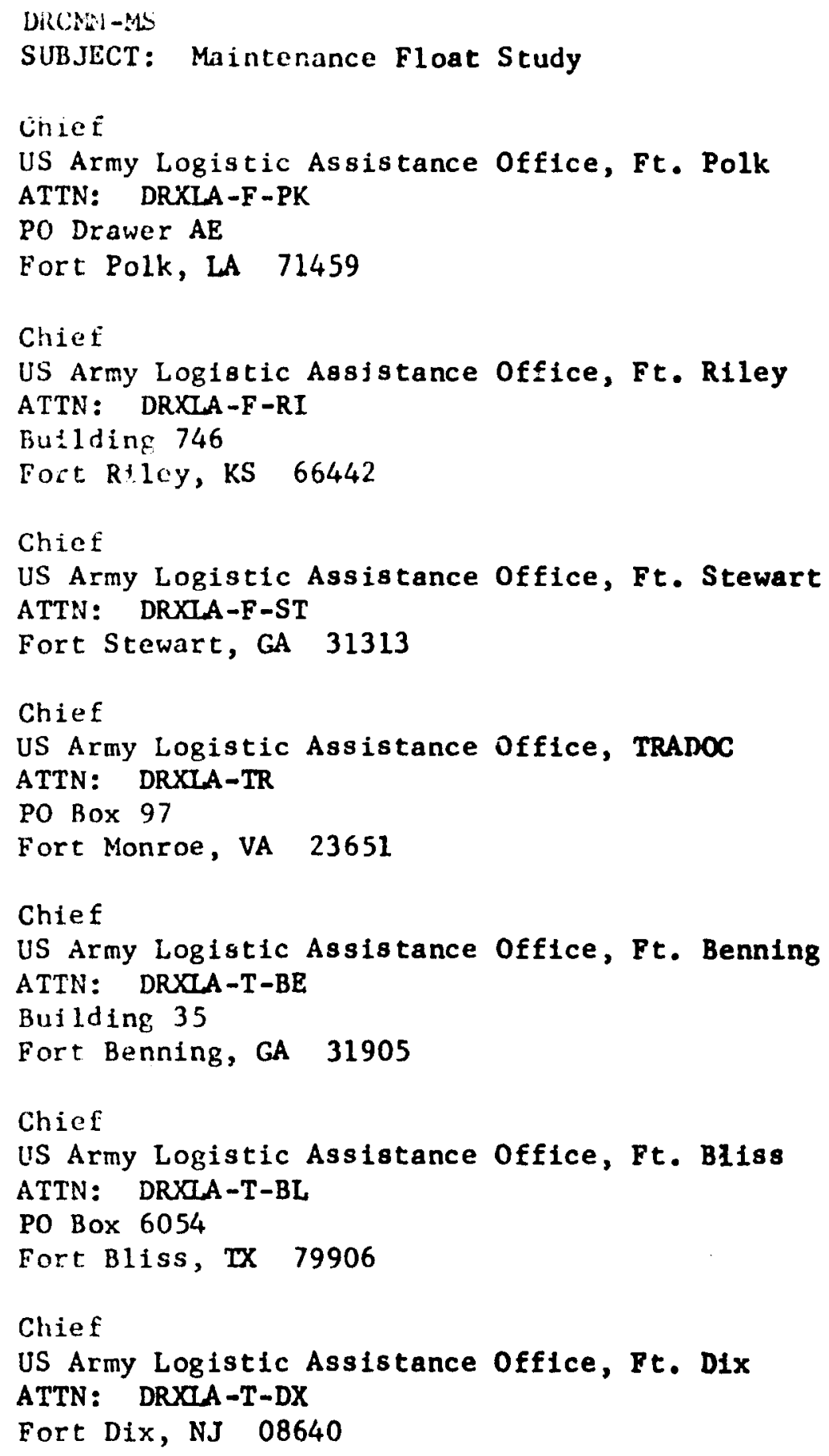




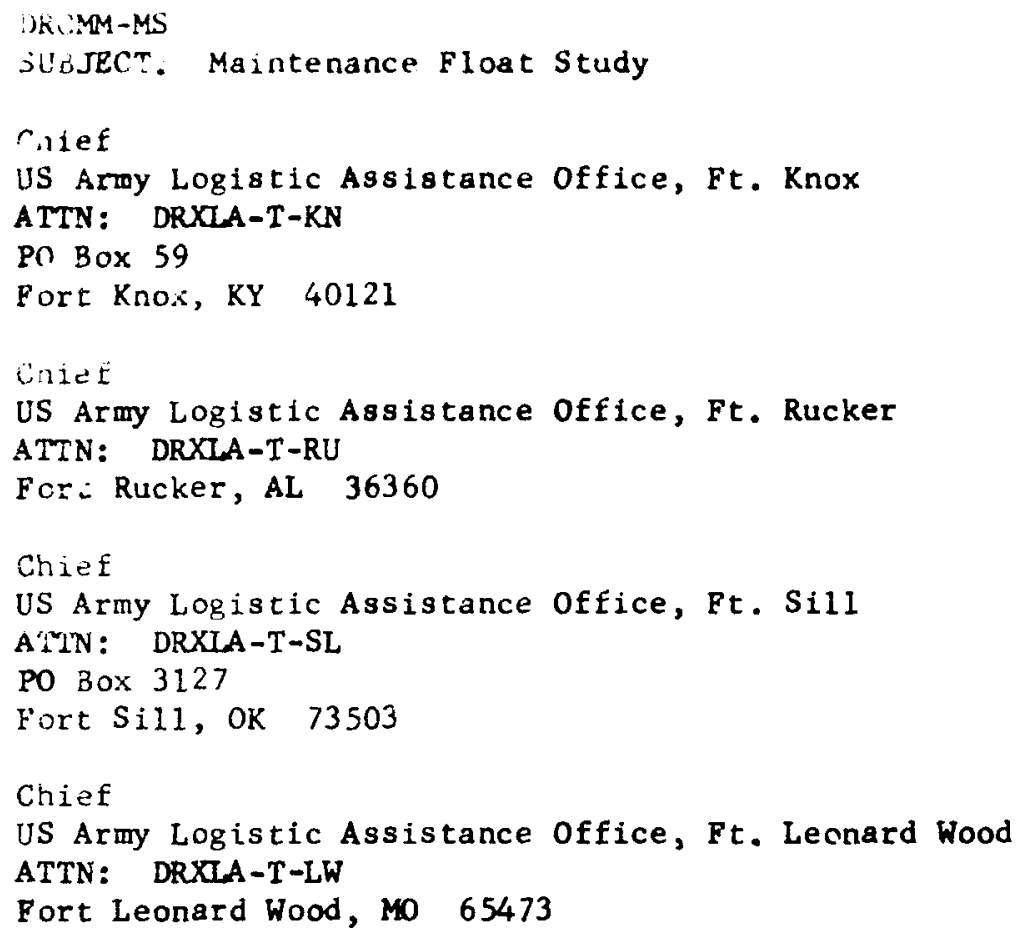


1

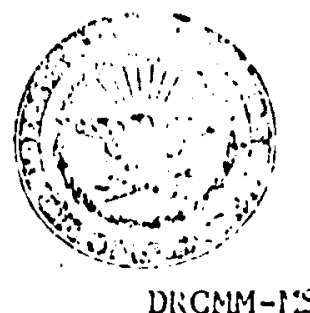

SUBJECT: Maintenance Float Study

SEE DISTRIEUTION

1. This cornmand has been directed to conduct a study of maintenance float as a follow-up to other studies conducted by LEA and within DARCON MSC's. As part of this study we were requested to conduct a survey of the process and problems of the float manager/user at the division and scparate brigade level. It is hoped that the information derived fron this survey will result in improved managerial direction and investment in operational readiness float (ORF) resources in a manner winich will insure the highest payoff to the Army. We solicit your participation in this undertaking.

2. In order to conduct the requested survey in the most accurate manner, and with the least expenditure of resources, we propose that it be conducted on a sampling basis by the DAROOM personnel most familiar with operations at the user level - the Commodity/Readiness Comriand field maintenance technicians (FMT). It is recognized that this is additional workload and beyond the normal scope of duties assigned to these personnel. However, because of the criticality of inaintenance float to Army operations, it is felt that the potential benefits are well worth the effort.

3. A questionnaire has been prepared by the DARCOM Inventory Research office for use in the conduct of tilis survey. A copy of the questionnaire and instructions for its use is attached. This will simplify the task for all concerned and help assure uniformity of the type of data required. By using a sampling method, it is anticipated that only a small percentage of the FMT's need be engaged and hopefully not more than one day of effort on the pait of. any individual.

4. Request that the attached questionnaire be filled out by your personnel assigned at the major user commands. The size of the sample for your commodity matcriel is linited to no more than three per MACOM and should be adjusted in accordance with the attached instructions. The precise number and distribution 18 left to your discretion. The 
DRCILI-MS

SUBJECl: Maintr.nance Float Study

completed questionnaires are to be returned directly to:

Director

DARCOM Inventory Research Office

Room 800, USA Customs House

philadelphia, YA 19106

5. DCSLOG will advise the MACOM's of this survey and request their cooperation in providing the information required by your FMT's.

6. Because the entire DARCOM study must be concluded by May 1977. request that the completed questionnaires be submitted no later than 25 March 1977. Thank you for your cooperation.

FOR THE COMANDRR:

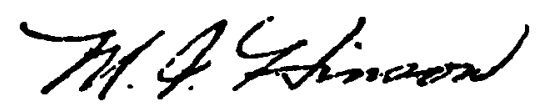

2 Incl

1. Questionnaire

\section{H. I. BIwsor!}

DEPUTY DI: : :

2. DA Ltr, 30 Dec 76

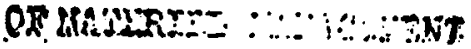

DISTRIBUTION:

CDR, AVSCOM, St. Louj.s, 10

CDR, TROSCOM, St. Louis, MO

CDR, ECOM, Ft. Monmouth, NJ

CDR, TARCOM, Warren, MI

CDR, MIRCOM, Redstone Ars, AL

CDR, ARICOM, Rock Island, IL

Copy Furnished:

HQDA (DALO-SHL) WASH DC 


\section{QUESTI ONNA IRE}

OPERATIONAL READINESS FLOAT

Ma jor Command:

Support Unit Surveyed:

Commodity Group:

Division and/or Separate Brigades Supported:

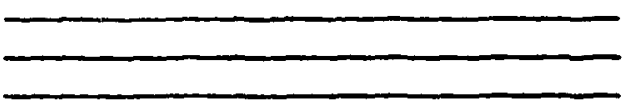

Support Unit Personnel Contacted (Name, Rank, Position)

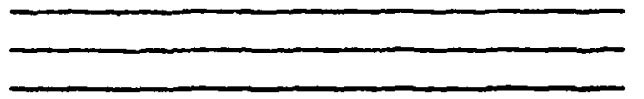

Person Conducting Survey (Name, Title):

Signature

Date

D.11 
OPERATIONAL READINESS FLOAT

\section{GENERAL INSTRUCTIONS FOR SURVEY}

1. Only maintenance battalions or companies supporting tactical

divisions or separate brigades are to be included in the survey.

2. A separate questionnaire is to be completed for each comodity

group of materiel, e.8., communications-electronics, firepower-

mobility, etc.

3. The questionnaire should be filled out by the FMT for that

commodity in coordination with personnel in the maintenance battalion or DS company.

4. The survey should be confined to a representative sample of $1-3$

support units per commodity per MACOM, according to the size and

diversity of operations within the MACOM. For instance, only one

set of commodity questionnaires might be appropriate for USARAL and

three for USAREUR.

D.12 


\section{QUESTIONNA IRE \\ OPERATIONAL READINESS FLOAT}

Use a continuation sheet for any narrative answers requiring more space then provided on the form.

1. The attached form is designed to provide a broad sample of maintenance float items held by support units. Please fill out the form in accordance with its preceding instructions.

2. Location of ORF stock, e.g., DS, GS Maintenance, GS Supply, Installation Support, other, etc.

a. Opinion on where to position large items of float if other than location stated above - for instance at the tactical unit or threater stockage.

3. Is float stock differentiated from other stock?

How?

4. Maintenance of float.

a. How often is float stock inspected/tested for serviceability?

b. What is percentage of tota 1 maintenance workload expended on float stocks? (If precise records are not available, give best estimate.)

c. What priority is usually assigned to work orders on float items? 
5. Briefly describe how the decision is made to issue a flot item. Include the following considerations.

a. Criteria of magnitude and time to perform the required maintenance.

b. Who is involved in making the decision?

c. Influence that the user has on the decision to accept a float in exchange? Any differences whether the flost is a component or an end item.

6. Is there a difference between the accountable property officer, the person who signs for the equipment, and the person responsible for maintenance of it? Describe the differences, inter-relationships and Impact on management of float.

7. Pick the three highest density items which have float support and for the past three months indicate for each:

a. The number of times the items were repaired and returned to the user without issuance of a float.

b. Average turn around time for these repairs.

1.

2.

3. 
8. Is there an adequate number and type of personnel and facilities avallable in the support unit to maintain, store and assure optimum utilization of the float?

a. If not, how many additional personnel, their MOS and what facilities are required to support the authorized float?

9. Is any record kept that documents the float transaction? (yes/no)

a. If so identify or describe what form is used - DA or local?

b. Is this data kept in any files?

c. Where are the files kept?

d. What report and how often is it provided to the MACOM HQ for management of float assets?

10. Please provide your recommendations to improve DA or local policies and procedures for management of operational readiness float. Describe how these recommendation would benefit the equipment user and the support organizations. Your recommendations will be given serious consideration during the current revision efforts to ARs governing maintenance float. 
Ceneral. This form is intended to provide a statistical survey of the disposition and condition of ORF items on the day 1 it is filled out. Only columns 10,11 and 12 w111 require any historical data search. If estimated data is entered in these columns, it should be so noted.

1. End Iter. List by name and NSN all end items that are authorized to be supported with fioat such as tanks, APCs, aircraft. In the case of communication, electronic and other equipments for which float is provided mainly as major components, enter the 10 most populous float components. If components are 1 isted, add a note at the bottom showing the total number of lines of component float carried, including the 10 individual lines listed above.

2. Components of End Items. When end items listed in Column 1 also have major components which are carried as float, list these opposite the end item.

3. Substitute Items. Indicate if float stock consists wholly or partially of items different than that assigned to supported TOE's but is issued as a substitute when required. An example is a gasoline powered APC which is issued in lieu of a diesel powered APC.

4. Number Supported. The number of items in TOE units supported by the authorized float.

5. Authorized. Number of float authorized by the MACOM.

6. On-Hand. Number of float items actually on hand.

7. Serviceable. Number of float on-hand that is serviceable and available for issue. (On date of questionnaire.)

8. Not Operationally Ready, Supply. Number of float items that are NORS and average length of time NORS in days. (On date of questionnaire.)

9. Not Operationally Ready, Maintenance. Number of items NORM, due either to waiting for maintenance or in process of maintenance. (On date of questionnaire.)

10. Demands, 90 days. Number of ORF exchanges requested by supported TOE's during the prior 90 day period. 
11. Satisfied Demands. Number of requests for a float item which could be satisfied by the support unit within 24 hours, over the prior 90 day period.

12. Number Repaired, 90 days. Number of float repaired and returned to serviceable condition in the past 90 days. This does not include items repaired and returned to user without issuance of a float.

13. Turn Around Time, 90 Day Average. Average time to return to a serviceable condition, an item for which a float had been exchanged. 


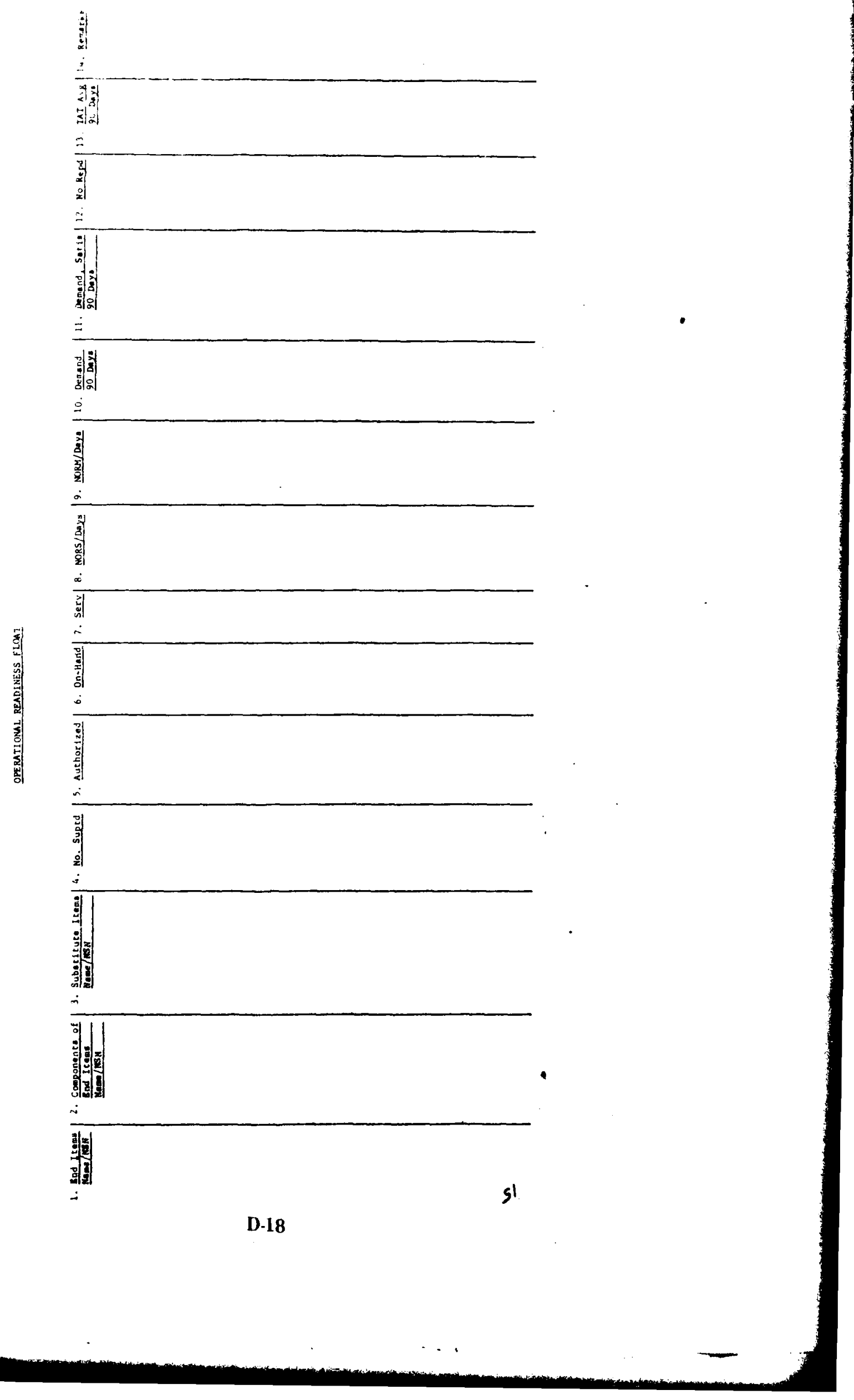




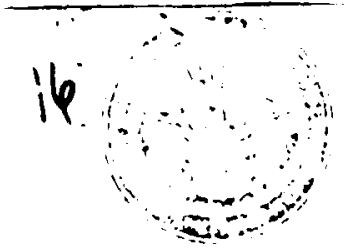

DAI.O-SMI.

SUBJECT: Repair Cycle Float Study

\section{3 .90}

DEFARTAIS"T OF THE NBMIY'

ORFICE OI THE DEPUTY

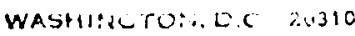

¿ LEQ 1970

Commander

US Army iateriel Dovelopincut

and? Reudiness Command

5001 Eisconhower Avenue.

Alubindia, VA 22333

\section{References:}

a. Letter DALO-SML dated 7 September 1976 , subject, Repair cycle float (RCF).

b. LEA Draft Report, dated November 1976, subject, Review of Operational Readiness Float (ORF) Concept.

2. Referenced 1etter requested DARCOM perform a study on the Repair Cycle Float (RCF) portion of Maintenance Float. Because maintenance float is the total number of spare major components and end items required to sustain military operations at a desired level while repair or overhaul is perforned, it is the combined cffect of ORF and RCF which relates to operational readiness. It makes little or no difference to the user whether the items are being repaired at DSU/GSU or at a depot; in either case they are not available to him. Consequent1y, all float assets, both OKF and $R C F$, and their individual and collective impacts on availability or serviceable items to the user should be studied.

3. The problems of the float manager/user at the Division and separate Brigade level are keynote to this study. Request that in conjunction with the overall maintenance float study, a survey to disclose current problems at the retail level be conducted. This should result in a philosophy of investing ORF resources only in high payoff strategies.

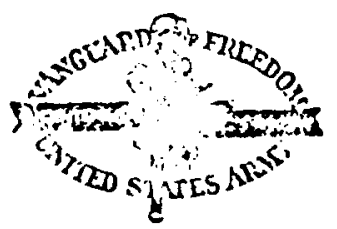

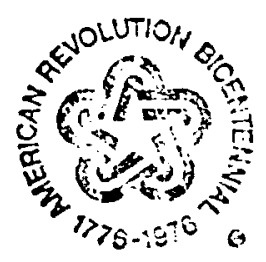


DALO-SML 21190

\$O DEO ISTO

SUBUECT: Repa1r Cyelo Float stury

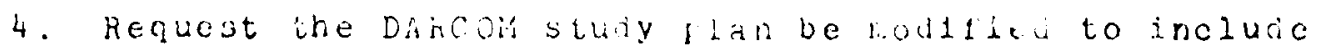
methods for establishing ORF requirements and management of ORF, as well as for RCF. Care should be exercised to avoid duplication of efforts already expended by the LEA during their study, referencei l.b. above.

5. This additional requirement does not change the expected completion date of May 1977.

FOR THE DEPUTY CHIEF OF STAFF FOR LOGISTICS:

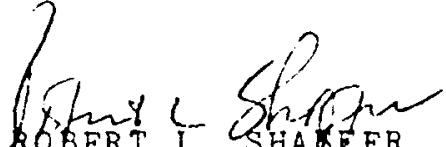

ROEERT L. CSTIARER

COL, GS

Chief, ILS and Mairtenance

Ensineer1ng Division 
D.3 Sunniary of Resporses to the Field Questionnaire.

\section{D.3.1 Responses Part One.}

1. The attached form is designed to provide a broad sample of Maintenance Float item: heid by support units. Please fill out the form in accordance with its preceding instructions.

2. Locition of ORF stoch, e.g., DS, GS maintenance, CS supply, isstallation support, wher, etc.

a. Opinion on where to position large items of float if other than location stated above-for instance at the tactical tmit or theatre stockage.

In response to the current location of ORF stoch. the majority indicated that it is kept at the DS level (especially OCONUS) or at installation support (especially CONLS). Only one of the OCONUS responses indicated GS location of the ORF.

In response to their opinion on where to position float, 60 percent of the respondents said that they preferred to keep or move the ORF to the IS level whereas is percent (CONLS) fre erred to heep the stoch at the installation support. Other replies were theatre stockage and cuntrolled by shop officer.

3. Is float stoch difierentiated irom other stock? How?

An overwhelming 93 percent of the respondents indicat nd that ORF stoch is managed on a control basis and is indeed differentiated from other stocl. Most of OCONUS said that they heep their ORF stock physically separated from other stochage. Separate records for float items are hept by 5 percent of the respondents.

4. Maintenance of float.

a. How often is noat stock inspected/tested for serviceability?

b. What is percentage of total maintenance workioad expended on float storks:? (11 precise records are not available, give beat estimate.) 
c. What priority is usually assigned to work orders on float items?

Responses to 4a ranged from no check. to weekly checks. Inference is that no set guidelines have been established, either by the commodity commands or by the MACOM's.

In response to $4 \mathrm{~b}$, MIRCOM led with an approximate 30 -percent workload dedication to ORF whereas ARRCOM had the least with about 2-percent dedications. These differences may imply that the type of equipment plays a major role in deciding ORF workload requirements.

In $4 c, 44$ percent gave their ORF an 02 priority rating and 24 percent said that they gave the same priority as the end item. Hence, the float work orders were given a high priority in 68 percent of the cases.

5. Briefly describe how the decision is made to iseue a float item. Include the following considerations.

a. Criteria of magnitude and time to perform the required maintenance.

b. Who is involved in making the decision?

c. Influence that the user has on the decision to accept a float in exchange? Any differences whether the float is a component or an end item.

At first glance, the responses to these questions seem to dramatize the lack of continuity in the decision process of float transactions. However, we feel the replies indicate that the field environment is so varied even within theatre that different policies are followed depending on the local conditions.

For example, 23 percent of the responses to $5 \mathrm{~b}$ cited production control as being primarily involved in the decision process, 29 percent cited the maintenance shop officer, 17 percent DMMC, 8 percent company maintenance officer, and 8 percent battalion commander. 
Most (80 percent) of the responses to $5 \mathrm{a}$ indicated a time and mission priority criteria, but based on our interviews in the field, we saw that this time interval has a large variance.

An interesting point was that 80 percent said that the user had an active role in negotiating the float transactions. In 10 cases the users were cited as having the option of accepting or rejecting the float items.

6. Is there a difference between the accountable property officer, the person who signs for the equipment, and the person responsible for maintenance of it? Describe the differences, interrelationships and impact on management of float.

In this question, an effort was made to define the duties/responsibilities and "pindown" those actually held accountable for such. By specifically segregating the leading question into the difference between the accountable property officer, the person who eigns for the equipment, and the person responsible for its maintenance, the differences concerning accountability among the units could surface.

Although several gave good responses, answers by some, such as "The Float Officer is appointed on orders as the Float Accountable Officer. He is the Float Manager.," indicate that many personnel in the field really do not know the hierarchy involved.

The accountable property officer was stated to be the division property officer in 39 percent of the responses and to be the battalion maintenance officer in 25 percent. He was listed in other areas in 20 percent of the responses and not applicable or no difference, etc., in the remainder.

The maintenance officers at both battalion and company are normally the personnel responsible for signing for the equipment although approximately 10 percent are signed for by supply officers. Twenty percent were signed for by installation support organizations (CONUS only) but did not indicate who actually signed for the equipment.

Responsibility for pulling maintenance on equipment was roughly proportional to those that signed for the equipment. One exception noted was that the company production control unit may have had responsibility in one or two units. 
7. Pick the three highest density items which have float aupport and for the past 3 months indicate for each:

a. The number of times the items were repaired and returned to the user without issuance of a float.

b. Average turnaround time for these repairs.

The intent of this question was to determine the typical length of turnaround time (TAT) of those maintenance actions on float supported items which required no issuance of float.

Significantly, the array of these TAT's was so dispersed that no common time-to-issue float criterion appeared within theatre or commodity command.

As an example, by simply comparing the highs and lows within theatre yields the following table:

$\begin{array}{lll}\text { THEATRE } & \text { HIGH (COMMAND) } & \text { LOW (COMMAND) } \\ \text { Pacific } & 12 \text { days (TARCOM) } & 1 \text { day (ECOM) } \\ \text { Europe } & 55 \text { days (TARCOM) } & 2 \text { days (AVSCOM \& MIRCOM) } \\ \text { CONUS } & 700^{+} \text {days (TARCOM) } & 2 \text { days (ECOM) }\end{array}$

The results from this question shows that the old AR 750-1 time requirements are invalid in that they do not reflect the differences of commodity. For instance, TARCOM items had the highest average TAT's on the questionnaires (OCONUS \& CONUS) (and in all theatres) and were over the AR timeframes whereas ECOM items generally had the lowest TAT of the high density items and seldom exceeded the AR timeframe.

8. Is there an adequate number and type of personnel and facilities available in the support unit to maintain, store, and insure optimum utilization of the float? 
a. If not, how many additional personnel, their MOS, and what facilities are required io support the authorized float?

A sturprising 70 percent said that they had both aderguate facilities a:ad adequate personnel to maintain and manage ORF. Of the 30 percent who requested increases in either iacilities or personnel, the desired additions varied with no common rationale apparent in the opinions.

It was interesting that many of the responses of the 30-percent group did require clerical assistance to maintain float records. Evidently, they casnot maintain the many different records required for management.

If the record system could be streamlined and purged, no dnubt the abilities of the units to keep accurate files would eliminate the need for clerical help.

9. Is any record kept that dociuments the float transaction (yes/no)?

a. If so, identify or describe what form is used-DA or local?

b. Is this data kept in any files?

c. Where are the files liept?

d. What report and how often is it provided to the MACOM HQ for management of thoat assets?

The responses to these questions reinforced the comments made to the previous questions in regards to a streamlined record aystem.

There are so many forms to fill out that the troops seem vague as to what goes where. A case in point, 3 percent of the replies said that they used the DA Form 3029 as part of the record system to keep track of float-DA Form 3029 is a direct exchange (DX) record and should not be used as a float record. Conversely, only 42 percent of the respondents indicated that they used the DA Form 1296 and this form is required as a record as stated in FM 29-25. Fifty-three percent used the maintenance form, DA Form 
$\therefore$ wit, for float documentation. To our knowledge, the latest requirement for float code on (1) IA form 2.407 is for aircraft use only. Only 21 percent said that they used the DA ris 2067 which should be used to keep summary of float transactions by the supply ciements within the maintenance units. A total of $\mathbf{1 0}$ different forms were wed to record Iive noat position. All respondents that were authorized float indicated that they did keep records of some kind or other. The records were stored basically at 3d echelon although the CCoYUS units, using the SAILS, stored at the Division Materiel Management Center. Since tice esponses ave answers that ranged from company shop to float storage area to Battalion Miantenance Operations Office at $3 d$ echelon, we can surmise that the record storage process is somewhat less than standardized.

In reporting to the MACOM the field response again showed diversity. In fact, 10.7 percent indicated no reporting to MACOM at all. Those units using the SAILS iciwarded tloat data using the SAILS reports. Eighteen percent used the Form 589-R. The latter is a form that is tailored to each MACOM's needs and is currently required by FORSCOM on a semiannual basis. Other reporting methods are in the appendix.

10. Please provide your recommendations to improve DA or local policies and procedures for management of operational readiness float. Describe how these recommendations would benefit the equipment user and the support organizations. Your recommendations will be given serious consideration during the current revision efforts to AR's governing Maintenance Float.

Twenty -one (70 percent) of the respondents made recommendations in an effort to improve the local policies and procedures for ORF management. The most popular of th: ese dealt with: the addition of equipment and personnel to maintain float assets, the need ior a more efficient recordkeeping system, the use of component items as float rather than the items itself, and the overall updating or revision of the present regulations. Some of the individual comments are as follows:

1. Larger amount of float stock for using activitie because of the iransportation problem to the GS shop (AVSCOM-Europe).

2. a. Float should be hand receipted to user in order to facilitate the t. ansaction. 
b. The units that maintain the float should be signed with the item.

c. ORF should be available to all units within a theatre.

d. Component floating from end item (MIRCOM-Europe).

3. The unit turning in a vehicle be held responsible for any other conditions, (to prevent a total rebuild) then original fault (ARRCOM-Europe).

4. Special requirements are placed on the float by commanders such as some of the float is directed to critical radio nets, to backup critical nets or stations or used during field exercises. At these times, the equipment is pulled away from the float, thus reducing the quantity of float on hand. Recommendations: Radio should be authorized on the units' TOE to fully support the division's mission (ECOM-CONUS).

5. Recommend some of the low density items which have more than one commodity command involved be included in a RCF rather than a local ORF. Example: Chapparrels, Vulcans, M551 AR/AAV, M60 Tanks, TOW, etc., can be repaired at DS level for the automotive but to no great extent on the armament portion of the system. An ORF, if used right, needs a section dedicated to support, account, and exchange it as it was orginally intended to be used (ARCOM-Pacific).

\section{D.3.2 Observation.}

One problem area needing further consideration and study is that of the communication form between the MACOM's and the DARCOM commodity commands. The problem itself is that no effective means of transferring the information of float usage, demands, etc., from the MACOM to the commodity command is in existence. For instance, FORSCOM uses the 589-R forms and compiles a semiannual demand/usage data base but the data has not been received at the commodity command's maintenance divisions who could we the information in recomputing ORF requirements and updating ORF factors.

\section{D.3.3 Responses Part Two: ORF FLOAT DISPOSITION AND CONDITION.}

The field questionnaire included a section on the present disposition and condition of ORF items. The type of information requested included such items as the amount of float 
atutiorized, amount on hand, amount serviceable, number of demands on float, number of $\therefore$-mands satisfied, etc. Since these data elements by themselves are not readily comparable, .di ator functions were developed (e.g., number of float items per number items supported as opposed to only the number of float items). The remainder of the analysis of the field questions addresses these indicators.

1. Fstimated Float Factor. (Number of noat items authorized by the MACOM $\div$ the number of items in TOF units supported by the authorized float.) This indicator showed a variation from a low average .006 for a CONUS airborne division to high average of 24 for many of the MIRCOM supported items. Uniformity within the commodity commands was evident indicating the use of consistent float factors within commands.

2. Percent Authorized Which Were on Hand. (Number of float items actually on hand $\div$ number of float items authorized by the MACOM.) Across the board this indicator appeared relatively high. In some instances, AVSCOM items, there were more on hand than authurized. Seventy percent of the units reported having at least 80 percent of their authorized float items on hand. Of the remaining units, values as low as 14 percent were submitted. One of the low responses was attributed to having had their float removed from the theatre to support a much needed overhaul program (IHAWK).

3. Percent on Hand in Serviceable Condition. (Number of noat on hand that is serviceable and available for use $\div$ number of float items actually on hand.) This indicator also appears to be relatively high with 65 percent of the respondents indicating at least 60 percent of their float assets in serviceable condition. On the other hand, there were three units with extremely low values (MIRCOM-Europe, ECOM-Europe, TARCOM-CONUS). In the case of ECOM with large quantities of float assets, the respondent indicated that the current field exercises had depleted most of his/her float stock hence causing a low serviceable condition to prevail.

t. Demands on Float Per Supported End Item. (Number of ORF exchanges requested b: supported TOE's during the prior 90 day period $\div$ number of items in the TOE unit supported by the authorized float.)

This indicator was developed to compare the demands on float per supported end item bet ween the various commodities. 
It is interesting to note that there appears to be a correlation between this and the fint indicator. Those items with high estimated foat factors also exhibited the greatent demands per supported item and similarly those with low float factors were related to those with lesser demands. This observation gives credence to the present authorized float quantities exhibited by the responses.

5. Percent Demands Satisfied. (Number of requests satified for a float item over the prior 90 days $\div$ number of requests made in the prior 90 days.)

This percentage is relatively high (85 percent-100 percent) across the board except in the following cases:

a. MIRCOM-Europe-Their response was low because they had only 26 percent of their authorized float on hand.

b. TARCOM-Pacific-In this case only 43 percent of their on-hand rock wa in serviceable condition.

c. AVSCOM-CONUS-70 percent of authorized was in serviceable condition implying that the quantity authorized was low.

d. ECOM-Europe-66 percent authorized was on hand and the 60 percent authorized was in serviceable condition.

6. Turnaround Time, 90-Day Average. (Average time to return to a serviceable condition, an item for which a float had been exchanged.)

ARRCOM reported an average of $\mathbf{5 4}$ hours per item. AVSCOM did not submit any data in response to this question. The range for the ECOM items was from 4.17 hours to 90 days. For the item taking 90 days, all of the time was attributed to NORS. MIRCOM's average per reporting unit varied from 5 days to 22 days. Again a oubstantial amount of the large TAT were attributed to NORS time. TARCOM exhibited the greatest variation with a low of 1 day and a high of 190 days. Both of these values were reported for the M551. (The 190 days was reported in CONUS with 80 days NORS and the 1 day was reported by the Pacific.) These variations of TAT again demonstrate the use of local criteria in determining float transactions. 
i. Other data elements required by this portion of the questionnaire but which had only a is,minal number of responses are listed below.

a. Components of End Items. Wher end items listed in Column 1 also have major components which are carried as float, list these opposite the end item.)

Only ECOM and MIRCOM reported component items which are carried as float.

b. Substitute Items. (Indicate if float stock consists wholly or partially of items different than that assigned to supported TOE's but is isoued a substitute when required. An example is a gasoline powered APC which is issued in lieu of a diesel powered APC.)

AVSCOM, ECOM, MIRCOM reported only a few of these items.

c. Not Operationally Ready, Supply. (Number of float items that are NORS and average length of time NORS in days. (On date of questionnaire).)

d. Not Operationally Ready, Maintenance. (Number of float items NORM, due either to waiting for maintenance or in process of maintenance. (On date of questionnaire and average length of time NORM in days).)

Not being able to differentiate from blanks and zeros in the response to these questions made any kind of average misleading. The variation of the nonzero or nonblank responses was great. In general the NORM was much less than the NORS. A comparison of the max and min NORS/NORM times are given in the table.

MAX

NORS

NORM
290 days (ARRCOM-Pacific)

187 days (TARCOM-Europe)
MIN

21 days (ECOM-Europe)

9 days (ECOM-Europe) 


\section{(DISTRIBUTION REQUIREMENT)}

\section{F.L DATA REQUIREMENTS.}

As mentioned earlier in the report, sufficient quantities will be distributed as ORF stock during peacetime in order to insure that the units maintain their readiness objective. These quantities, as determined by the distribution model, are dependent on the different failure rates and downtimes experienced by the given system at the various installations. Since the distribition model may be used for both CONUS and OCONUS (OCONUS used at the discretion: of the command) operations, the data requirements described herein will be applicable to both unless otherwise noted.

A major assumption made by: the model which simplifies the data collection tash is that the number of maintenance actions on a given system at each maintenance level for a fixed length of time are Poisson distributed. This means that the number of items in maintenance at any level depends only on the mean turnaround time.

Hence, the principal data necessary is the average turnaround time and average maintenance frequency experienced for each system at the various installations and maintenance levels.

In the context used above, the turnaround time is defined as the time it takes to return the system back to operational status once the decision is made to repair the system at the piven maintenance level. This time can conceptually be broken down into the following components:

a. Transportation time to the repair facility.

b. Waiting time prior to or during repair and/or transportation.

\footnotetext{
"Note since the item is up once the repair is completed, transportation time from the maintenance shop is not considered as part of TAT.
} 
$\therefore \quad$ Repair time spent undergoing actual repairs.

Similarl. the maintenance frequency (MF) is defined as the number of visits a given system makes to a given maintenance shop for repairs during a fixed length of time.

With minor modifications to the current procedures, these data elements may be recorded on Forms DA-2407 and DD.314 and rolled up on DA Form 2406 which is processed at MMC. The specific details of these modifications are given in the next section.

\section{E.2 MODIFICATION TO CURRENT PROCEDURES.}

In order to assemble the necessary data. TAT'B and MF's for organization and support maintenance have to be collected on each serial number in the field from every unit requiring noat support for the given system (For OCONUS, support has to be further divided into DS and GS maintenance.) DD Form 314 provides a record, Figure E-1, of NORS/NORM time-both organizational and support. This form is filled out for each item of equipment by the TAMMS clerk of the unit supporting the item. The TM 38-750 instruction for recording the data are: "(6) Nonavailable days will be recorded for all items by the symbol " $O$ " for organizational NORM and " $X$ " for support maintenance. For items reported on DA Form 2406, Appendix C, not operationally ready, supply (NORS) at oryanizational level will be recorded on a daily basis by an " $S$ " within the " 0 " symbol (Fig. F.1). Half days will be recorded by dividing the " $O$ " symbol; e.g., 0 . All other nonavailable days organizational level will be considered as not operationally ready, maintenance (NORM)."

Currently, the TAMMS clerk uses Blocks 24 and 26 of the (Work Accomplished by Support Maintenance) DA Form 2407, Figure E-2, to get the nonavailable days due to support maintenance. This period includes the time between the date that support received the item and the date support completed the maintenance. Apparently, that period herein defined as transportation time, between the submitted date (Block 23, the date of the decision to repair the item at support) and the receipt date (Block 24) is not included in the nonavailable days. Individuals at MMC and LOGC confirmed these findings and agreed that it was due to the fact that neither organization nor support wanted to be held accountable for this time. 
In order to report the total time the item is not available due to needed support inaistenance, it is recommended that the current icporting procedure be changed to include lik additional transportation time, i.e., support time should be considered as the time between the submitted date (Block 23) and the inspected date (Bloch 26) and be reported as such on the DD Form 314. The other change to the DD Form 314 reporting procedures is ior OCONUS commands only and requires that the support time be identified by DS and GS indicators.

Since only averages are needed, the DD Form 314 data can be compiled in the field for each system and then submitted to DARCOM in a simplified summary report. With a fen: changes in the reporting format, the presently used "Materiel Readiness Report," I)A Form 2406, can be used for this purpose.

The Form 2406 as shown in Figure $E-3$ is a monthly composite of the Form 314 data rolled up for each line item by the organizational TAMM's clerk; in turn, the Forms 2406 are rolled up at the battalion level on a quarterly basis and then submitted to MMC for processing. From this input, various management reports are produced indicatin: information as to the readiness status of equipment and possible reasons for short falls.

With the addition of two columns to the equipment availability portion of this form, the ORF distributional data requirements would be satisfied. The additional data would be the number of maintenance actions incurred by the reported system at organization and at support. Once this data is incorporated into the form, MMC could compute average TAT and MF's for an! user level above battalion for the given system. These statistics would then be submitted to DFSCOM for processing in the distributional model.

The additional requirement made of the field is that the TAMM's clerk record the number of runs of $O^{\prime}$ 's or $X^{\prime}$ ' on DD Form 314 for the month. A consecutive series of X's (runs) would count as one maintenance action at support and similarly the same for O's for orcanization. The total count of these runs for each line item would then be recorded on DA Form 2406 as the number of maintenance actions experienced by the system.

\section{¿.3 PROJECT LMBRELLA.}

At the request of IXCSLOG, a committee "Project Umbrella" was formed to look into the possibility of reducing and consolidating the number of reports required of the units in 
i licid. As a result of the committee's recommendation, the LOC, was tasked to revise in. ateriel readiness reporting currently contained in TM 38.750 in a manner consistent i. I the reporting requirements of the new AK $220-1$ for unit readiness reporting. As part II iits effort, I.OG,C intends to produce a draft $A R$ containing all required procedures for repurtung materiel readiness on a revised DA form 2406. This form will consolidate IIA Forms 2406, 1352, the Materiel Assistance Designated Repurt, and the Army Missile and Rochet Report (RCS 139).

In order to give better visibility to the problem areas for the comnodity commands, DOD requested that not only the readiness of the system be recorded but also that of the critica! sthsystems and end items which could cause a deadline. To capture this additional information in the field, LOGC intends to replace the DD Form 314 for recording the daily availability of the system with a more extensive daily record form. Finure F.4 represents this proposed form referred to as DA Form 2406-1 wort; form. This form is designed to be filled out on a daily basis by the maintenance technician in charge of the system and then rolled up on a monthy basis by the organizational TAMM's clerk.

The replacement of DD Form 314 impacts on the ORF data collection scheme presented in the preceding section. LOGC agreed to work with IRO in an effort to revise DA Form 2406.1 in order to record the necessary ORF data in the field.

Figure E-5 represents the proposed new DA Forn 2406: 106;C agreed to chiange this form in accordance with the requirements cited in the preceding section referring $t o$ the infently used DA Form 2406.

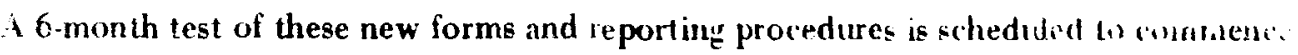
on January 1978 and, hopefully, the ORF data collection will lilewise be tested. Upon approval, implementations of these changes would then occur in the second quarter of $\mathrm{FY}$ 79. 


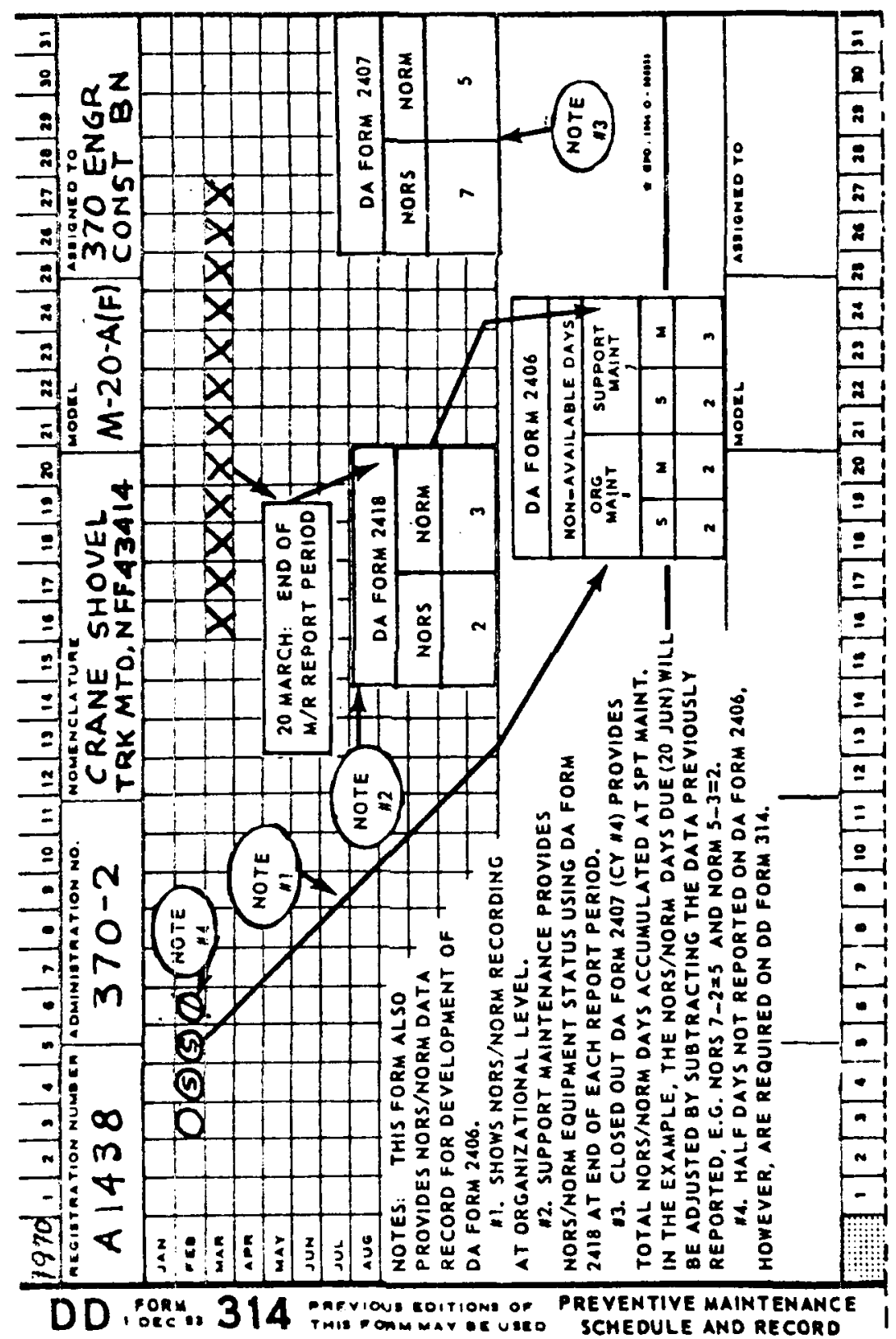

可

F.-5 


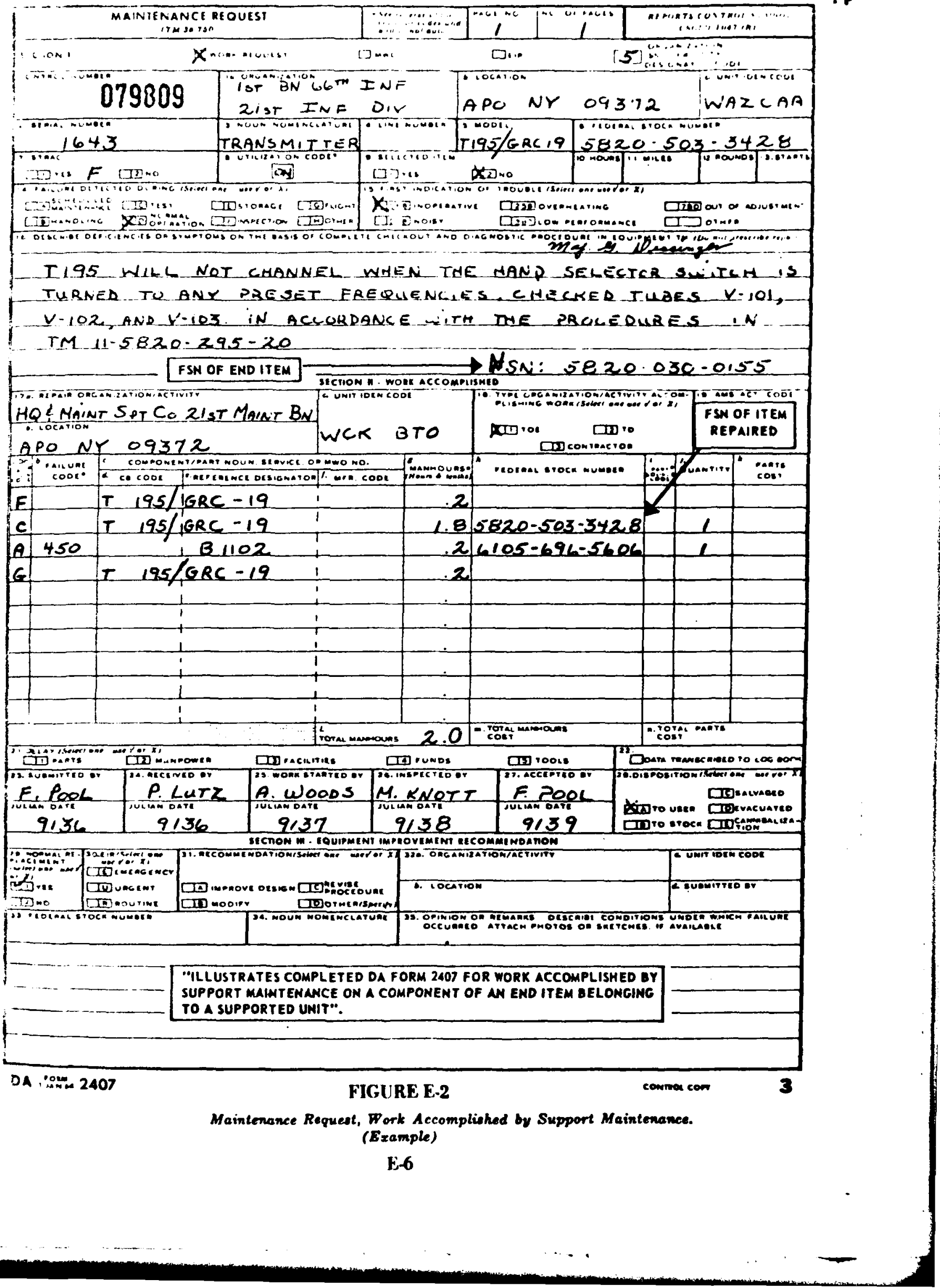




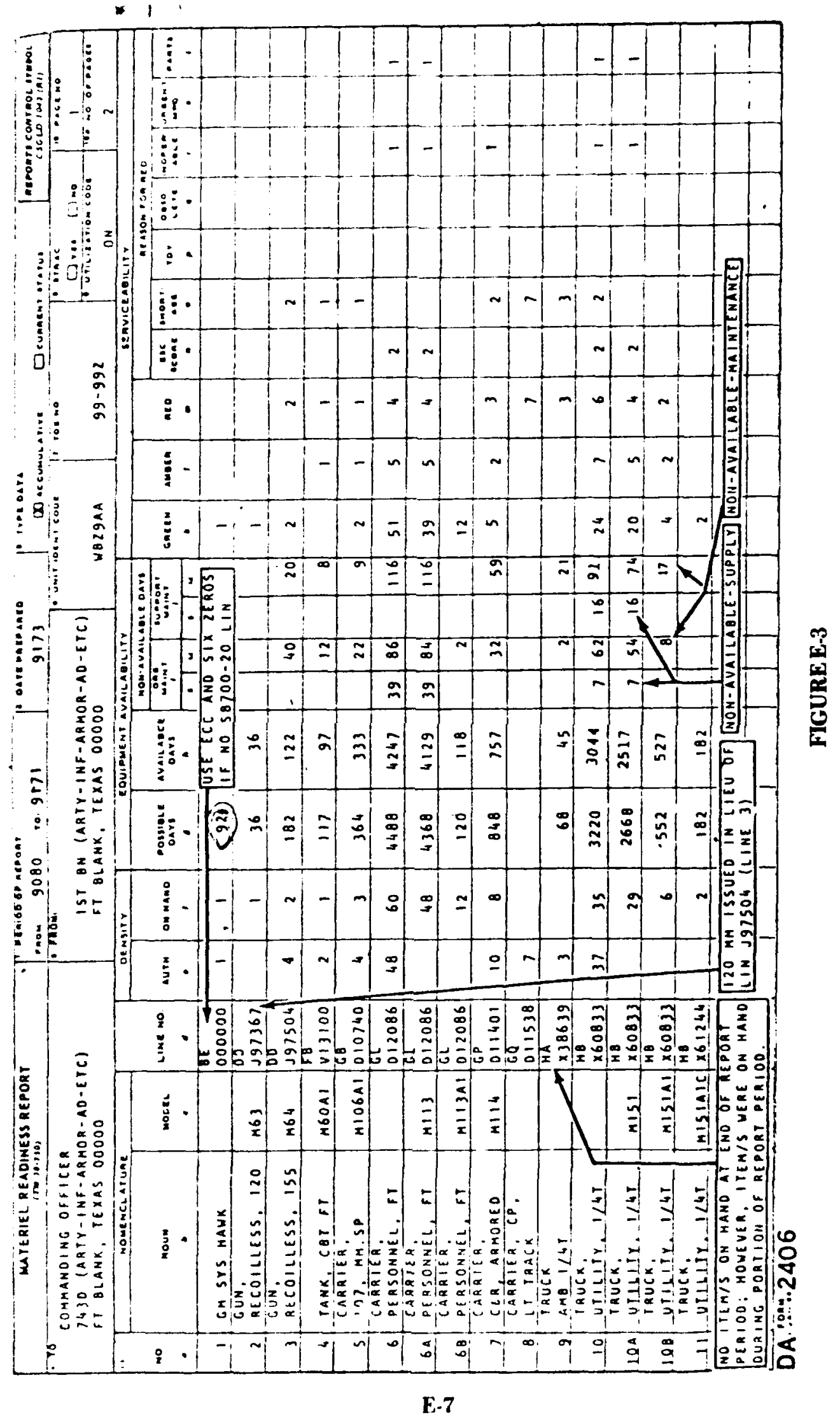




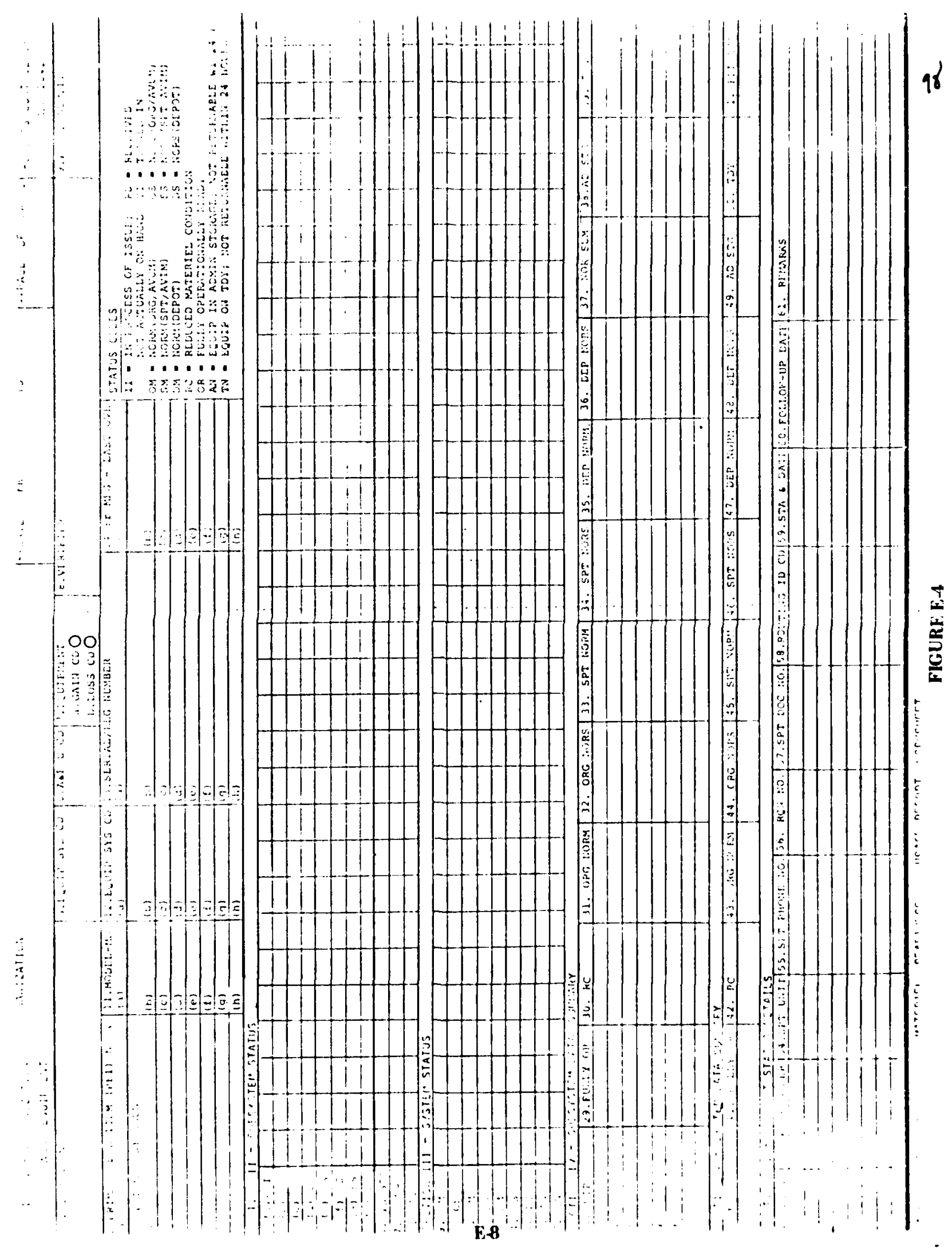




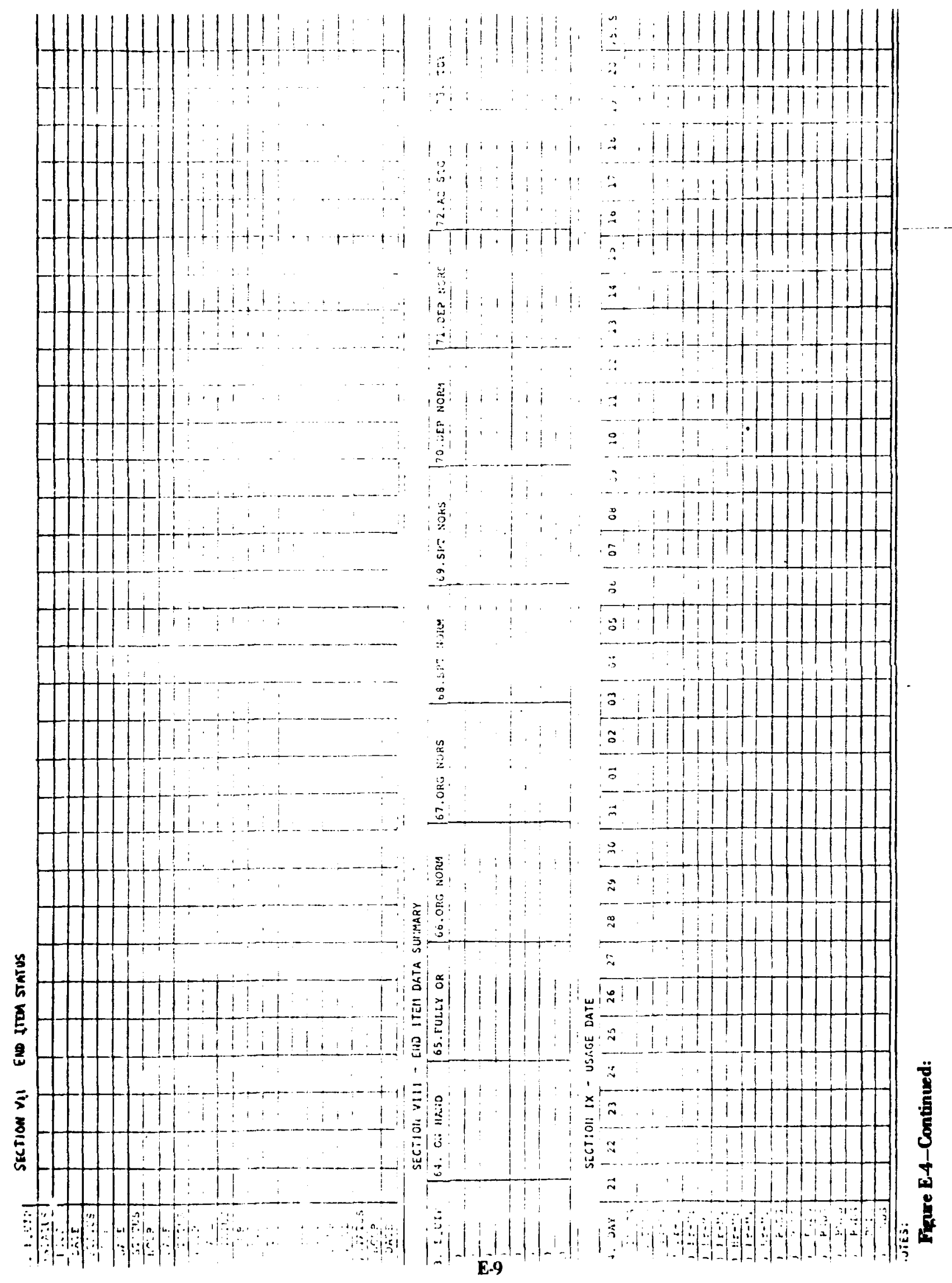




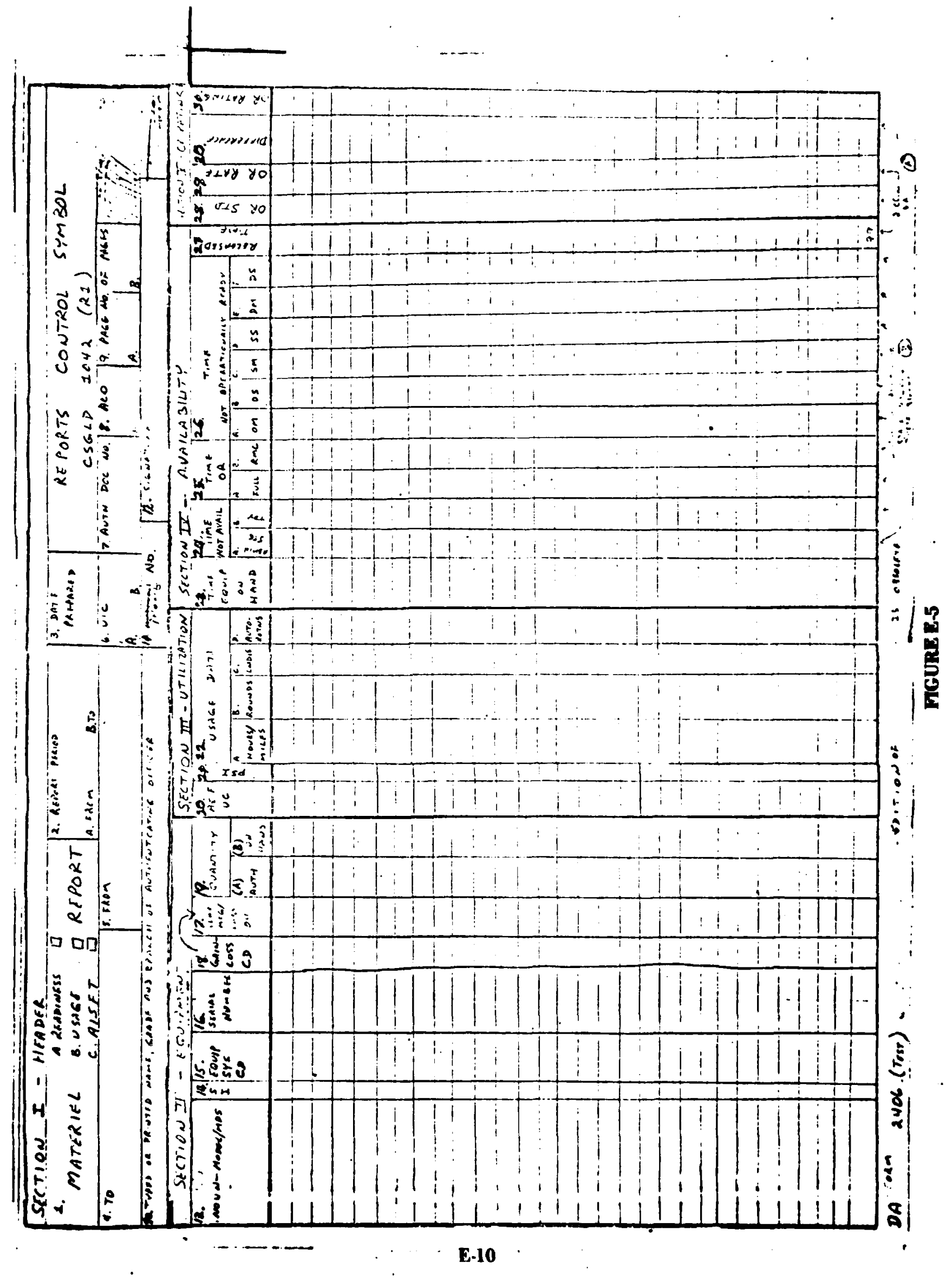




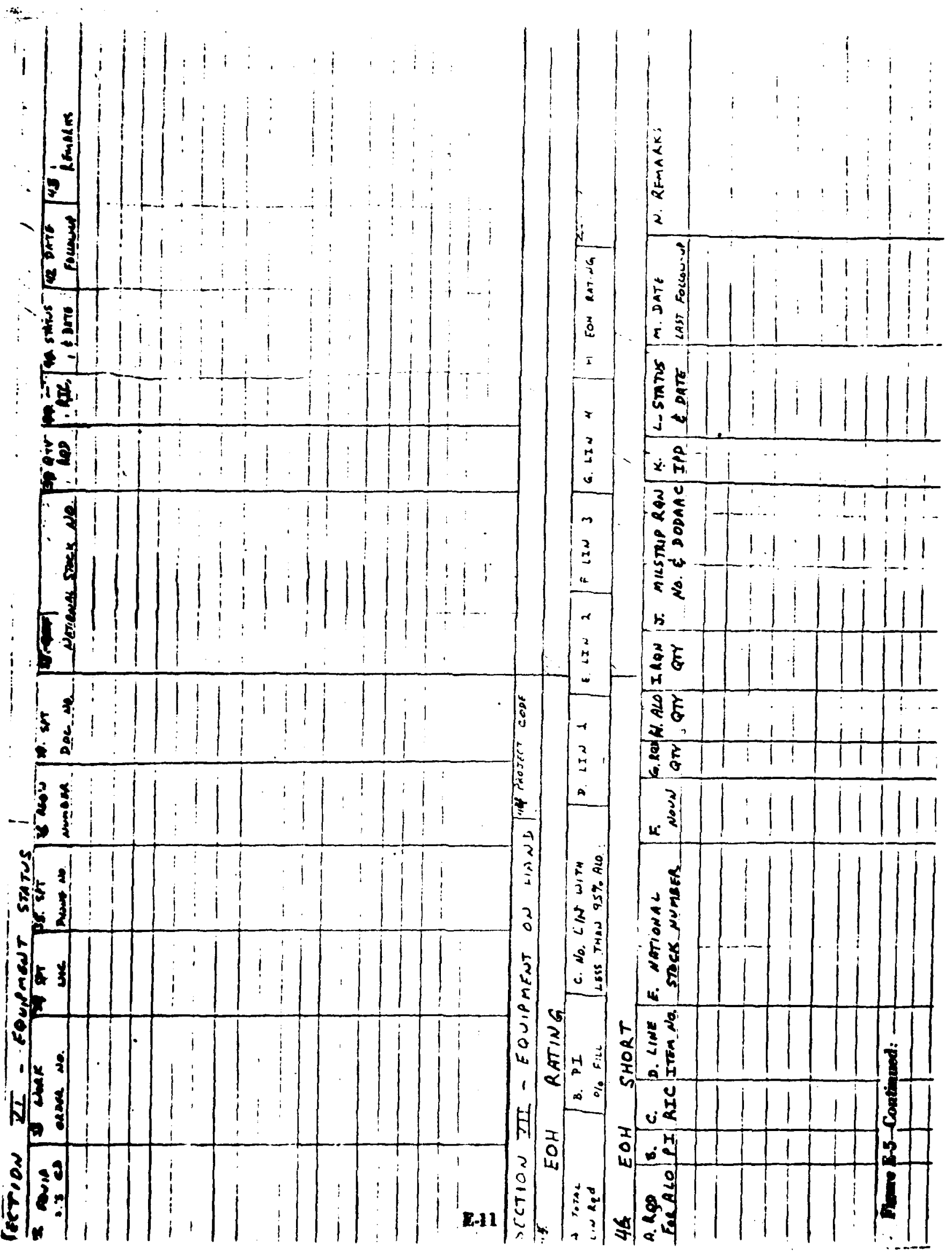




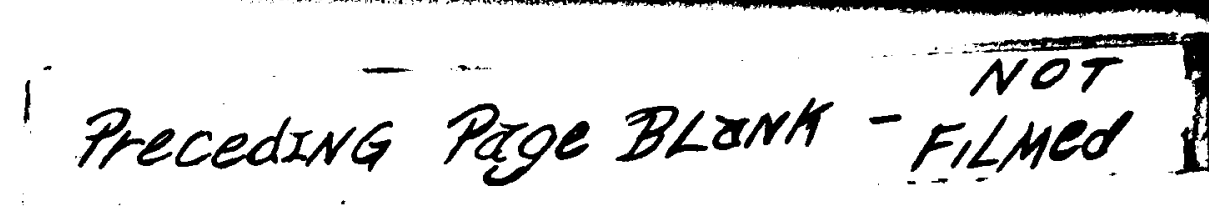

APPENDIX $\mathbf{F}$

ORF PEACETIME DISTRIBU TION MODEL

\section{F.1 GENERAL.}

Paragraph 3.2.6 stated that the overall availability of equipment in an area and not necessarily each unit's equipment availability is what most matters to deployment and training readiness. Clearly, this is true with sufficient warning time or preparation time and the proper control of equipment allocation in an area. In CONUS this means that all float stocks at an installation are available to any unit in need of equipment when deploying or training. In OCONUS theatres it means that all float stochs in the corpe are similarly available. The model to be described below is constructed around this concept. Specifically, for a given area (e.g., installation in CONUS, or corps in OCONLS) if the target for equipment availability is $A_{T}$, and the number of supported equipment is $N$, then the number of float equipments, $S_{f}$ is selected such that the expected number up, $N_{u p}=N+S_{f}-$ expected number in repair pipeline $=\mathbf{N} \times A_{r}$. This approach has an implicit interpretation of AR 220-1 availability goals. The Army philosophy on readiness, specifically equipment readiness, is that equipment availability equal to or above the targets reflects a ready unit. From a statistical sense, though unit equipment readiness may be controlled through ORF, the availability targets cannot be met all of the time. Naturally, the more the ORF the more frequently the availability targets can be met. But AR 220-1 provides only the availability targets; it says nothing at all about an acceptable frequency for achieving these targets although, of course, all of the time is desired. The above approach assumes that a satisfactory equipment readiness may be maintained by achieving the targets on an average basis. This, in fact, is consistent with the current method of collecting readiness statistics. So, if an installations' equipment readiness posture were observed and mesoured over a long time, the average of the measurements would be $A_{r} \times N$. Clearly the burden of the model is to determine the expected number of equipments in the repair pipeline as a function of the equipment failure characteristics, the repair time, and the amount of float, which has a sort of eccondary effect on the number in repair since it primarily increases the number up and able to fail.

In developing the model it is ansumed that authorized TOE quantities are necesary to enable the units to perform their minsions. Consequently, when computing the expected 
number down it is assumed that float is used to keep as many TOE equipments up possible. Float stock, then, is computed so that it has the potential to provide the target availability even if it were to be drawn for every failure of the equipment. However, as

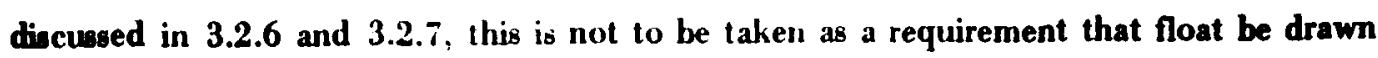
everytime in the actual operating environment.

\section{F.2 CONUS DLSTRIBUTION MODEL.}

\section{Definitions:}

$$
\begin{aligned}
& \mathbf{S}_{\mathbf{f}} \quad=\text { amount of float stock } \\
& \lambda=\text { failure rate for a given fielded equipment } \\
& \text { M = number of units authorized the item. } \\
& \mathbf{N}_{\mathbf{i}}=\text { authorized quantity of the item for unit } \mathbf{i} \\
& \text { N } \quad=\text { number of equipments to be supported by float } \\
& \mathbf{M} \\
& =\sum_{\mathbf{i}=\mathbf{1}} \mathbf{N}_{\mathbf{i}} \\
& \text { A }=\text { availability requirement at the installation level. } \\
& \underset{i=1}{M} \mathbf{N}_{\mathbf{i}} A_{\mathrm{i}} \quad \sum_{\mathbf{i}=\mathbf{1}}^{\mathbf{M}} \mathbf{N}_{\mathbf{i}} \\
& \mathbf{T}_{\mathbf{0}}=\text { average repair time at organization } \\
& \mathbf{T}_{\mathbf{0}} \quad=\quad \text { average support turnaround time to include time to ship } \\
& \text { the item to support maintenance and the in-shop time } \\
& P_{\text {org }}=\text { probability that a failure will be repaired at the } \\
& \text { organization level }
\end{aligned}
$$


When a failure occurs, the equipment is sent to organizational repair and with probability $P_{\text {org }}$ is repaired there. With probability (1-P $\left.{ }_{\text {org }}\right)$ the equipment requires support maintenance. Turnaround times at both organization and support level are independent of one another and are taken to be realizations generated from exponential distributions of means $T_{0}$, and $T_{B}$, respectively. The assumption of exponentially distributed times is not critical to the model itself, but greatly simplifies the collection of repair time data. See Appendix E.

To model this system we make use of an analogous system, the infinite server Markov queue with state dependent arrival rates. Sherbrooke [22] treats this in sufficient detail for our purposes.

If $\phi(k)=$ probability that $k$ units are in the repair pipeline, then

$$
\begin{aligned}
& \phi(0)=C \\
& \phi(k)=C \quad \frac{\left(\lambda_{0}\right)\left(\lambda_{1}\right)\left(\lambda_{2}\right)-\left(\lambda_{k-1}\right)}{k !} \cdot(T)^{k}
\end{aligned}
$$

where

$$
\begin{aligned}
& \lambda_{i}=\lambda N \text { if } i \leq S_{f} \\
& \lambda_{i}=\lambda\left(N-i+S_{f}\right) \text { if } S_{f}<i \leq N+S_{f} \\
& T=\left(P_{\text {org }}\right)\left(T_{o}\right)+\left(1-P_{\text {org }}\right) T_{B}
\end{aligned}
$$

C is a normalizing constant chosen such that

$$
\begin{aligned}
& N+S_{f} \\
& \sum \quad \phi(k)=1 \\
& k=0
\end{aligned}
$$

The expected number in the repair pipeline is

$$
E(D)=\sum_{k=0}^{N+S_{f}} k \phi(k)
$$


and consequently the expected number up is $E(U)=N+S_{f}-E(D)$

Then $\mathrm{E}(\mathrm{U}) / \mathrm{N}$ is the expected percent of fielded equipments available. Note that because of the emphasis on area availability, it is possible with large float quantities, to get a result greater than 100 percent. This only means that on the average there are more than enough up equipments at support level to compensate for those in the repair pipelines.

\section{F.3 OVERSEAS DISTRIBUTION MODEL.}

Paragraph 3.4.2 stated that overseas commands may requisition their full wartime ORF requirement for distribution to their units as they see fit. It also stated that the CONUS model would be made available to assist with the distribution problem. The quantity provided by the model is the minimum amount of ORF the commands should requisition.

The CONUS distribution model can also assist the commands in determining how many of the float assets to put in the field and consequently how many to retain in controlled storage. Naturally, it does so based upon the AR 220-1 availability targets. However, in an overseas theatre the issues are more complex than at a CONUS installation.

With the concept of area availability, it does not much matter whether assets are fielded or in controlled storage as long as sufficient warning time exists to get the stored item in the field where it is needed. With restructured general support, this certainly seems to be the case since GSU's will serve as storage locations for major items in the corps. Even though the model will show how much float should be available to the field during peacetime to maintain the readiness standards, it does not necessarily follow that this amount must be put in the field provided the amounts in storage are able to be eavily drawn in case of need. Another implication of the availability concept is that the GSU ahould be the primary holder of ORF aince this eases the problems of making assets available to units when needed.

\section{F.4 EXAMPLE:}

Application of Model to M551

The following failure and repair time estimates were obtained through analysis of SDC data for the M551. 


\begin{tabular}{|c|c|c|c|}
\hline$\lambda$ & $=$ & \multicolumn{2}{|c|}{.0369 failures/end item/day } \\
\hline $\mathbf{N}$ & $=$ & \multicolumn{2}{|c|}{116 supported equipments } \\
\hline $\mathrm{T}_{\mathbf{o}}$ & $=$ & \multicolumn{2}{|c|}{ 6.5 days (based on NORS and NORM figures) } \\
\hline $\mathrm{T}_{\mathrm{s}}$ & $=$ & 18 days & \\
\hline $\mathbf{P}_{\text {org }}$ & $=$ & .7245 & \\
\hline \multicolumn{2}{|c|}{ Float Stock } & & Expected Equipment Avail. \\
\hline & 0 & & .737 \\
\hline & 1 & & .743 \\
\hline & 3 & & .756 \\
\hline & 0 & & .801 \\
\hline & 0 & & .864 \\
\hline & 0 & & .928 \\
\hline
\end{tabular}

If 80 percent were the availability target, then 10 float items would be required to support the 116 M551 equipments. Were the target 85 percent, then 18 float equipments would be required. 


\section{Preceding Page BLank - Filmed}

APPFNDIX C;

FLOAT EFFECTIVENESS REPORT

\section{G.1 INDICATORS.}

As stated in paragraph 3.2.6 and in Appendix F, it is the overall availability of the equipment in an area (installation, corps) which is critical in distributing ORF asets. This means that the combined availability of both the float and fielded assets should be considered in determining the adequate use and/or distribution of float to the given area. It is recommended that the statistics "Available Days" (including float) vs. "Required Days" be used as a management comparison for reviewing float effectiveness. Required days is the number of equipments which needs to be operational in order for materiel units to achieve their target availability as cited in paragraph 3.4.3 and Available Days is the materiel availability actually experienced by the units.

\section{G.2 USE.}

In practical use, this comparison for a given area is only an initial indicator of problems in the field. Low available days may be caused by:

(1) Not sufficient float assets distributed to the area to support the necessary maintenance actions.

(2) Abuse of float assets such as uncontrolled cannibalization, resulting in a low float availability.

(3) An increase in failure rates and/or maintenance times (higher than those used in determining the float distribution quantities).

On the other hand, high available days compared with required days may indicate, especially to OCONUS, that too much float is in the field and portions of it should be returned to storage. 


\section{G.3 DATA REQUIRF.MENTS AND CALCIILATIONG.}

For illustration purposes, the calculations and dala sources for the "Available Days" and "Required Days" indicators will be limited I" the hittlation level. Higher levels (installation, command) may be calculated by rolling up the haltalion values and lower levels (support, unit) which probably wouldn't be required. can be calculated in the same manner as battalion but with a lower level of inpust data. Beporting for several levels gives management the visibility of the interactions of the lower levels and their net effect on the total availability of the installation or command. $A_{s}$ in the case of the ORF Data Requirements, Appendix $\mathrm{E}$, the vehicle for capturing this necessary data is the Materiel Readiness Report, DA Form 2406. This form as shown in Figure G.1 is filled out monthly at the unit level and quarterly at the battalion level. The two statistics may be calculated and compared from the quarterly report in the following.

G.3.1 Available Days: The overall availability of the item at battalion level is the total available days of both the float and fielded requirements reported by each unit in column h of Form 2406; i.e.,

$$
\mathbf{D}_{\mathbf{B}}=\sum_{\mathbf{i}=1}^{\mathbf{M}} \mathbf{D}_{\mathbf{i}}+\sum_{j=1}^{\mathbf{N}} \quad \mathbf{b}_{\mathbf{j}}^{\prime}
$$

where $D_{B}=$ the number of Available Ijays of the item for the battalion.

$\mathbf{M}=$ number of units in battalion

$D_{i}=$ the number of available days of the item for the unit per column h (excluding float items)

$\mathrm{N}=$ number of units holding float equipments for the item (usually a maintenance support unit).

$\mathbf{b}_{j}^{\prime} \quad=\quad$ the number of available days of the float equipment for the unit per column h. 
G.3.2 Required Days: Based on the total possible days (column g, Form 2406) excluding float equipment, the required days is the total number of days the battalion is required to have equipment available in accordance with the units availability target (ref. par. 3.4.3), i.e.,

$$
\mathbf{R}_{\mathbf{B}}=\sum_{\mathbf{i}=\mathbf{1}}^{\mathbf{M}} \quad \mathbf{A}_{\mathbf{i}} \mathbf{R}_{\mathbf{i}}
$$

where

$$
\begin{aligned}
& \mathbf{R}_{\mathbf{B}}=\begin{array}{l}
\text { required number of available days of the items for } \\
\text { the battalion }
\end{array} \\
& \mathbf{M}=\text { number of units in the battalion } \\
& \mathbf{R}_{\mathbf{i}}=\text { the number of possible available days (column } \mathrm{g} \text { ) of the } \\
& \text { item for the unit } \\
& \mathbf{A}_{\mathbf{i}}=\text { availability target for the item, depending upon the } \\
& \text { ALO of each unit. }
\end{aligned}
$$

G.3.3 Comparions: The reaults from subtracting the available days from the required days and dividing by the number of days in the period $\left(\left(R_{B}-D_{B}\right) \div 90\right.$ days $\left.]\right)$ gives a rough extimate as to the number of additional float items needed to achieve the battalion's target availability. As atated in the preceding section, this comparison is only an initial indicator and other problem areas chould be explored before requesting additional float atock.

Note: In order to identify the availability of float assete, the support units with float item on their property book must report the availability of these items on a reparate DA Form 2406 with utilization code 4 (indicating flont stock). Based on the number of float items currently being reported on DA Form 2406, this requirement is not being satisfied. 


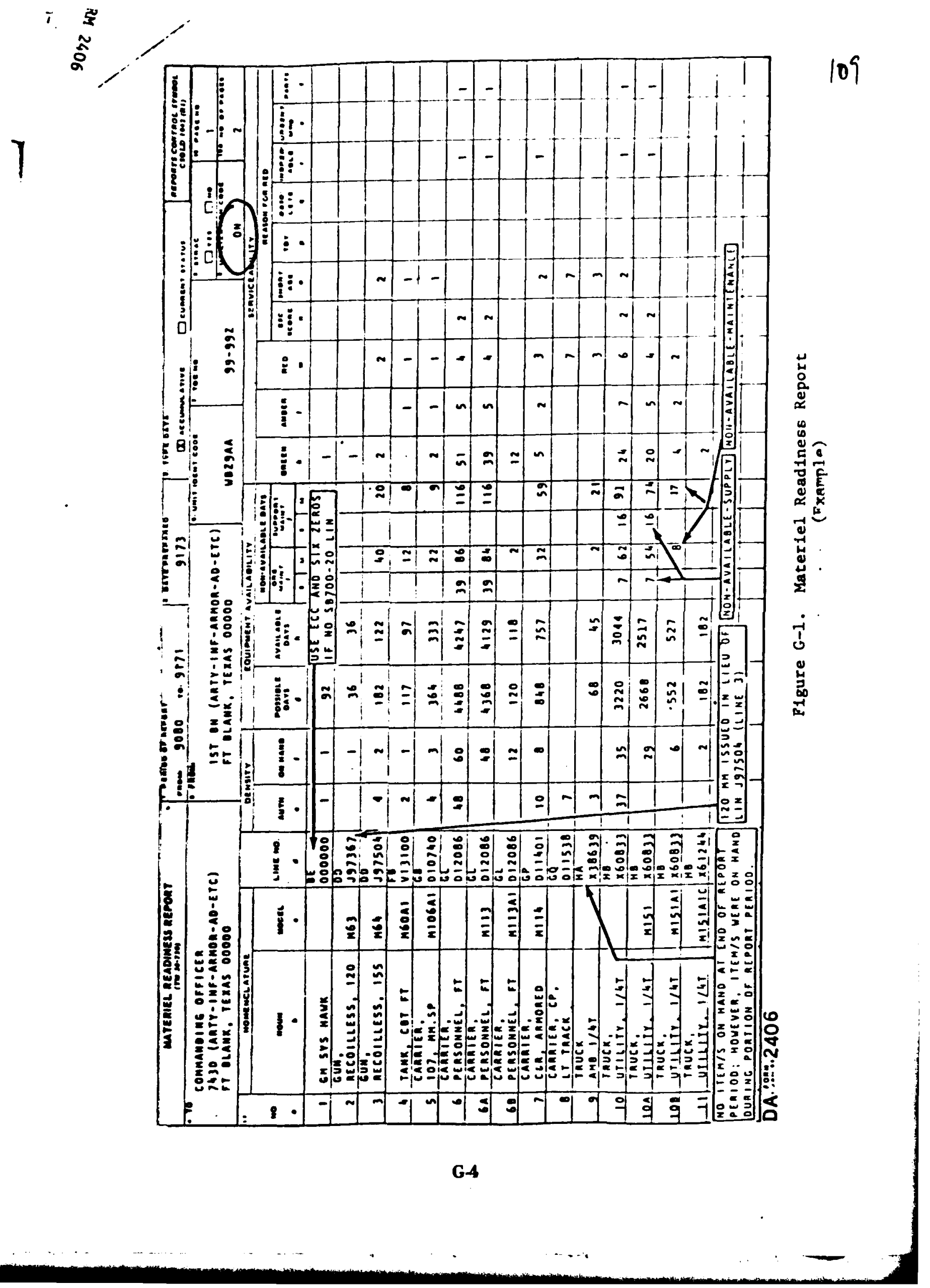


The changes in DA Form 2406 being recommended by the LOC; $C$ : should sut alfert the methods of data collection and calculation mentioned above, IRO will I..."P albreast of an! artivities in this area that might impact the availability of the required dat:. 
APPENDIX H

\section{H.1 Example 1.}

The following example illustrates the application of the proposed wartime RCF method to a hypothetical item.

\section{EXAMPLE}

A. Assume the following input data.

1. Length of war $=8$ months.

2. Average in-theatre densities, by month after D-Day.

Month

I

2

3

4

5

6

7

8
Average Density

500

700

800

850

875

900

900

900

H-1 
3. Unearviceable generations, by month.

This includes generations due to equipment usage and due to combat damage requiring depot-level repair.

\begin{tabular}{cc} 
Month & $\begin{array}{c}\text { Uneerviceable } \\
\text { Generations }\end{array}$ \\
\hline 1 & 20
\end{tabular}

2

8

Note: These unserviceable generations reflect a 4-month "intense" period and a 4-month "surtaining" period; hence, the decrease between months 4 and 5.

4. Unerviceables on-hand at the depot on D-Day $=20$. 
5. Maximum depot induction rate, by month, baed on a given allocation of depot capacity.

\section{Month}

1

2

3

4

5

6

7

8

\author{
Maximum \\ Induction Rate
}

10

15

20

25

25

25

25

25

6. Transportation Times

Theatre-To-Depot $=1$ month

Depot-To-Theatre $=1$ month

7. Depot Repair Time $=1$ month

B. Float Determination.

1. First, adjust the depot induction rate for the D-Day unserviceables. In this example, the 20 items on hand at D.Day require all of the capacity of Month 1 and reduces the Month 2 capacity for inducting new returns to five items. 
Thun, the depot capacity available for proceasing now inductions would be follows:

\section{Maximum}

Month

1

2

3

4

5

6

7

8
Induction Rate for New Returns

0

5

20

25

25

25

25

25

H-4 
2. Second, calculate the arrivals of now generations to the depots. This is the schedule of generations, delayed by the threatre-to-depot transportation time (in this example, 1 month).

Arrivals

At Depot

0

20

28

32

34

17

18

18

II-5 
3. Next, calculate depot inductions during each month.

Let $\quad \mathbf{l}_{\text {inductions during month } \mathrm{i}}$

MAX $_{\mathbf{i}}=\max$. induction e during month $\mathrm{i}$

A $\quad=$ arrivals at depot in month $i$

$E_{i} \quad=$ unserviceable item inventory at the end of month $i$

$\mathrm{I}_{\mathrm{i}}=\operatorname{Min}\left\{\mathrm{E}_{\mathrm{i}-\mathrm{I}}+\mathrm{A}_{\mathrm{i}}, \operatorname{MAX}_{\mathrm{i}}\right\}$

$E_{i}=E_{i-1}+A_{i}-I_{i}$

$\mathbf{E}_{\mathbf{o}}=\mathbf{0}$

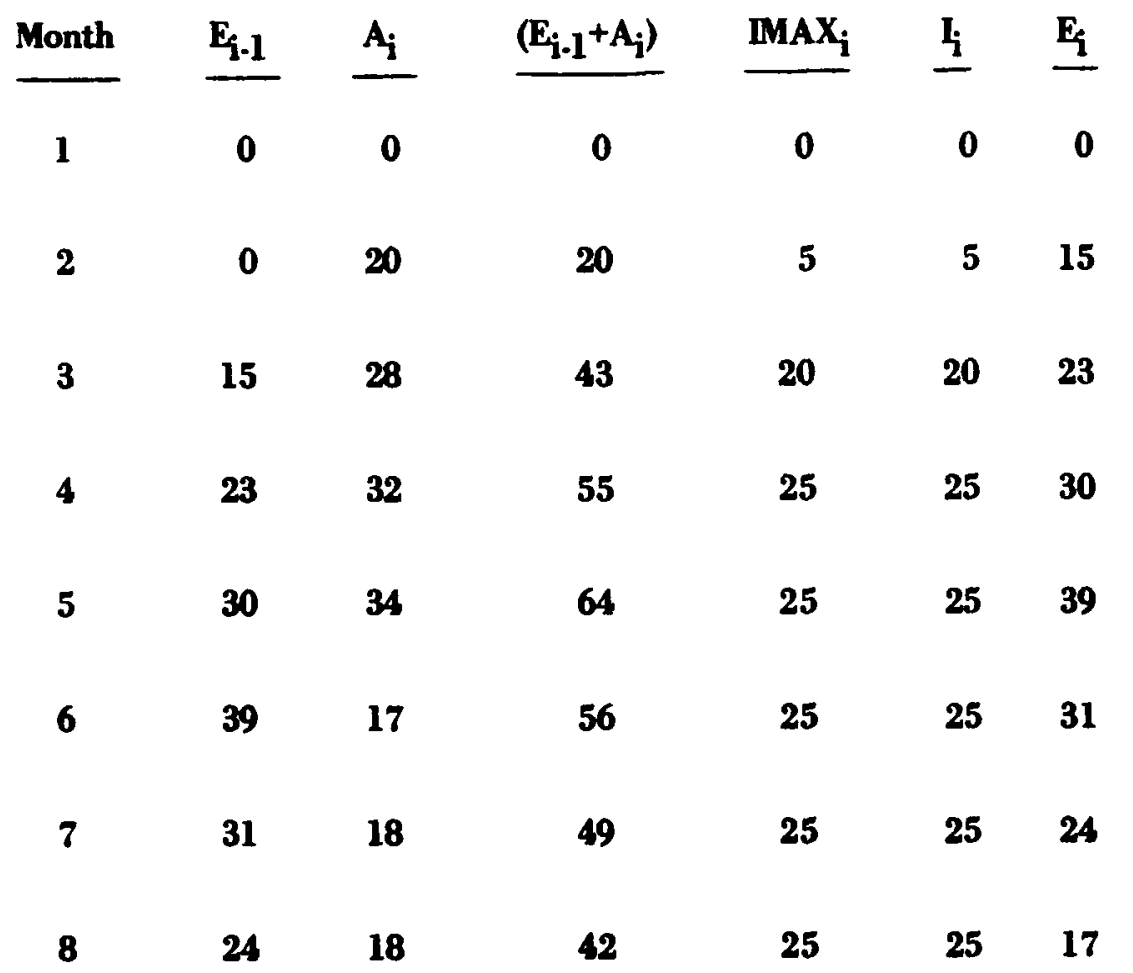

H. 6 
4. Next, calculate the depot output, which is the induction schedule delayed by the depot repair time (in this example, 1 month).

\begin{tabular}{cc} 
Month & $\begin{array}{c}\text { Depot Output } \\
\text { During Month }\end{array}$ \\
\cline { 2 - 2 } 2 & 0 \\
2 & 0 \\
3 & 5 \\
4 & 20 \\
5 & 25 \\
6 & 25 \\
7 & 25 \\
8 &
\end{tabular}


5. Next, calculate the returne to the theatre, which is the depot output delayed by the depot-to-theatre transportation time.

\begin{tabular}{cc} 
Month & $\begin{array}{c}\text { Returns to Theatre } \\
\text { During Month }\end{array}$ \\
\cline { 2 - 2 } 2 & 0 \\
2 & 0 \\
3 & 0 \\
4 & 5 \\
5 & 20 \\
6 & 25 \\
7 & 25 \\
8 & \\
\hline
\end{tabular}

8 
6. Calculate the cumulative generations, the cumulative returns to the theatre, and the difference between the two (which is the RCF requirement).

\begin{tabular}{|c|c|c|c|}
\hline Month & $\begin{array}{c}\text { Cum. } \\
\text { Generations }\end{array}$ & $\begin{array}{c}\text { Cum. } \\
\text { Returns }\end{array}$ & $\begin{array}{c}\text { RCF } \\
\text { Requirement }\end{array}$ \\
\hline 1 & 20 & 0 & 20 \\
\hline 2 & 48 & 0 & 48 \\
\hline 3 & 80 & 0 & 80 \\
\hline 4 & 114 & 5 & 109 \\
\hline 5 & 131 & 25 & 106 \\
\hline 6 & 149 & 50 & 99 \\
\hline 7 & 167 & 75 & 92 \\
\hline 8 & 185 & 100 & 85 \\
\hline
\end{tabular}

In this example, the maximum of 109 occurs during month 4.

\section{H.2 Example 2.}

This example illustrates the method for jointly determining the RCF and combat consumption requirements. 
Asoume that in the first 4 monthe, that the combat lose in 20 percent per month, and that in the last 4 months, it is 10 percent per month. Based on the deployment schedule jiven in Example 1, the following table shows the monthly and cumulative loseses.

\begin{tabular}{|c|c|c|c|c|}
\hline Month & $\begin{array}{c}\text { Ang. Deployed } \\
\text { Density }\end{array}$ & Los Factor & Losses & $\begin{array}{l}\text { Cum. } \\
\text { Losses }\end{array}$ \\
\hline 1 & 500 & .2 & 100 & 100 \\
\hline 2 & 700 & .2 & 140 & 240 \\
\hline 3 & 800 & .2 & 160 & 400 \\
\hline 4 & 850 & .2 & 170 & 570 \\
\hline 5 & 875 & .1 & 88 & 658 \\
\hline 6 & 900 & .1 & 90 & 748 \\
\hline 7 & 900 & .1 & 90 & 928 \\
\hline
\end{tabular}

The combat consumption requirement is 928 . The RCF requirement previously calculated was 109 , for a total of 1,037 . 
The following table shows what happens if the requirements are computed jointly.

\begin{tabular}{|c|c|c|c|c|c|}
\hline Month & $\begin{array}{l}\text { Cum. } \\
\text { Conbat } \\
\text { Cons. }\end{array}$ & $\begin{array}{l}\text { Cum. } \\
\text { Uns. } \\
\text { Gen. }\end{array}$ & Total & $\begin{array}{c}\text { Ret. } \\
\text { From } \\
\text { Depot }\end{array}$ & $\begin{array}{c}= \\
\text { Total } \\
\text { Requirement }\end{array}$ \\
\hline 1 & 100 & 20 & 120 & 0 & 120 \\
\hline 2 & 240 & 48 & 288 & 0 & 288 \\
\hline 3 & 400 & 80 & 480 & 0 & 480 \\
\hline 4 & 570 & 114 & 684 & 5 & 679 \\
\hline 5 & 658 & 131 & 789 & 25 & 764 \\
\hline 6 & 748 & 149 & 897 & 50 & 847 \\
\hline 7 & 838 & 167 & 1005 & 75 & 930 \\
\hline 8 & 928 & 185 & 1113 & 100 & 1013 \\
\hline
\end{tabular}

The joint calculation yields a maximum requirement for combat consumption and $\mathrm{RCF}$ of 1013 , occurring for the eighth month which is a 2.3 percent less than the sum of the separate calculations. 


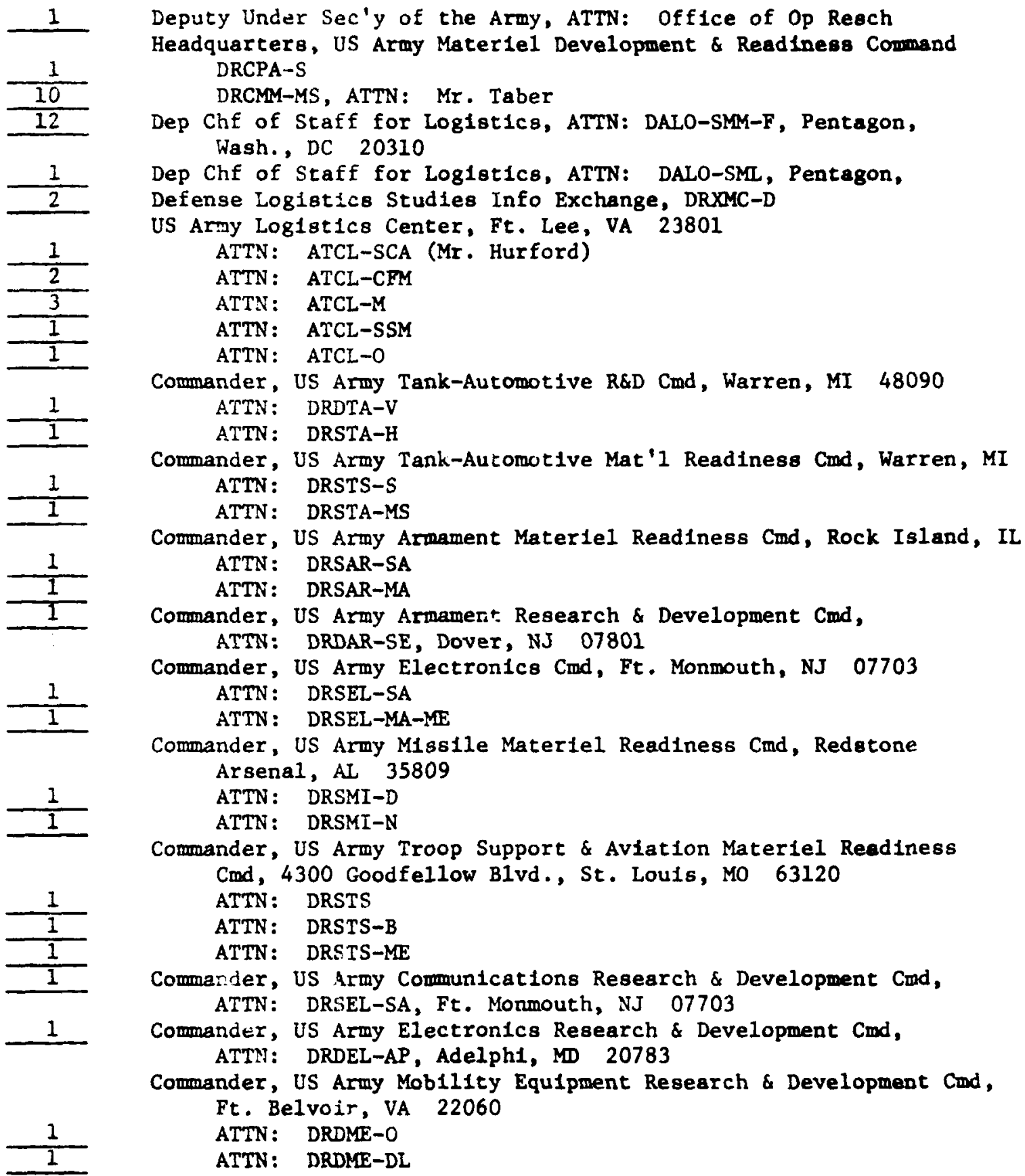


Commander, US Army Nat1ck Research \& Development Cmd, ATTN: DRXAMY-0, Nat1ck, MA 01760

1

$\frac{\frac{10}{2}}{2}$

$\frac{1}{1}$

1

\section{2}

1

1

1

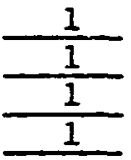

4

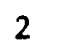

$\frac{-\frac{2}{1}}{1}$

Commander, US Army Aviation Research \& Development Cmd, P.0. Box 209, St. Louis, MO 63166

Defense Documentation Center, Cameron Sta., Alexandria, VA 22314

The Army Library, Room 1A518, Pentagon, Wash., DC 20310

US Army Materlel Systems Analysis Activity, ATTN: AMXSY-P, Aberdeen Proving Ground, MD 21005

ALOG Magazine, ATTN: Tom Johnson, USALMC, Ft. Lee, VA 23801

Commander, USDRC Automated Log18t1cs Mgt Systems Activity, P.O. Box 1578, St. Louis, MO 63188

Commander, US Army Materiel Readiness Support Activity, ATTN: DRXMD-MS, Lexington, KY 40507

Commander, US Army Depot Systems Command, Letterkenny Army Depot, Chambersburg, PA 17201 ATTN: DRSDS-LL

Commander, US Army Missile R\&D Cmd, ATTN: DRDMI-X-C, Redstone Arsenal, AL 35809

Commander, US Army Missile R\&D Cmd, ATTN: DRDMI-X-D, Redatone Arsenal, AL 35809

Commandant, USA Armor School, ATTN: MAJ Harold E. Burch, Leadership Dept, Ft. Knox, KY 40121

Logistics Studies office, DRXMC-LSO, ALMC, Ft. Lee, VA 23801

Procurement Research office, DRXMC-PRO, ALMC, Ft. Lee, VA 23801

Commander, US Army Communication Command, ATTN: Dr. Forrey,

Commander, Communications Security Logistic Activity, ATTN: Mr. Foster, Ft. Huachuca, AZ, DRSEL-CCM-NMP

Commander, US Army Logistics Evaluation Agency, ATTN: DALO-LEP, New Cumberland Army Depot, New Cumberland, PA 17070

US General Accounting Office, ATTN: Mr. J. Morr1s, Room 5840, 441 G St., N.W., Wash1ngton, DC 20548

US Army Training \& Doctrine Command, Ft. Monroe, VA 23651

ATTN: ATCD-S-I

ATTN: ATTNG-TDD

ATTN : ATLG-MSP-M 